\title{
Optimization of Rhodium-Based Catalysts for Mixed Alcohol Synthesis - 2010 Progress Report
}
MA Gerber
JF White
MJ Gray
BL Rummel
KO Albrecht
DJ Stevens

October 2010

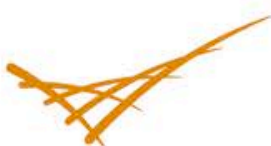

Pacific Northwest

NATIONAL LABORATORY

Proudly Operated by Battelle Since 1965 


\title{
DISCLAIMER
}

This report was prepared as an account of work sponsored by an agency of the United States Government. Neither the United States Government nor any agency thereof, nor Battelle Memorial Institute, nor any of their employees, makes any warranty, express or implied, or assumes any legal liability or responsibility for the accuracy, completeness, or usefulness of any information, apparatus, product, or process disclosed, or represents that its use would not infringe privately owned rights. Reference herein to any specific commercial product, process, or service by trade name, trademark, manufacturer, or otherwise does not necessarily constitute or imply its endorsement, recommendation, or favoring by the United States Government or any agency thereof, or Battelle Memorial Institute. The views and opinions of authors expressed herein do not necessarily state or reflect those of the United States Government or any agency thereof.

\author{
PACIFIC NORTHWEST NATIONAL LABORATORY \\ operated by \\ BATTELLE \\ for the \\ UNITED STATES DEPARTMENT OF ENERGY \\ under Contract DE-AC05-76RL01830
}

Printed in the United States of America

Available to DOE and DOE contractors from the

Office of Scientific and Technical Information,

P.O. Box 62, Oak Ridge, TN 37831-0062;

ph: (865) 576-8401

fax: $(865) 576-5728$

email: reports@adonis.osti.gov

\footnotetext{
Available to the public from the National Technical Information Service,

U.S. Department of Commerce, 5285 Port Royal Rd., Springfield, VA 22161 ph: (800) 553-6847 fax: (703) 605-6900

email: orders@ntis.fedworld.gov

online ordering: http://www.ntis.gov/ordering.htm
}

This document was printed on recycled paper. 


\title{
Optimization of Rhodium-Based Catalysts for Mixed Alcohol Synthesis - 2010 Progress Report
}

\author{
MA Gerber \\ JF White \\ MJ Gray \\ KO Albrecht \\ BL Rummel \\ DJ Stevens
}

October 2010

Prepared for

the U.S. Department of Energy

under Contract DE-AC05-76RL01830

Pacific Northwest National Laboratory

Richland, Washington 99352 



\section{Summary}

The U.S. Department of Energy's (DOE) Pacific Northwest National Laboratory (PNNL) has been conducting research since 2005 to develop a catalyst for the conversion of synthesis gas (hydrogen $\left[\mathrm{H}_{2}\right]$ and carbon monoxide [CO]) into a mixed alcohol product for use in liquid transportation fuels. Initially, research involved screening possible catalysts based on a review of the literature, because at that time, no commercial catalysts were available for this application. The screening effort resulted in a decision to focus on silica-supported catalysts containing rhodium $(\mathrm{Rh})$ and manganese $(\mathrm{Mn})$, and further research has been conducted since then to investigate the effects of different promoters and supports for the catalyst and to optimize the better performing catalysts.

This report summarizes research conducted in FY 2010. A major effort during the year was to examine alternative catalyst supports to determine whether other supports offered superior performance compared to the results achieved using Davisil 645 silica $\left(\mathrm{SiO}_{2}\right)$. Three other silica supports were identified that had comparable or superior performance in terms of space-time-yield (STY) and that converted carbon selectivity to $\mathrm{C}_{2}+$ oxygenates. In addition, several carbon supports were found that had comparable performance characteristics, but also had a significantly higher selectivity of oxygenates to $\mathrm{C}_{2}+$ alcohols. This is of interest because it may favorably affect the costs of further upgrading the oxygenate product to mixed alcohols.

Optimization of the Davisil 645 silica-supported catalyst was also continued with respect to candidate promoters, iridium (Ir), platinum $(\mathrm{Pt})$, and gallium $(\mathrm{Ga})$, and examination of selected preparation alternatives for the baseline $\mathrm{RhMn} / \mathrm{SiO}_{2}$ catalyst. Overall, there may be a minor increasing trend in carbon conversion, a decreasing trend in converted carbon selectivity to $\mathrm{C}_{2}+$ oxygenates, and no trend in $\mathrm{C}_{2}+$ oxygenates STY with increasing Ir concentration for the catalysts prepared with a single coimpregnation. However, with the scatter in the data for these catalysts as well as that for the doubleimpregnated catalysts, these trends should be treated with caution. No clear trends could be ascertained for the double-impregnated catalysts because of the scatter in the data. Before any conclusions can be drawn, additional testing is needed to repeat tests with both currently available catalyst samples and freshly made catalysts, and to examine a greater range of Ir concentrations.

It appears that adding $\mathrm{Pt}$ to the $\mathrm{RhMn} / \mathrm{SiO}_{2}$ catalyst, via a single co-impregnation of all three metals, decreases the activity of the catalyst (carbon conversion) but increases its carbon selectivity to $\mathrm{C}_{2}+$ oxygenates. The net result is that there appears to be a maximum STY at the lower concentrations, possibly below a concentration of about $0.35 \% \mathrm{Pt}$. Further testing would be required to confirm this observation. It also appears that the double-impregnated catalyst, where Pt is added in the second impregnation, is much more active, at least at the baseline Pt concentration with comparable or higher converted carbon selectivity to $\mathrm{C}_{2}+$ oxygenates, depending on the temperature. Further testing is needed to optimize Pt concentration for the double-impregnated catalysts.

The addition of Ga to the RhMn catalyst is very different from the other two promoters (Ir and Pt). Addition of relatively small quantities of Ga causes a pronounced decrease in carbon conversion, although the effect is less pronounced at higher catalyst temperatures. On the other hand, addition of small quantities of Ga causes an increase in converted carbon selectivity to $\mathrm{C}_{2}+$ oxygenates that is more 
pronounced at higher operating temperatures. The net result is an apparent optimum at or below a concentration of $0.005 \% \mathrm{Ga}$ that produces a maximum $\mathrm{C}_{2}+$ oxygenates STY when the catalyst is operated at higher temperatures.

Tests also were conducted to evaluate different methods of adding Rh and Mn to the catalyst support - adding both metals in a single impregnation, or adding either Rh or $\mathrm{Mn}$ in a single impregnation followed by a second impregnation of the other metal with drying in between impregnations. It appears that the co-impregnated catalyst has the best overall performance combination at the lower temperatures with a higher $\mathrm{C}_{2}+$ oxygenates STY and converted carbon selectivity to $\mathrm{C}_{2}+$ oxygenates. The doubleimpregnated catalyst with Mn added first had a significantly lower STY, while the double-impregnated catalyst with Rh added first had a significantly lower selectivity. At higher temperatures, the doubleimpregnated catalyst, with Mn added in the first impregnation, had the best overall performance in terms of these parameters. However, that performance is attributed to the fact that it did not undergo temperature excursions at higher temperatures, which appeared to partially deactivate the other two catalysts. If heat management was better for all three catalysts, the other two may have behaved better at higher temperatures.

Research was conducted to further examine one of the better carbon supports tested to date and to optimize both the Rh and Mn on the catalyst with respect to total metals and the ratio of the metals to one another. Research was also begun to optimize Ir as a promoter for the carbon-supported catalyst.

For co-impregnated catalysts where $\mathrm{Rh}$ and $\mathrm{Mn}$ were added at a fixed metals ratio in a single impregnation, there appears to be a regular increase in carbon conversion and converted carbon selectivity to $\mathrm{C}_{2}+$ oxygenates with increasing total metals concentration, although there is a fair amount of scatter in the data for the latter parameter. The selectivity of all oxygenates to $\mathrm{C}_{2}+$ alcohols decreases with increasing total metals concentration.

Tests were conducted with the carbon-supported catalysts containing $\mathrm{Rh}$ and $\mathrm{Mn}$ to examine the three different methods of adding metals to the carbon support as was done with the silica-supported catalysts. It appears that the co-impregnated catalyst is as good or superior to both double-impregnated catalysts.

Tests also were conducted on $\mathrm{RhMn} /$ carbon catalysts with different Mn concentrations and a fixed Rh concentration. The results indicate that increasing the Mn concentration results in improvements in all of the performance parameters over the entire range of concentrations examined. Further testing at even higher concentrations is warranted to determine the optimum concentration.

Tests were conducted to examine the effect of different Ir concentrations on a RhMnIr/carbon catalyst where all three metals were added to the support in a single impregnation. It appears that increasing the Ir concentration above a threshold concentration significantly improves the performance of the catalyst in terms of carbon conversion, $\mathrm{C}_{2}+$ oxygenates STYs and the converted carbon selectivity to $\mathrm{C}_{2}+$ oxygenates, without adversely affecting the selectivity of the oxygenates to $\mathrm{C}_{2}+$ alcohols. Additional testing at concentrations above $2.06 \%$ is needed to determine an upper limit for the beneficial effects of higher Ir concentrations.

One series of tests examined the effect of total metals concentration at fixed metals ratios on catalyst performance with Ir either co-impregnated with the $\mathrm{Rh}$ and $\mathrm{Mn}$ or it was added by first co-impregnating of Rh and Mn, drying the catalyst and then impregnating with Ir. It appears that increasing the metal 
loading significantly increases carbon conversion and $\mathrm{C}_{2}+$ oxygenates STYs, as would be expected; however, it does not significantly affect the selectivity of the converted carbon to $\mathrm{C}_{2}+$ oxygenates or the selectivity of the oxygenates to alcohols. There was no clear effect on the method of impregnating the catalyst support on catalyst performance, mainly because of scatter in the data.

Finally, the effect of the reducing temperature on catalyst performance for the $\mathrm{RhMnIr/carbon}$ catalyst was investigated in a series of tests. The results showed that a catalyst reduced at $200^{\circ} \mathrm{C}$ was inferior to catalysts reduced at $260^{\circ} \mathrm{C}$ or $360^{\circ} \mathrm{C}$. In some respects, the catalyst reduced at $260^{\circ} \mathrm{C}$, behaved similarly to the catalyst reduced at $360^{\circ} \mathrm{C}$. However, there were significant differences at some testing conditions that cannot be explained so additional tests are warranted to explain them. 



\section{Acronyms and Abbreviations}

$\begin{array}{ll}\mathrm{BET} & \text { Brunauer-Emmett-Teller } \\ \mathrm{CO} & \text { carbon monoxide } \\ \mathrm{Cu} & \text { copper } \\ \mathrm{DOE} & \text { U.S. Department of Energy } \\ \mathrm{FT} & \text { Fischer-Tropsch } \\ \mathrm{Ga} & \text { gallium } \\ \mathrm{GC} & \text { gas chromatograph } \\ \mathrm{GHSV} & \text { gas hourly space velocity } \\ \mathrm{H}_{2} & \text { hydrogen } \\ \mathrm{HPLC} & \text { high-pressure liquid chromatograph } \\ \mathrm{Ir} & \text { iridium } \\ \mathrm{Li} & \text { lithium } \\ \mathrm{Mo} & \text { molybdenum } \\ \mathrm{Mn} & \text { manganese } \\ \mathrm{N}_{2} & \text { nitrogen } \\ \mathrm{PNNL} & \text { Pacific Northwest National Laboratory } \\ \mathrm{Pt} & \text { platinum } \\ \mathrm{Rh} & \text { rhodium } \\ \mathrm{SiO} & \text { silica } \\ \mathrm{STY} & \text { space-time-yield } \\ \mathrm{Zn} & \text { zinc }\end{array}$





\section{Contents}

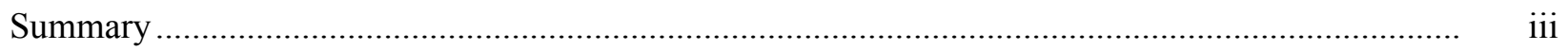

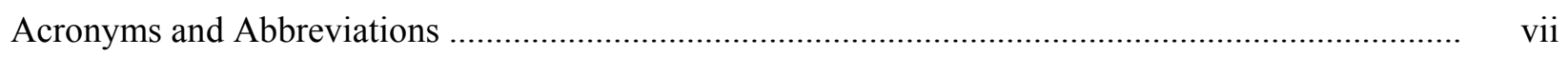

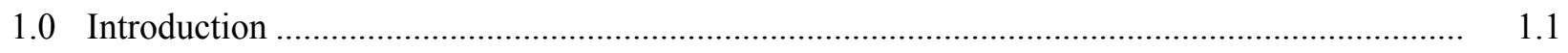

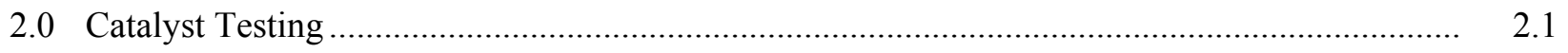

2.1 Synthesis Reactor System Description ....................................................................... 2.1

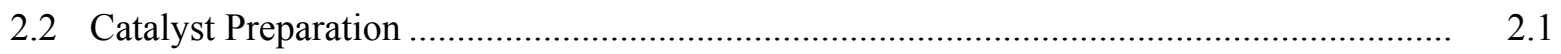

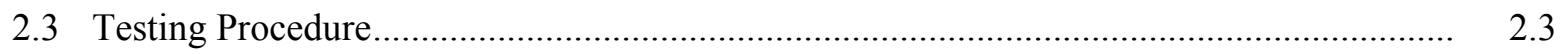

3.0 Performance of Rhodium-Manganese-Based Catalyst on Alternative Supports ....................... 3.1

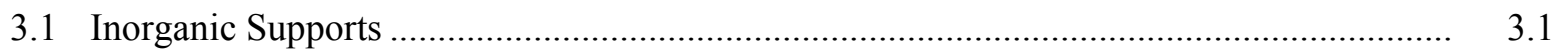

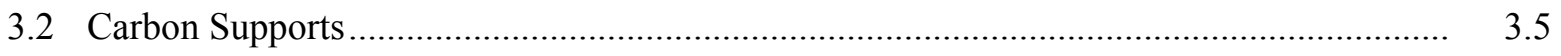

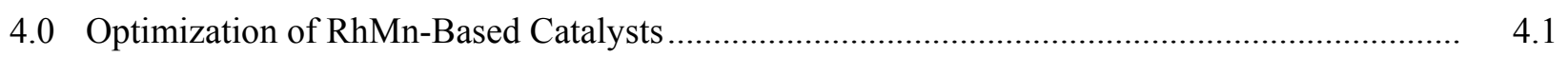

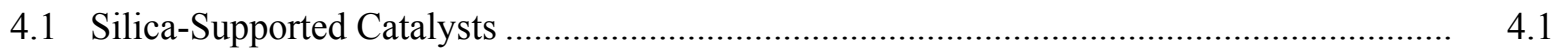

4.1.1 Effect of the Method of Iridium Addition on $\mathrm{Rh}-\mathrm{Mn} / \mathrm{SiO}_{2}$ Catalysts ..................... 4.1

4.1.2 Effect of Platinum Concentration on Platinum-Promoted Rh- $\mathrm{Mn} / \mathrm{SiO}_{2}$ Catalysts ... $\quad 4.7$

4.1.3 Effect of Gallium Concentration on Gallium-Promoted Rh- $\mathrm{Mn} / \mathrm{SiO}_{2}$ Catalysts....... 4.12

4.1.4 Effect of the Order of Metal Addition for Unpromoted Rh- $\mathrm{Mn} / \mathrm{SiO}_{2}$ Catalysts ....... 4.17

4.2 Carbon-Supported Catalysts................................................................................ 4.20

4.2.1 RhMn Total Metal Loadings ........................................................................... 4.21

4.2.2 Effect of the Order of Metal Addition for Unpromoted Rh-Mn/Carbon Catalysts ... 4.25

4.2.3 Effect of Manganese Concentration on Catalyst Performance Unpromoted $\mathrm{Rh}-\mathrm{Mn} /$ Carbon Catalysts................................................................................. 4.29

4.2.4 Effect of Iridium Concentration on Iridium-Promoted RhMn/Carbon Catalyst Performance .............................................................................................. 4.33

4.2.5 Effect of Total Metal Concentration and the Method of Ir Addition on Catalyst Performance for RhMnIr/Carbon Catalysts ......................................................... 4.39

4.2.6 Effect of Reducing Conditions on Catalyst Performance...................................... 4.43

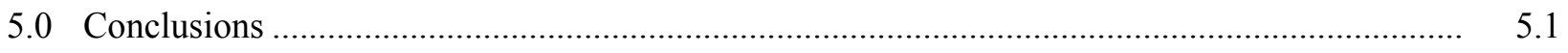

5.1 Catalyst Supports ….................................................................................... 5.1

5.2 Optimization of Silica-Supported Catalysts .............................................................. 5.1

5.3 Optimization of Carbon-Supported Catalysts ............................................................. 5.2

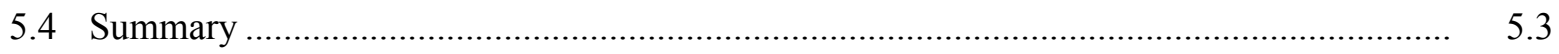

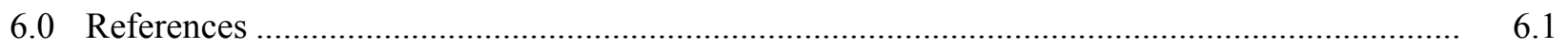




\section{Figures}

2.1 Simplified Diagram of the Reactor System Used to Test Catalysts ........................................ 2.2

3.1 STYs for RhMn Catalyst on Alternative Inorganic Supports at $300^{\circ} \mathrm{C}$................................... 3.3

3.2 Converted Carbon Selectivities to Various Products for RhMn Catalyst on Alternative

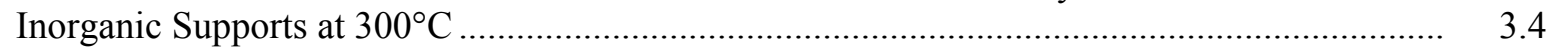

3.3 Weight-Based STY for RhMn Catalyst on Alternative Carbon Supports at $300^{\circ} \mathrm{C} \ldots \ldots \ldots \ldots \ldots \ldots \ldots . . . . . . .3 .7$

3.4 Converted Carbon Selectivities to Various Products for RhMn Catalyst on Alternative Carbon Supports at $300^{\circ} \mathrm{C}$.

3.5 Comparison of the $\mathrm{C}_{2}+$ Oxygenates STYs and Converted Carbon Selectivities at $300^{\circ} \mathrm{C}$ for the Various Carbon-Supported RhMn Catalysts.

4.1 Effect of Ir Concentration on Carbon Conversion for the Davisil 645 Silica-Supported RhMn Catalysts at $256^{\circ} \mathrm{C}$ and $275^{\circ} \mathrm{C}$.

4.2 Effect of Ir Concentration on Carbon Selectivity to $\mathrm{C}_{2}+$ Oxygenates for the Davisil 645 Silica-Supported RhMn Catalysts at $256^{\circ} \mathrm{C}$ and $275^{\circ} \mathrm{C}$

4.3 Effect of Ir Concentration on $\mathrm{C}_{2}+$ Oxygenates STY for the Davisil 645 Silica-Supported RhMn Catalysts at $256^{\circ} \mathrm{C}$ and $275^{\circ} \mathrm{C}$.

4.4 Effect of Ir Concentration on Carbon Selectivity of $\mathrm{C}_{2}+$ Oxygenates to Alcohols for the Davisil 645 Silica-Supported RhMn Catalysts at $256^{\circ} \mathrm{C}$ and $275^{\circ} \mathrm{C}$.

4.5 Effect of Pt Concentration on Carbon Conversion for the Davisil 645 Silica-Supported RhMn Catalysts at $275^{\circ} \mathrm{C}$ and $315^{\circ} \mathrm{C}$.

4.6 Effect of Pt Concentration on Carbon Selectivity to $\mathrm{C}_{2}+$ Oxygenates for the Davisil 645 Silica-Supported $\mathrm{RhMn}$ Catalysts at $275^{\circ} \mathrm{C}$ and $315^{\circ} \mathrm{C}$.

4.7 Effect of Pt Concentration on $\mathrm{C}_{2}+$ Oxygenates STY for the Davisil 645 Silica-Supported $\mathrm{RhMn}$ Catalysts at $275^{\circ} \mathrm{C}$ and $315^{\circ} \mathrm{C}$....

4.8 Effect of Pt Concentration on Carbon Selectivity of $\mathrm{C}_{2}+$ Oxygenates to Alcohols for the Davisil 645 Silica-Supported RhMn Catalysts at $275^{\circ} \mathrm{C}$ and $315 \mathrm{C}$

4.9 Effect of Ga Concentration on Carbon Conversion for the Davisil 645 Silica-Supported RhMn Catalysts at $275^{\circ} \mathrm{C}$ and $315^{\circ} \mathrm{C}$

4.10 Effect of Ga Concentration on Carbon Selectivity to $\mathrm{C}_{2}+$ Oxygenates for the Davisil 645 Silica-Supported RhMn Catalysts at $275^{\circ} \mathrm{C}$ and $315^{\circ} \mathrm{C}$.

4.11 Effect of $\mathrm{Ga}$ Concentration on $\mathrm{C}_{2}+$ Oxygenates STY for the Davisil 645 Silica-Supported RhMn Catalysts at $275^{\circ} \mathrm{C}$ and $315^{\circ} \mathrm{C}$....

4.12 Effect of $\mathrm{Ga}$ Concentration on Carbon Selectivity of $\mathrm{C}_{2}+$ Oxygenates to Alcohols for the Davisil 645 Silica-Supported RhMn Catalysts at $275^{\circ} \mathrm{C}$ and $315^{\circ} \mathrm{C}$.

4.13 Comparison of Carbon Conversions for $\mathrm{RhMn} / \mathrm{SiO}_{2}$ Catalyst Prepared Using Different Orders of Metal Additions to the Support.

4.14 Comparison of Carbon Selectivities to $\mathrm{C}_{2}+$ Oyxgenates for $\mathrm{RhMn} / \mathrm{SiO}_{2}$ Catalyst Prepared Using Different Orders of Metal Additions to the Support.

4.15 Comparison of $\mathrm{C}_{2}+$ Oyxgenates $\mathrm{STYs}$ for $\mathrm{RhMn} / \mathrm{SiO}_{2}$ Catalyst Prepared Using Different Orders of Metal Additions to the Support.

4.16 Comparison of the Selectivities of all Oxygenates to $\mathrm{C}_{2}+$ Alcohols for $\mathrm{RhMn} / \mathrm{SiO}_{2}$ Catalyst Prepared Using Different Orders of Metal Additions to the Support..... 
4.17 Effect of Total $\mathrm{Rh}+\mathrm{Mn}$ Metal Concentration on Carbon Conversion for the Hyperion CS-02C-063-Supported RhMn Catalysts at $275^{\circ} \mathrm{C}$ and $300^{\circ} \mathrm{C}$

4.18 Effect of Total Rh + Mn Metal Concentration on Converted Carbon Selectivity to $\mathrm{C} 2+$ Oxygenates for the Hyperion CS-02C-063-Supported RhMn Catalysts at $275^{\circ} \mathrm{C}$ and $300^{\circ} \mathrm{C} \ldots$.

4.19 Effect of Total $\mathrm{Rh}+\mathrm{Mn}$ Metal Concentration on $\mathrm{C}_{2}+$ Oxygenates Stys for the Hyperion CS-02C-063-Supported RhMn Catalysts at $275^{\circ} \mathrm{C}$ and $300^{\circ} \mathrm{C}$

4.20 Effect of Total $\mathrm{Rh}+\mathrm{Mn}$ metals Concentration on Selectivities of all Oxygenates to $\mathrm{C}_{2}+$ Alcohols for the Hyperion CS-02C-063-Supported RhMn Catalysts at $275^{\circ} \mathrm{C}$ and $300^{\circ} \mathrm{C}$

4.21 Comparison of Carbon Conversions for Hyperion CS-02C-063-Supported RhMn Catalysts Prepared Using Different Orders of Metal Additions to the Support.

4.22 Comparison of Carbon Selectivities to $\mathrm{C}_{2}+$ Oyxgenates for the Hyperion CS-02C-063Supported RhMn Prepared Using Different Orders of Metal Additions to the Support

4.23 Comparison of $\mathrm{C}_{2}+$ Oyxgenate STYs for the Hyperion CS-02C-063-Supported RhMn Catalyst Prepared Using Different Orders of Metal Additions to the Support.

4.24 Comparison of the Selectivities of All Oxygenates to $\mathrm{C}_{2}+$ Alcohols for the Hyperion CS-02C-063-Supported RhMn Catalyst Prepared Using Different Orders Of Metal Additions to the Support

4.25 Comparison of Carbon Conversions for the Hyperion CS-02C-063 Supported RhMn Catalysts Prepared Using Different Concentrations of $\mathrm{Mn}$ at $275^{\circ} \mathrm{C}$ and $300^{\circ} \mathrm{C}$.

4.26 Comparison of Converted Carbon Selectivity to $\mathrm{C}_{2}+$ Oxygenates for the Hyperion CS-02C-063 Supported RhMn Catalysts Prepared Using Different Concentrations of Mn at $275^{\circ} \mathrm{C}$ and $300^{\circ} \mathrm{C}$

4.27 Comparison of $\mathrm{C}_{2}+$ Oxygenates STYs for the Hyperion CS-02C-063-Supported RhMn Catalysts Prepared Using Different Concentrations of $\mathrm{Mn}$ at $275^{\circ} \mathrm{C}$ and $300^{\circ} \mathrm{C}$

4.28 Comparison of Selectivities of All Oxygenates to $\mathrm{C}_{2}+$ Alcohols for the Hyperion CS-02C-063-Supported RhMn Catalyst Prepared Using Different Mn Concentrations at $275^{\circ} \mathrm{C}$ and $300^{\circ} \mathrm{C}$.

4.29 Comparison of Carbon Conversions for the Hyperion CS-02C-063-Supported Co-Impregnated RhMnIr Catalysts Prepared Using Different Concentrations of Ir at $256^{\circ} \mathrm{C}$ and $300^{\circ} \mathrm{C}$.

4.30 Comparison of Converted Carbon Selectivity to $\mathrm{C}_{2}+$ Oxygenates for the Hyperion CS-02C-063-Supported Co-Impregnated RhMnIr Catalysts Prepared Using Different Concentrations of $\operatorname{Ir}$ at $256^{\circ} \mathrm{C}$ and $300^{\circ} \mathrm{C}$

4.31 Comparison of $\mathrm{C}_{2}+$ Oxygenates STYs for the Hyperion CS-02C-063-Supported Co-Impregnated RhMnIr Catalysts Prepared Using Different Concentrations of Ir at $265^{\circ} \mathrm{C}$ and $300^{\circ} \mathrm{C}$.

4.32 Comparison of the Selectivities of All Oxygenates to $\mathrm{C}_{2}+$ Alcohols for the Hyperion CS-02C-063-Supported Rh-Mn-Ir Catalysts Prepared Using Different Concentrations of Ir at $256^{\circ} \mathrm{C}$ and $300^{\circ} \mathrm{C}$

4.33 Comparison of Carbon Conversions for the Hyperion CS-02C-063-Supported RhMnI Catalysts Prepared Using Different Total Metal Loadings at $275^{\circ} \mathrm{C}$ and $300^{\circ} \mathrm{C}$

4.34 Comparison of Converted Carbon Selectivities to $\mathrm{C}_{2}+$ Oxygenates for the Hyperion CS-02C-063-Supported Co-Impregnated RhMnIr Catalysts Prepared Using Different Total Metal Loadings at $275^{\circ} \mathrm{C}$ and $300^{\circ} \mathrm{C}$ 
4.35 Comparison of $\mathrm{C}_{2}+$ Oxygenates STYs for the Hyperion CS-02C-063-Supported Co-Impregnated RhMnIr Catalysts Prepared Using Different Total Metal Loadings at $275^{\circ} \mathrm{C}$ and $300^{\circ} \mathrm{C}$

4.36 Comparison of the Selectivities of All Oxygenates to $\mathrm{C}_{2}+$ Alcohols for the Hyperion CS-02C-063-Supported RhMn Catalyst Prepared Using Different Total Metal Loadings at $275^{\circ} \mathrm{C}$ and $300^{\circ} \mathrm{C}$

4.37 Effect of Catalyst Reduction Temperature on Carbon Conversion for Hyperion CS-02C-063-Supported 2.11X Baseline RhMnIr Catalysts

4.38 Effect of Catalyst Reduction Temperature on Converted Carbon Selectivity to $\mathrm{C}_{2}+$ Oxygenates for Hyperion CS-02C-063-Supported 2.11X Baseline RhMnIr Catalysts

4.39 Effect of Catalyst Reduction Temperature on $\mathrm{C}_{2}+$ Oxygenates STYs for Hyperion CS-02C-063-Supported 2.11X Baseline RhMnIr Catalysts

4.40 Effect of Catalyst Reduction Temperature on Selectivity of Oxygenates to $\mathrm{C}_{2}+$ Alcohols for Hyperion CS-02C-063-Supported 2.11X Baseline RhMnIr Catalysts

\section{Tables}

3.1 Surface Area and Porosity Data of the Tested Inorganic Supports ......................................... 3.1

3.2 Surface Area and Porosity Data of Tested Carbon Supports ................................................. 3.6 


\subsection{Introduction}

The U.S. Department of Energy's (DOE) Pacific Northwest National Laboratory (PNNL) is conducting research on the conversion of synthesis gas (hydrogen $\left[\mathrm{H}_{2}\right]$ and carbon monoxide [CO]) into a mixed alcohol product for use in liquid transportation fuels. This research was initially started in 2005 to identify and confirm the performance of commercially available catalysts at that time, as part of DOE's effort to demonstrate mixed alcohols synthesis via indirect liquefaction. That effort failed to identify any commercially available catalysts although one company offered a modified methanol synthesis catalyst for testing. In the absence of commercially available catalysts having higher alcohol production rates at levels needed to achieve economic viability, this project was expanded to identify the most promising catalysts and testing them in a bench-scale system. Potential catalysts were divided into five general classes:

- Modified methanol catalysts (copper $[\mathrm{Cu}]$-zinc [Zn] and $\mathrm{Cu}$-manganese [Mn] based)

- Modified molybdenum (Mo) sulfide catalysts

- Modified Mo oxide catalysts

- Rhodium (Rh)-based catalysts

- Modified Fischer-Tropsch (FT) catalysts.

The initial approach taken in this study was to obtain or prepare catalysts that were either representative of each class of catalysts or that had the potential to achieve high space-time-yields (STYs) for $\mathrm{C}_{2}+$ oxygenates, and to test them under conditions that would optimize the STYs at a common operating pressure (i.e., $1200 \mathrm{psig}$ ). Ten catalysts representative of the different catalyst classes were prepared and tested along with a modified methanol catalyst provided by a catalyst manufacturer during 2006 and in early 2007 (Gerber et al. 2007). Of these catalysts, only the modified FT and Rh-based catalysts showed promise for achieving the necessary STYs. The two FT catalysts, which were modified to improve oxygenate yields, achieved $\mathrm{C}_{2}+$-oxygenate STYs that were within the recommended range. However, because of their much higher selectivity to FT liquids, the STYs for total organic liquids exceeded the recommended range under optimum operating conditions. Under test conditions that produced a total organic liquid within the recommended range (i.e., $1200 \mathrm{~g} / \mathrm{L}_{\text {cat }} / \mathrm{hr}$ total organic liquids STY), one of these catalysts achieved a much lower $\mathrm{C}_{2}+$-oxygenate STY (i.e., $230 \mathrm{~g} / \mathrm{L}_{\text {cat }} / \mathrm{hr}$ ) that, while higher than that achieved by the modified methanol and modified molybdenum catalysts, was still well below the recommended STY range. Carbon selectivity to $\mathrm{C}_{2}+$ oxygenates was only about $10 \%$ under these conditions.

The two Rh-based catalysts, $\mathrm{RhMn} /$ silica $\left(\mathrm{SiO}_{2}\right)$ and $\mathrm{RhMnFe} / \mathrm{SiO}_{2}$, were very selective to $\mathrm{C}_{2}+$ oxygenates. The $\mathrm{RhMnFe} / \mathrm{SiO}_{2}$ achieved higher $\mathrm{C}_{2}+$ oxygenate $\mathrm{STYs}$ under optimum conditions than any of the modified methanol and Mo-based catalysts tested at their optimum conditions and the FT catalysts at conditions that limited the total organic STYs to within the recommended range. The maximum achieved $\mathrm{C}_{2}+$-oxygenate STY (approximately $400 \mathrm{~g} / \mathrm{L}_{\text {cat }} / \mathrm{hr}$ ), however, was still below the recommended minimum. The carbon selectivity to $\mathrm{C}_{2}+$ oxygenates under this condition was approximately $24 \%$, which was significantly better than the FT catalysts. This Rh catalyst also was unique because it produced very few $\mathrm{C}_{1}+$ oxygenates or FT liquids. Based on these results, catalyst testing beginning in 2007 focused on the silica-supported Rh-based catalyst to examine the effects of 21 other promoters besides iron $(\mathrm{Fe})$ on 
catalyst performance. All of these catalysts used the same Rh:Mn:M atomic ratio (M representing the promoter) except one that used lithium (Li) as the promoter. The results of these tests identified several promoters that showed promise for improving the $\mathrm{C}_{2}+$ oxygenates STY and/or improving the selectivity of the $\mathrm{C}_{2}+$ oxygenates to alcohols (Gerber et al. 2008).

In 2009, the testing program shifted to optimization of the silica-supported RhMn-based catalysts that were reported by Gerber et al. (2010). Optimization involved examination of different total concentrations and atomic ratios of $\mathrm{Rh}$ and $\mathrm{Mn}$, as well as some of the more promising promoters identified in the earlier tests (iridium [Ir] and Li). In addition, limited catalyst screening continued to examine some additional promoters that had not been tested previously.

This report summarizes the progress made in FY 2010 on further catalyst optimization and screening. During FY 2010, catalyst optimization tests continued with further examination of the concentration effects of promising catalyst promoters as well as the effects of catalyst support alternatives to the Davisil 645 silica used in most of the testing to date. 


\subsection{Catalyst Testing}

\subsection{Synthesis Reactor System Description}

The bench-scale tubular reactor system used to test catalysts at PNNL is designed to operate at pressures up to $1400 \mathrm{psig}$ and temperatures up to $400^{\circ} \mathrm{C}$. This system is shown in Figure 2.1. The catalyst chamber is $1.67 \mathrm{~cm}$ long and $0.635 \mathrm{~cm}$ in diameter. It is filled with catalyst to a depth of $0.39 \mathrm{~cm}$ with porous metal frits holding the catalyst in place. A $0.159 \mathrm{~cm}$ outer diameter thermocouple sheath is extended through the center of the reactor, creating an annulus-shaped catalyst chamber. Two thermocouples inside the sheath are spaced so one thermocouple is at the center of the catalyst bed and the other just upstream. The catalyst temperature during a test is based on the thermocouple temperature at the center of the catalyst bed. The reactor is heated with circulating hot oil to obtain better temperature control because this approach more efficiently removes the heat of reaction, thus minimizing a thermal excursion when the carbon conversion is too high.

The syngas fed to the reactor is metered through a mass flow controller. The system also meters nitrogen $\left(\mathrm{N}_{2}\right)$ to purge the system of air before starting a test, and reducing gas $\left(10 \% \mathrm{H}_{2}\right.$ in) to the reactor during catalyst reduction. The raw product gas leaving the reactor is passed through one of two cold traps to condense liquids at $0^{\circ} \mathrm{C}$ and through a back-pressure regulator that controls the system pressure. Gas flow is redirected from one trap to the other to isolate the former trap for liquid sample recovery. Once the isolated cold trap is emptied, it is backfilled with pressurized nitrogen (not shown in the figure) to the system operating pressure to minimize pressure fluctuations when the cold trap is next used to collect a liquid sample.

The nominal feed rate to the reactor is determined by calibrating the mass flow controllers at system pressure before the tests. A Bios DryCal flow meter located downstream of the back-pressure regulator is used for this calibration. Flow meter readings are corrected for standard pressure and temperature. The flow meter also is used to monitor the product gas flow rate downstream of the liquid sample cold traps during each test.

Dry product gas samples for analysis in a gas chromatograph (GC) are obtained downstream of the back-pressure regulator in a line separate from that containing the DryCal flow meter, as shown in Figure 2.1. The reactor inlet, catalyst bed, cold sample trap, ambient temperature, and the upstream gas and ambient pressures are monitored during tests.

Gas cylinders containing a specified syngas mixture are used in the tests. The gas mixture has a nominal $\mathrm{H}_{2}$ : $\mathrm{CO}$ ratio of $2: 1$. The nominal concentrations of carbon dioxide and nitrogen are each $4 \%$ in the gas mixture.

\subsection{Catalyst Preparation}

Catalysts tested during this part of the testing program were based on a baseline catalyst composition of $5.56 \% \mathrm{Rh}$ and $1.69 \% \mathrm{Mn}$, and if used, a promoter was added at a concentration so the Rh:Mn:M $(\mathrm{M}=$ promoter) atomic ratios were 1.00:0.57:0.10, respectively. Catalyst optimization tests involved variations in the overall metals concentrations while maintaining the baseline atomic ratios, and/or varying one of the three components of a three-component catalyst from the baseline atomic ratio. 


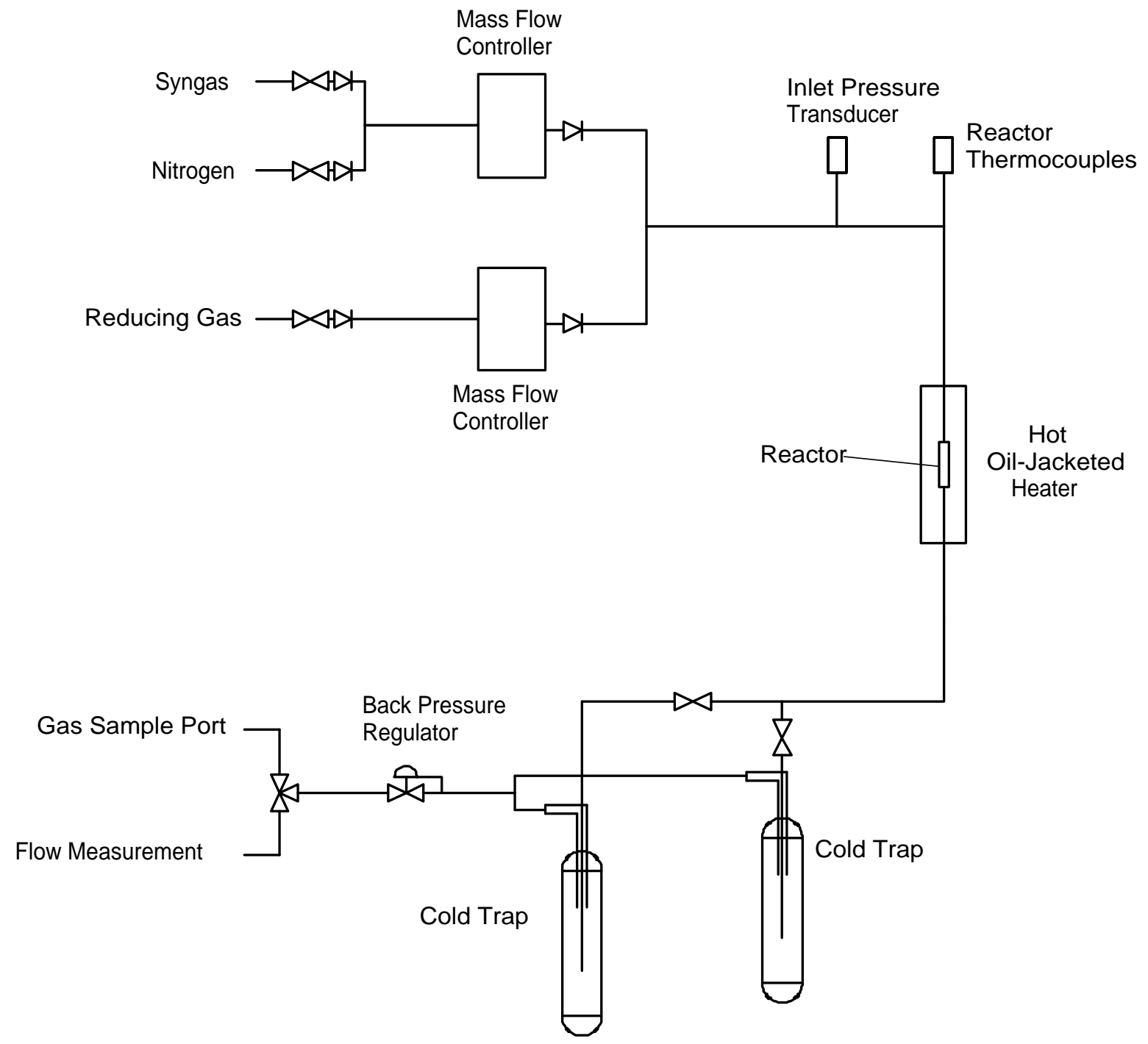

Figure 2.1. Simplified Diagram of the Reactor System Used to Test Catalysts

The catalysts that were tested were supported on inorganic and carbon supports. The reagents used to prepare most of the catalysts tested during FY 2010 were rhodium nitrate solution (10 wt $\% \mathrm{Rh}$ concentration in solution), a 50\% Mn (II) nitrate solution in dilute nitric acid, and, if used, dihydrogen hexachloroiridium (IV) hydrate solution (14\% Ir). Platinum nitrate solution (12.96\% Pt) and Ga (III) nitrate were used as reagents for catalysts containing these metals.

Most catalyst preparations consisted of a single-step impregnation procedure (co-impregnation) using the incipient wetness technique. The appropriate quantities of each metal used in the preparation were combined with enough deionized water to bring the total volume of the impregnation solution to $90 \%$ of the water adsorption pore volume of the support. The solution was impregnated in drop-wise fashion onto nominally $3 \mathrm{~g}$ of support in a small vial placed upright on a vibrating table to keep the support solids in motion during impregnation. The impregnated catalysts were dried under an infrared lamp while being shaken until a steady weight was achieved, and then vacuum dried overnight at $110^{\circ} \mathrm{C}$ in a drying oven. 
The dried catalysts on inorganic supports were calcined at $400^{\circ} \mathrm{C}$ for 2 hours in a muffle furnace. To preserve the integrity of the supports, carbon-supported catalysts were not calcined.

Some catalysts were prepared using two impregnations (double impregnation) with drying between impregnations to investigate the effect of the order of metal addition on catalyst performance. Each impregnation solution volume, containing the appropriate metal concentrations, was equal to $90 \%$ of the water adsorption pore volume of the support.

\subsection{Testing Procedure}

During a typical test series, a measured volume of catalyst was loaded into the reactor, and its net weight was determined. The packing density for catalyst supported on Davisil 645 and Hyperion CS-02C-063 were typically $0.46 \mathrm{~g} / \mathrm{mL} \pm 10 \%$. The packing densities for many of the other catalyst supports were significantly different from these values, so comparisons were made on a catalyst weight basis.

The reactor was placed in the reactor system, and the system purged with nitrogen to remove any traces of air from the system. The catalysts were then reduced in situ using a $50 \mathrm{sccm}$ flowrate of a $10 \%$ hydrogen-in-nitrogen gas mixture at atmospheric pressure. Except where noted, all catalysts were heated in the reducing atmosphere to $220^{\circ} \mathrm{C}$ at $2.5^{\circ} \mathrm{C} / \mathrm{min}$ ramp-up rate and held that temperature for 1 hour, then heated from $220^{\circ} \mathrm{C}$ to $260^{\circ} \mathrm{C}$ at a rate of $1^{\circ} \mathrm{C} / \mathrm{min}$ and held at that temperature for 8 hours, and finally heated to $350^{\circ} \mathrm{C}$ at a rate of $1.5^{\circ} \mathrm{C} / \mathrm{min}$ and held at that temperature for 2 hours before cooling to ambient temperature.

Once the reactor was cooled after catalyst reduction, the reactor was purged with syngas and the desired syngas feed rate and pressure were established. The reactor was heated slowly to the temperature for the first test condition (typically $256^{\circ} \mathrm{C}$ ) and maintained at that temperature for at least 24 hours to allow the catalyst to age. The product stream was directed through one of the cold traps during this time. After aging the catalyst, the product stream was redirected through the other cold trap for a period sufficient for at least 10 bed volumes of gas feed (based on the operating pressure and gas feed rate) to pass through the cold trap. This period of time provides a representative gas sample and a sufficiently large liquid sample for subsequent analysis. The operating conditions were recorded before sampling with two or more grab samples of product gas obtained and analyzed in a GC along with a feed gas sample and a calibration gas sample. The liquid recovered from the cold trap was weighed and, if two phases were present, separated into an aqueous phase and an organic phase. The weighed organic phase was not analyzed and was assumed to have a composition comparable to hexane for purposes of a carbon balance. The weighed aqueous phase was analyzed using a high-pressure liquid chromatograph (HPLC) to quantify the $\mathrm{C}_{1}-\mathrm{C}_{5}$ oxygenates, which principally were alcohols, carboxylic acids, aldehydes, esters, and any other products associated with significant peaks identified by the HPLC. After sampling, a new set of conditions (i.e., temperature and feed rate) was established, and another cold trap sample was collected at the new conditions. This procedure was repeated until a representative set of conditions was obtained to evaluate catalyst performance in terms of single-pass carbon conversion, STY, and converted carbon selectivity. In most cases, tests progressively advanced to higher temperatures with one or more space velocities examined during each test. In most tests, an earlier test condition was repeated to determine whether further catalyst aging during testing affected the performance of the catalyst. 
Using the calibrated feed flow rates as a basis, a $100 \%$ nitrogen balance was performed to calculate the average outlet flow rate during a sample collection period. The product gas flow rate downstream of the cold trap also was monitored and recorded for estimating the product gas flow rate and to provide a rough check on the accuracy of the calculated flow using a nitrogen balance. Carbon balances determined using this method were usually within approximately $\pm 6 \%$ of $100 \%$. 


\subsection{Performance of Rhodium-Manganese-Based Catalyst on Alternative Supports}

Catalysts containing $\mathrm{Rh}$ and $\mathrm{Mn}$ on several alternative catalyst supports were evaluated to ascertain those that produced favorable performance characteristics. Tests were usually conducted at sequentially higher temperatures (nominally $256,275,300,315$, and $325^{\circ} \mathrm{C}$ ) followed by a repeat of an earlier condition (nominally $300^{\circ} \mathrm{C}$ ) to quantify any deactivation that had occurred. Catalyst performance with the different supports was determined for the common test condition of $300^{\circ} \mathrm{C}$. Comparison criteria were $\mathrm{C}_{2}+$ oxygenate STYs and converted carbon selectivities to $\mathrm{C}_{2}+$ oxygenates. Discussions of the results are separated into inorganic- and carbon-based supports.

\subsection{Inorganic Supports}

Fifteen inorganic supports were evaluated in addition to the Davisil 645 silica support. These included eight silica, two titania, one alumina, one calcium-modified-alumina, one silica-alumina, one zirconia, and one magnesia support. All catalysts used the same Rh and Mn concentrations (5.56 $\mathrm{wt} \% \mathrm{Rh}$ and $1.69 \mathrm{wt} \% \mathrm{Mn})$. The surface area and pore characteristics determined using BrunauerEmmett-Teller (BET) nitrogen adsorption tests for each support are shown in Table 3.1.

Table 3.1. Surface Area and Porosity Data of the Tested Inorganic Supports

\begin{tabular}{lcccc}
\hline \multicolumn{1}{c}{ Support Description } & $\begin{array}{c}\text { Surface } \\
\text { Area } \\
\mathrm{m}^{2} / \mathrm{g}\end{array}$ & $\begin{array}{c}\text { Micro-Pore } \\
\text { Surface Area, } \\
\mathrm{m}^{2} / \mathrm{g}\end{array}$ & $\begin{array}{c}\text { Pore } \\
\text { Volume } \\
\mathrm{cm}^{3} / \mathrm{g}\end{array}$ & $\begin{array}{c}\text { Pore } \\
\text { Size } \\
\AA^{\text {(a) }}\end{array}$ \\
\hline Davisil 645 Silica & 284.8 & 22.1 & 1.2 & $160 / 120$ \\
Norpro SS61137 Silica & 194.2 & 4 & 0.69 & $170 / 120$ \\
Norpro SS61138 Silica & 276.4 & 14.2 & 1.04 & $170 / 120$ \\
Engelhard Mod D Silica & 583.3 & 30.1 & 0.33 & 25 \\
PerlKat 97-0 Silica & 397.2 & 0 & 0.91 & $120 / 100$ \\
PerlKat 79-3 Silica & 327.9 & 29.1 & 0.61 & $120 / 100$ \\
Merck Aldrich Grade-60 Silica & 535 & 0 & 0.73 & 55 \\
Grace 408 Silica & 728 & 208.8 & 0.25 & $<15$ \\
Perlkat 29-3 Silica & 618.6 & 79.5 & 0.42 & 30 \\
Norpro SA5151 Alumina & 0.29 & 0.09 & Non-porous & Non-porous \\
SZ 31164 Zirconia & 97.1 & 1.29 & 0.34 & $90 / 80$ \\
Grace 980-25 Silica Alumina & 372 & 0 & 0.36 & 40 \\
BASF Al-5700 E 1/16 Ca on Alumina & 209 & 9.2 & 0.6 & $100 / 80$ \\
ST61165 Titania & 0.48 & 0 & Non-porous & Non-porous \\
Norpro ST 31119 Titania & 36.5 & 1.96 & 0.2 & $300 / 200$ \\
BASF 7264-109A MgO & 55.2 & 2.1 & 0.25 & $50-300$ \\
\hline (a) Qualitative determination & & & &
\end{tabular}


Figure 3.1 compares the STY performances, on a catalyst weight basis, of the RhMn catalysts at $300^{\circ} \mathrm{C}$ and a gas hourly space velocity (GHSV) of $11,000 \mathrm{~L} / \mathrm{L}_{\text {cat }} / \mathrm{hr}$. Three silica supports (Norpro SS1137 and SS1138, and Engelhard Mod D) showed performance comparable or superior to the performance of the Davisil 645-supported catalyst. The two Norpro silicas were significantly better than the other two with a $\mathrm{C}_{2}+$ oxygenate STYs that were approximately $9 \%$ greater than the Engelhard Mod D silica-supported catalyst and 16\% greater than the Davisil 645-supported catalyst. All of the other catalysts supports had activities that were significantly less than the Davisil 645 silica-supported catalyst. However, the Norpro SA5151 alumina and the Norpro SZ31164 zirconia had marginally acceptable activities ( $\left.>100 \mathrm{~g} / \mathrm{kg}_{\text {cat }} / \mathrm{hr}\right)$. Considering the wide range of activities for the different silica-supports, further testing using different sources made of these materials may be warranted.

Figure 3.2 compares the converted carbon selectivity to various products for the RhMn catalyst at $300^{\circ} \mathrm{C}$ and a GHSV of $11,000 \mathrm{~L} / \mathrm{L}_{\text {cat }} / \mathrm{hr}$ on the various supports. Relatively modest differences in the carbon selectivities to $\mathrm{C}_{2}+$ oxygenates were observed for the four most active silica-supported catalysts, with selectivities of $29 \%, 31 \%, 38 \%$, and $29 \%$ for the Davisil 645, Norpro SS1137, Norpro SS1138, and Engelhard Mod D silica-supported catalysts, respectively. There was considerably greater variation in the carbon selectivities to $\mathrm{C}_{2}+$ alcohols, with the alcohols accounting for $24 \%, 28 \%, 22 \%$, and $44 \%$, of the $\mathrm{C}_{2}+$ oxygenates, for the four respective catalysts. However, none of the selectivities to alcohols was particularly noteworthy because all products would require substantial hydrogenation to produce high yields of $\mathrm{C}_{2}+$ alcohols. Of the remaining catalysts that were tested, only the Merck Aldrich Grade 60 silica achieved significant carbon selectivities to $\mathrm{C}_{2}+$ oxygenates $(49 \%)$ that might warrant further testing. 


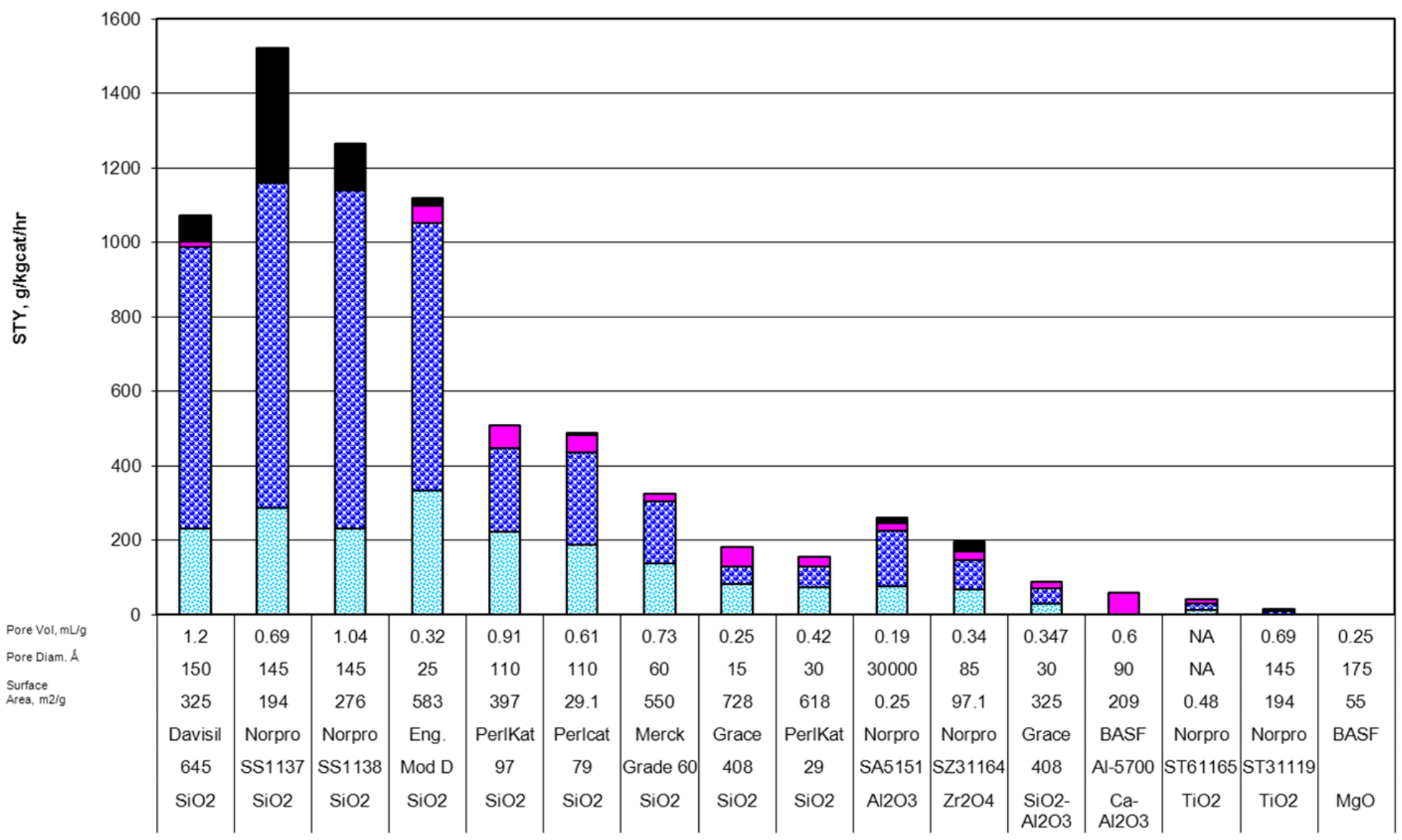

aC2+ Alcohols aOther $\mathrm{C} 2+$ Oxygenates $\quad$ aMEOH $\quad$ HC Liquids

Figure 3.1. STYs for RhMn Catalyst on Alternative Inorganic Supports at $300^{\circ} \mathrm{C}$ 


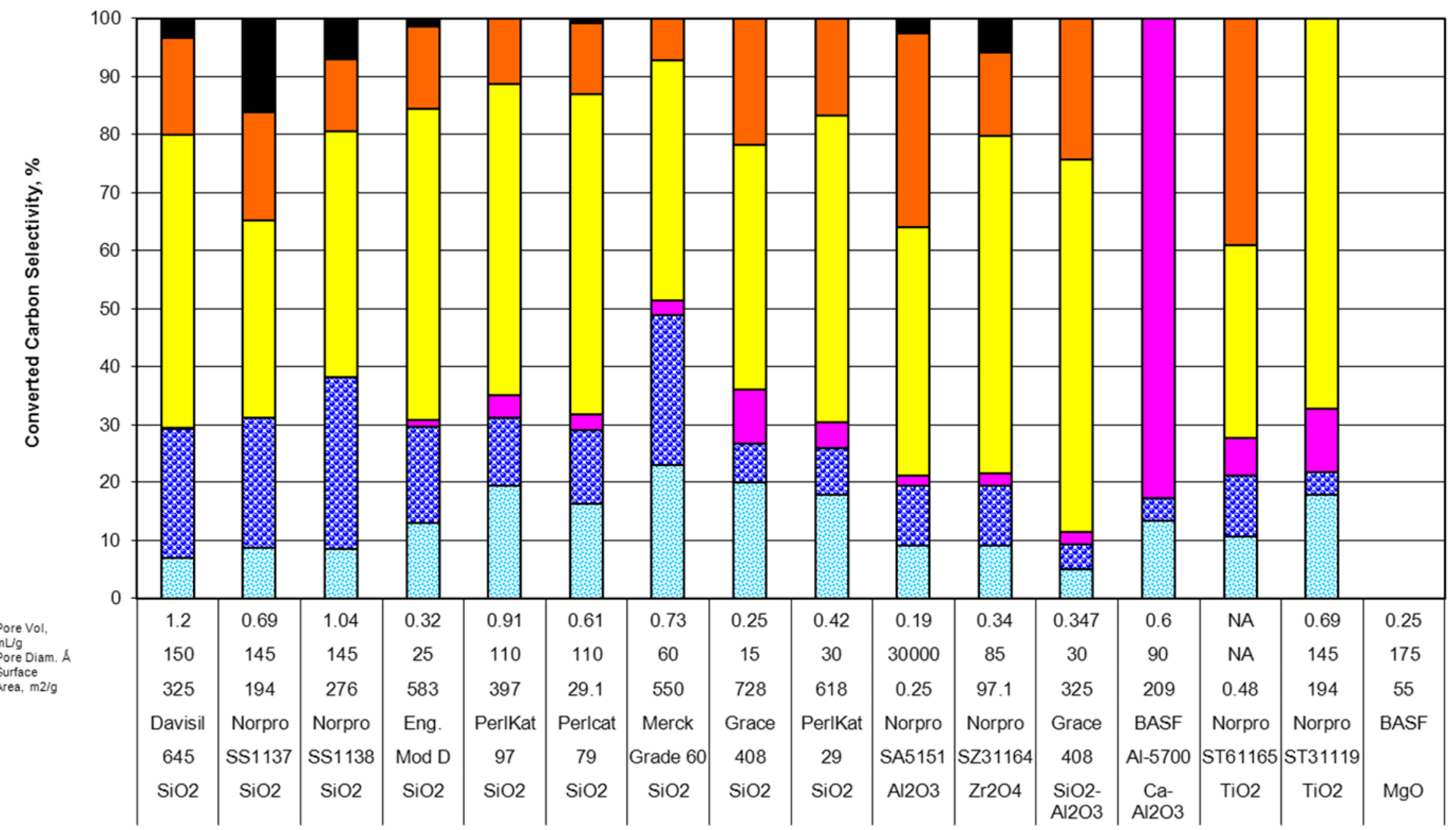

aC2+ Alcohols

هOther $\mathrm{C} 2+$ Oxygenates

वMEOH

aMethane

口Higher HC Gases

a HC Liquids

Figure 3.2. Converted Carbon Selectivities to Various Products for RhMn Catalyst on Alternative Inorganic Supports at $300^{\circ} \mathrm{C}$ 


\subsection{Carbon Supports}

Fifteen carbon supports were evaluated for comparison to the Davisil 645 silica support. These supports included activated carbons, graphitic carbons and carbon nanotube supports. The surface areas and pore characteristics determined using BET nitrogen adsorption tests are shown in Table 3.2. All of the carbons used 1.5X the baseline concentrations of Rh and Mn that were used in the Davisil 645 catalyst.

Figure 3.3 compares the $\mathrm{C}_{2}+$ oxygenate STY performances of the RhMn catalysts on the various carbon supports at $300^{\circ} \mathrm{C}$, along with that for the Davisil 645 silica-supported catalyst. The Hyperion CS-02C carbon nanotube and the Engelhard HiSA-2 graphitic carbon supports had the best performance of the carbon supports. However, their $\mathrm{C}_{2}+$ oxygenates STYs (716 and $715 \mathrm{~g} / \mathrm{kgcat} / \mathrm{hr}$, respectively) were only about $73 \%$ of that for the Davisil 645 silica support ( $987 \mathrm{~g} / \mathrm{kgcat} / \mathrm{hr})$, even though the metal loading was 50\% greater. The Engelhard HiSA-1 and TimCal Timrex 300 graphitic carbons were even less active (498 and $546 \mathrm{~g} / \mathrm{kgcat} / \mathrm{hr}$, respectively), but they still have very good activities. The HiSA-1 supported catalyst, however, lost significant activity at higher temperatures compared to the other catalyst supports and was considered to be too unstable. The Hyperion CS-07C carbon nanotube, Norit Darco activated carbon washed in hydrofluoric acid (HF), and the Engelhard Sibunit all had considerably lower but at least marginally acceptable activities. None of the other carbon-supported catalysts were particularly active.

Figure 3.4 compares the carbon selectivity to various products for the RhMn catalyst on the various carbon supports at $300^{\circ} \mathrm{C}$, along with that for the Davisil 645 silica-supported catalyst. There were considerable differences in the carbon selectivities to $\mathrm{C}_{2}+$ oxygenates for the top seven carbon-supported catalysts, ranging from a low of about $25 \%$ for the Timcal Timrex 300 graphitic carbon to a high of about $55 \%$ for the Engelhard Sibunit carbon. The Engelhard HiSA-1, and HiSA-2 graphitic carbons and the Hyperion 11 carbon nanotubes have the best overall combinations of $\mathrm{C}_{2}+$ oxygenates STYs and converted carbon selectivities to $\mathrm{C}_{2}+$ oxygenates as shown in Figure 3.5. The Engelhard Sibunit has a higher selectivity, but its STY is too low to be further considered at this time.

There was considerable variation in the carbon selectivities to $\mathrm{C}_{2}+$ alcohols, with the alcohols accounting for 45 to $82 \%$ of the $\mathrm{C}_{2}+$ oxygentates, for the top seven catalysts. These selectivities are much higher than those achieved by the Davisil 645 silica-supported catalyst ( $24 \%$ of total $\mathrm{C}_{2}+$ oxygenates). The Engelhard HiSA-1, and HiSA-2 graphitic carbons and the Hyperion 11 carbon nanotubes had alcohols accounting for $76 \%, 71 \%$, and $57 \%$ of the total $\mathrm{C}_{2}+$ oxygenates, respectively at the $300^{\circ} \mathrm{C}$ test condition. The Engelhard Sibunit carbon had the lowest selectivity to $\mathrm{C}_{2}+$ alcohols, and because it also was the least active, it probably does not warrant further consideration at this time.

An extensive characterization of the different carbons was conducted to help explain the wide range of activities and significantly higher fraction of $\mathrm{C}_{2}+$ oxygenates that are alcohols compared to the noncarbon-supported catalysts. Examination of Table 3.2 suggests that, while surface area may be an important criterion for activity, only the surface area not associated with micro-porosity maybe significant. There also appears to be a general sense that graphitic carbon (including nanotubes) and in particular functionalized graphitic carbons may enhance activity, based on the general descriptions for the carbon supports. 
Table 3.2. Surface Area and Porosity Data of Tested Carbon Supports

\begin{tabular}{|c|c|c|c|c|c|c|}
\hline Carbon & $\begin{array}{c}\text { Measured } \\
\text { Specific } \\
\text { Surface Area, } \\
\mathrm{M}^{2} / \mathrm{g}\end{array}$ & $\begin{array}{c}\text { Measured } \\
\text { Micropore } \\
\text { Surface Area } \\
\mathrm{M}^{2} / \mathrm{g}\end{array}$ & $\begin{array}{l}\text { Measured } \\
\text { Volume, } \\
\mathrm{mL} / \mathrm{g}\end{array}$ & $\begin{array}{l}\text { Measured } \\
\text { Micro-pore } \\
\text { Volume, } \\
\mathrm{mL} / \mathrm{g}\end{array}$ & Nominal Pore-Size, $\AA^{\text {(a) }}$ & Comments \\
\hline $\begin{array}{l}\text { Hyperion Fibril Catalyst } \\
\text { Support CS-02C-063 }\end{array}$ & 466 & 0 & 1.24 & $\begin{array}{c}\text { Not } \\
\text { Measured }\end{array}$ & $\begin{array}{l}\text { Small PV contribution }<50 \AA ̊ \\
50-550 \AA\end{array}$ & $\begin{array}{l}\text { Higher surface area hydrophilic } \\
\text { carbon nanotube extrudate }\end{array}$ \\
\hline $\begin{array}{l}\text { Englehard Hi Surface } \\
\text { Area Graphite (HSAG-2) }\end{array}$ & 640 & 67.6 & 0.5 & $\begin{array}{c}\text { Not } \\
\text { Measured }\end{array}$ & $\begin{array}{l}12-45 \AA \text { Á (centered at } 20 \AA \AA) ; 45- \\
300 \AA ̊\end{array}$ & $\begin{array}{l}\text { Highly graphitized \& surface } \\
\text { functionalized carbon }\end{array}$ \\
\hline $\begin{array}{l}\text { Englehard Hi Surface } \\
\text { Area Graphite (HSAG-1) }\end{array}$ & 580 & 307 & 0.35 & $\begin{array}{c}\text { Not } \\
\text { Measured }\end{array}$ & $\begin{array}{l}\text { Significant contribution }<20 \AA \dot{;} \\
\text { Relatively even distribution of pores } \\
20-100 \AA\end{array}$ & Highly graphitized carbon \\
\hline Timcal Timrex 300 & 318 & 62.7 & 0.52 & 0.03 & Evenly distributed pores $0-1500 \AA$ Á. & $\begin{array}{l}\text { High surface area graphitic } \\
\text { carbon }\end{array}$ \\
\hline $\begin{array}{l}\text { Hyperion Fibril Catalyst } \\
\text { Support CS-07C-063 }\end{array}$ & 335 & 0 & 2.47 & $\begin{array}{c}\text { Not } \\
\text { Measured }\end{array}$ & 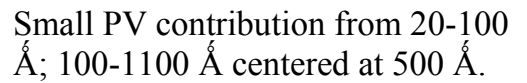 & $\begin{array}{l}\text { Medium surface area hydrophilic } \\
\text { carbon nanotube extrudate }\end{array}$ \\
\hline Norit Darco HF Washed & 776 & 380 & 0.68 & $\begin{array}{c}\text { Not } \\
\text { Measured }\end{array}$ & $\begin{array}{l}\text { Relatively even distribution from } \\
0-650 \AA \text { A. }\end{array}$ & $\begin{array}{l}\text { Demineralized using } \\
\text { concentrated hydrofluoric acid }\end{array}$ \\
\hline Engelhard Sibunit & 547 & 22.5 & 0.93 & $\begin{array}{c}\text { Not } \\
\text { Measured }\end{array}$ & $\begin{array}{l}\text { Bimodal PSD: } 15-100 \text { (center at } \\
50 \AA ̊) ; 100-1000 \AA \AA \text { (centered at } \\
500 \AA ̊)\end{array}$ & $\begin{array}{l}\text { Formed mixed amorphous \& } \\
\text { graphitic carbon }\end{array}$ \\
\hline $\begin{array}{l}\text { Kureha Carbon G-BAC- } \\
\text { G-70R }\end{array}$ & 1401 & 1122 & & 0.44 & 0-30 Á & $\begin{array}{l}\text { Bead shaped activated carbon } \\
\text { prepared from petroleum pitch }\end{array}$ \\
\hline $\begin{array}{l}\text { Hyperion Fibril Catalyst } \\
\text { Support CS-05C-063 }\end{array}$ & 218 & 23.4 & 1.36 & $\begin{array}{c}\text { Not } \\
\text { Measured }\end{array}$ & $\begin{array}{l}\text { Unimodal: } 60-1100 \AA \text { Á centered at } \\
400 \AA \hat{A} \text {. }\end{array}$ & $\begin{array}{l}\text { Lower surface area hydrophobic } \\
\text { carbon nanotube extrudate }\end{array}$ \\
\hline Norit Darco & 729 & 348 & 0.67 & $\begin{array}{c}\text { Not } \\
\text { Measured }\end{array}$ & $\begin{array}{l}\text { Relatively even distribution of pores } \\
12-650 \AA\end{array}$ & $\begin{array}{l}\text { Granular, amorphous activated } \\
\text { carbon }\end{array}$ \\
\hline $\begin{array}{l}\text { Norit ROX } 0.8 \mathrm{HF} \\
\text { Washed }\end{array}$ & 1139 & 851 & 0.46 & $\begin{array}{c}\text { Not } \\
\text { Measured }\end{array}$ & $\begin{array}{l}\text { Significant contribution }<25 \AA \text {; Even } \\
\text { distribution from } 25-600 \AA .\end{array}$ & $\begin{array}{l}\text { Demineralized using } \\
\text { concentrated hydrofluoric acid }\end{array}$ \\
\hline Norit ROX 0.8 & 1071 & 787 & 0.42 & $\begin{array}{c}\text { Not } \\
\text { Measured }\end{array}$ & $\begin{array}{l}\text { Significant contribution }<25 \AA \text {; } \\
\text { Relatively even distribution of pores } \\
25-650 \AA \text {. }\end{array}$ & $\begin{array}{l}\text { Amorphous activated carbon } \\
\text { extrudate; basic, modified by } \\
\text { calcining in } \mathrm{NH}_{3} 850^{\circ} \mathrm{C}\end{array}$ \\
\hline Cummings Moore 55865 & 1035 & 548 & 0.41 & $\begin{array}{c}\text { Not } \\
\text { Measured }\end{array}$ & $\begin{array}{l}\text { Large contribution }<20 \AA \dot{A} \text {; small } \\
\text { contribution } 20-100 \AA \AA\end{array}$ & $\begin{array}{l}\text { High surface area activated } \\
\text { carbon }\end{array}$ \\
\hline Cummings Moore 55595 & 1024 & 888 & 0.19 & $\begin{array}{c}\text { Not } \\
\text { Measured }\end{array}$ & Microporous; all pores $<30 \AA \AA$ & $\begin{array}{l}\text { High surface area activated } \\
\text { carbon }\end{array}$ \\
\hline
\end{tabular}




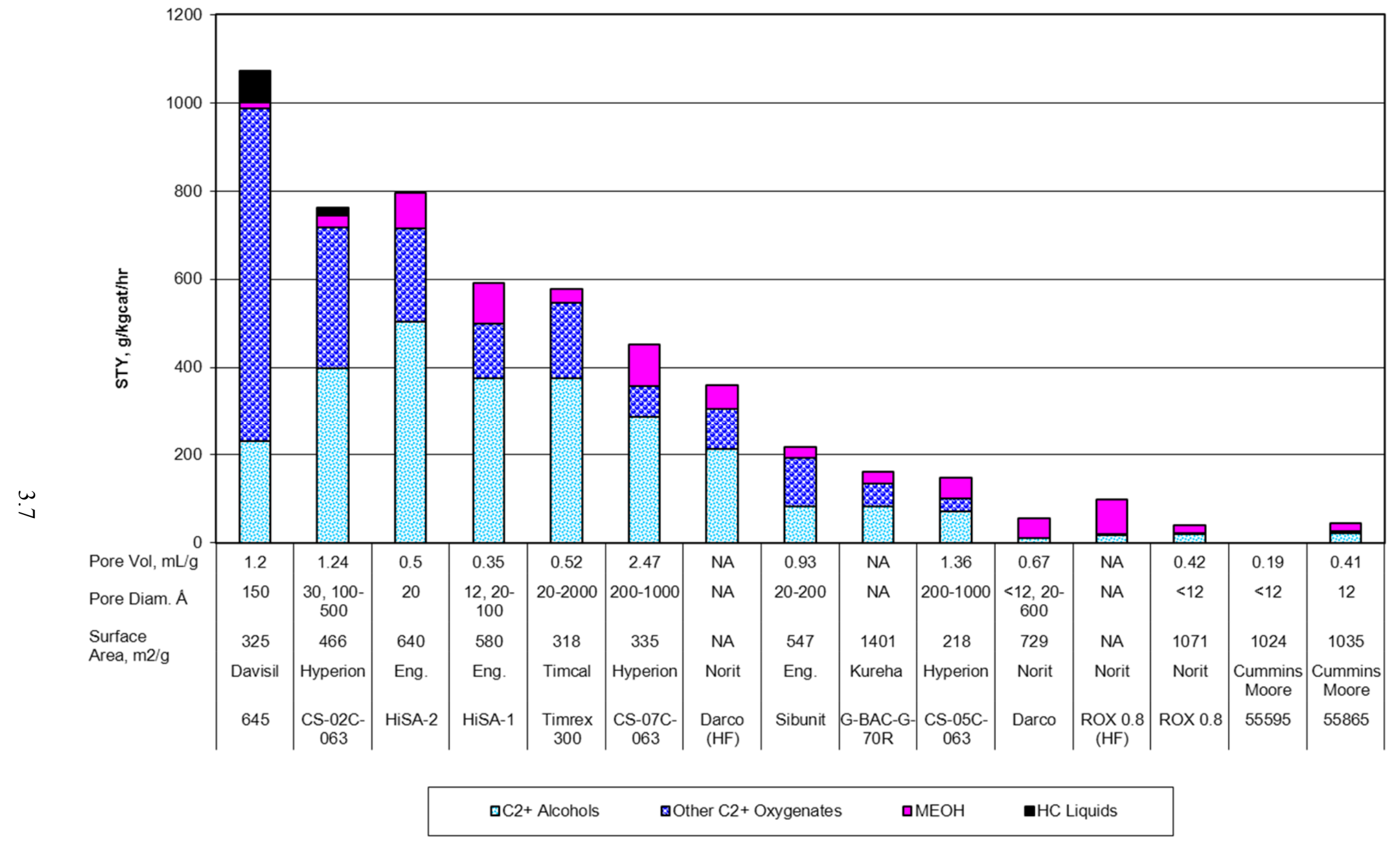

Figure 3.3. Weight-Based STY for RhMn Catalyst on Alternative Carbon Supports at $300^{\circ} \mathrm{C}$ 


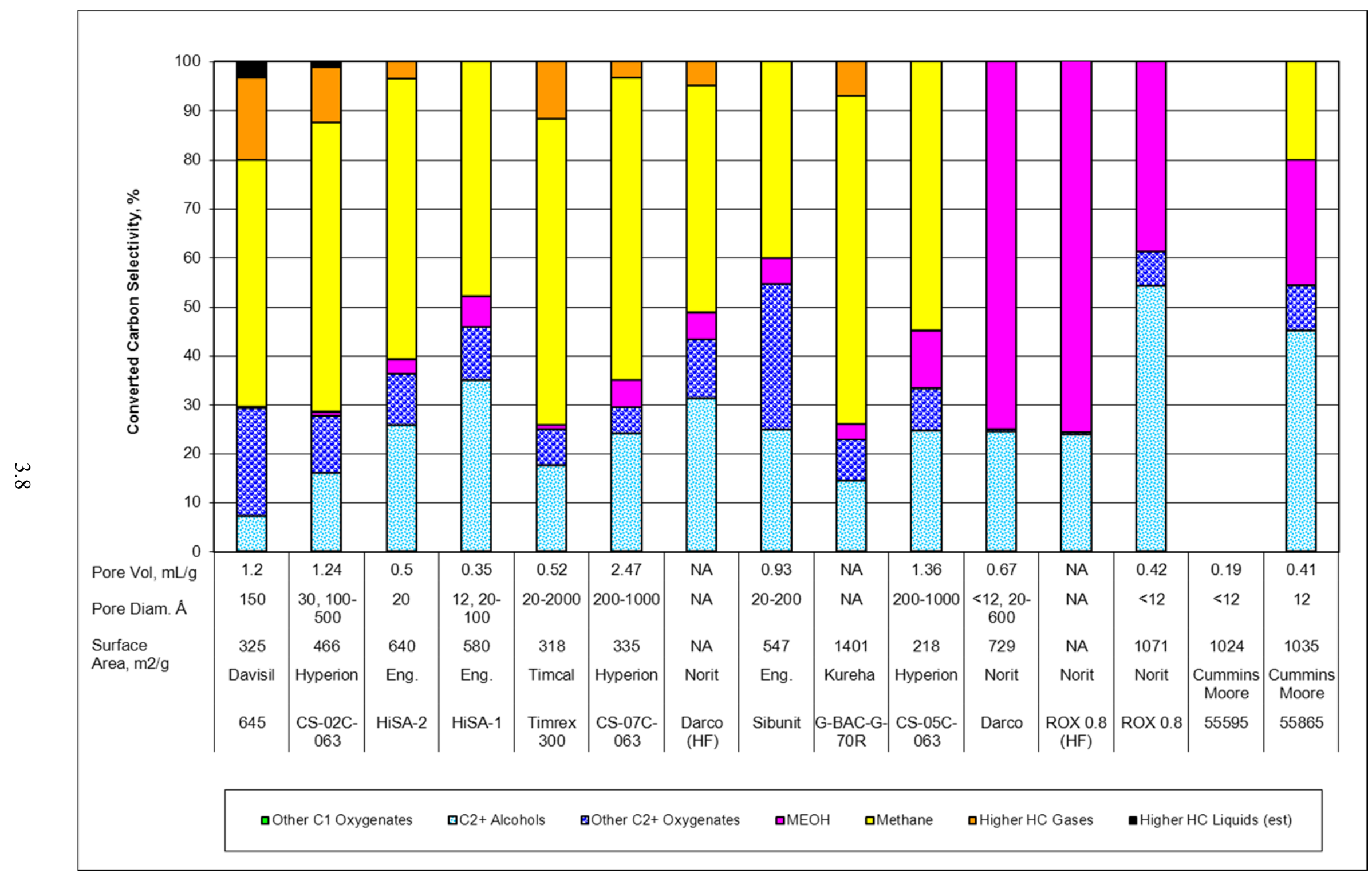

Figure 3.4. Converted Carbon Selectivities to Various Products for RhMn Catalyst on Alternative Carbon Supports at $300^{\circ} \mathrm{C}$ 


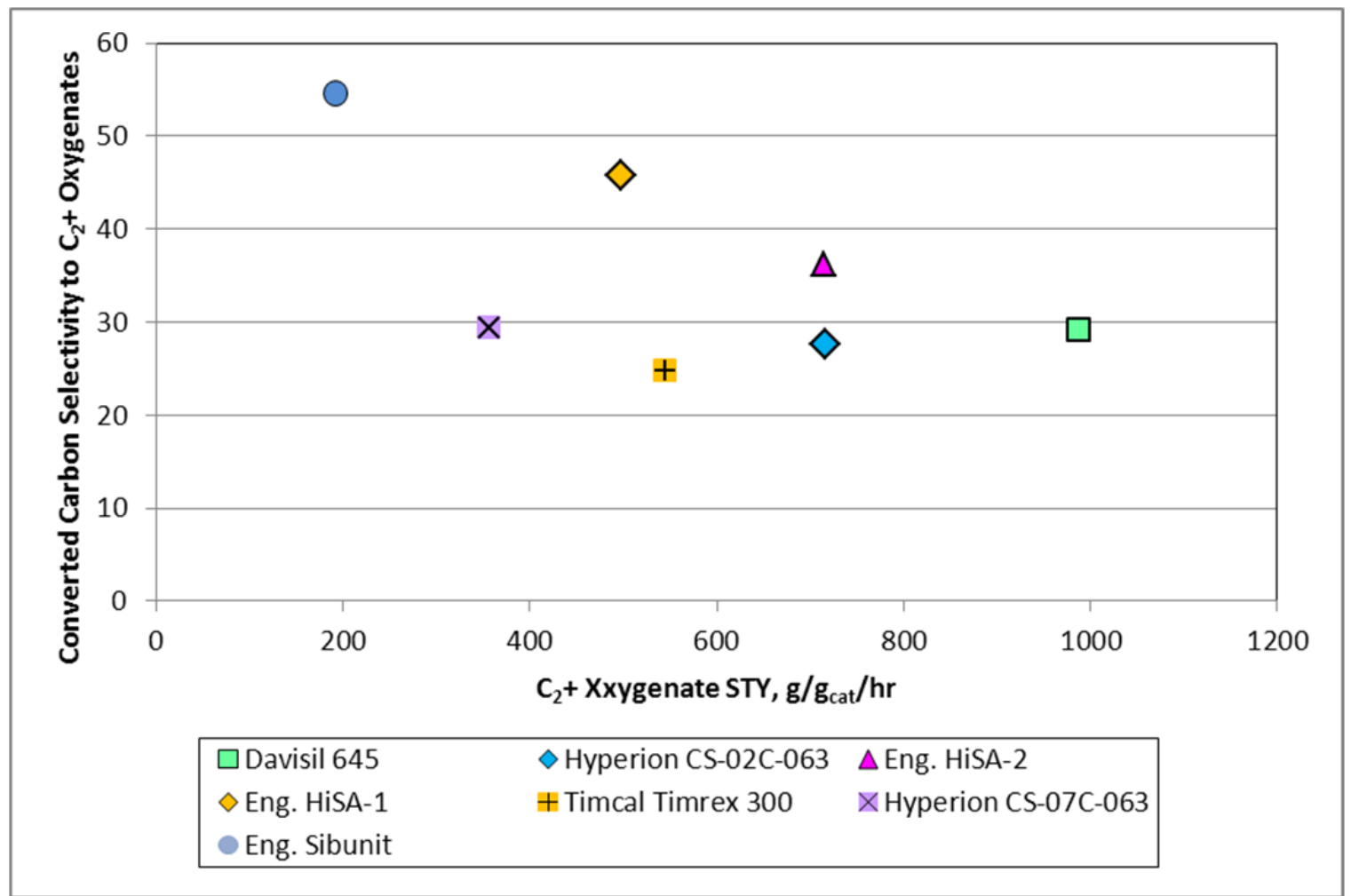

Figure 3.5. Comparison of the $\mathrm{C}_{2}+$ Oxygenates STYs and Converted Carbon Selectivities at $300^{\circ} \mathrm{C}$ for the Various Carbon-Supported RhMn Catalysts 



\subsection{Optimization of RhMn-Based Catalysts}

Tests were conducted during FY 2010 to optimize both silica- and carbon-supported catalysts containing $\mathrm{Rh}$ and $\mathrm{Mn}$ and selected promoters. The silica-supported catalyst tests are discussed in Section 4.1, and the carbon-supported catalysts are discussed in Section 4.2.

\subsection{Silica-Supported Catalysts}

Several test series were conducted to optimize the Rh-based catalysts supported on Davisil 645 silica. These test series investigated the manner of impregnating Ir, Rh, and Mn metals on catalysts containing all three metals, optimization of $\mathrm{Pt}$ and Ga concentration as the third promoter to the RhMn catalyst, and the effect of the manner of impregnating $\mathrm{Rh}$ and Mn onto the catalyst support. These test series are discussed in the following sections.

\subsubsection{Effect of the Method of Iridium Addition on $\mathrm{Rh}-\mathrm{Mn} / \mathrm{SiO}_{2}$ Catalysts}

Previously, six tests were conducted using different concentrations of Ir co-impregnated with the baseline concentrations of $\mathrm{Rh}(5.56 \% \mathrm{Rh})$ and $\mathrm{Mn}(1.69 \% \mathrm{Mn})$ using the Davisil 645 silica support to investigate the effect of the Ir concentration on catalyst performance. The Ir concentrations investigated included:

- $0.00 \mathrm{wt} \%$ (no Ir)

- $0.017 \mathrm{wt} \%(1 / 60 \mathrm{X}$ baseline concentration $)$

- $0.34 \mathrm{wt} \%$ (1/3X baseline concentration)

- $1.03 \mathrm{wt} \%$ (3/3X baseline concentration)

- $1.37 \mathrm{wt} \%$ (4/3X baseline concentration)

- $2.72 \mathrm{wt} \%$ (5/3X baseline concentration).

The baseline concentration of Ir corresponds to a 10:1 Rh:Ir atomic ratio.

During FY 2010, additional tests were conducted in which Rh and Mn first were co-impregnated on the silica support. The catalyst was dried at $120^{\circ} \mathrm{C}$ overnight and then impregnated with $\mathrm{Ir}$, followed by drying overnight at $120^{\circ} \mathrm{C}$ and calcining at $400^{\circ} \mathrm{C}$ for 2 hours. The Ir concentrations investigated in this set of tests included:

- $0.69 \mathrm{wt} \%$ (2/3X baseline concentration)

- $1.03 \mathrm{wt} \%$ (3/3X baseline concentration)

- $1.37 \mathrm{wt} \%$ (4/3X baseline concentration)

- $1.54 \mathrm{wt} \%$ (3/2X baseline concentration).

Figures 4.1 through 4.4 provide comparative data for the following two test conditions: 1) $255^{\circ} \mathrm{C}$ and $7500 / \mathrm{hr}$ GHSV and 2) $275^{\circ} \mathrm{C}$ and $7500 / \mathrm{hr}$ GHSV. These conditions were chosen because the carbon conversions were very high at these temperatures for several of the double-impregnated catalysts and because some of these catalysts were unstable at $300^{\circ} \mathrm{C}$ and higher temperatures and may have undergone deactivation to varying degrees, thereby making comparisons questionable. 

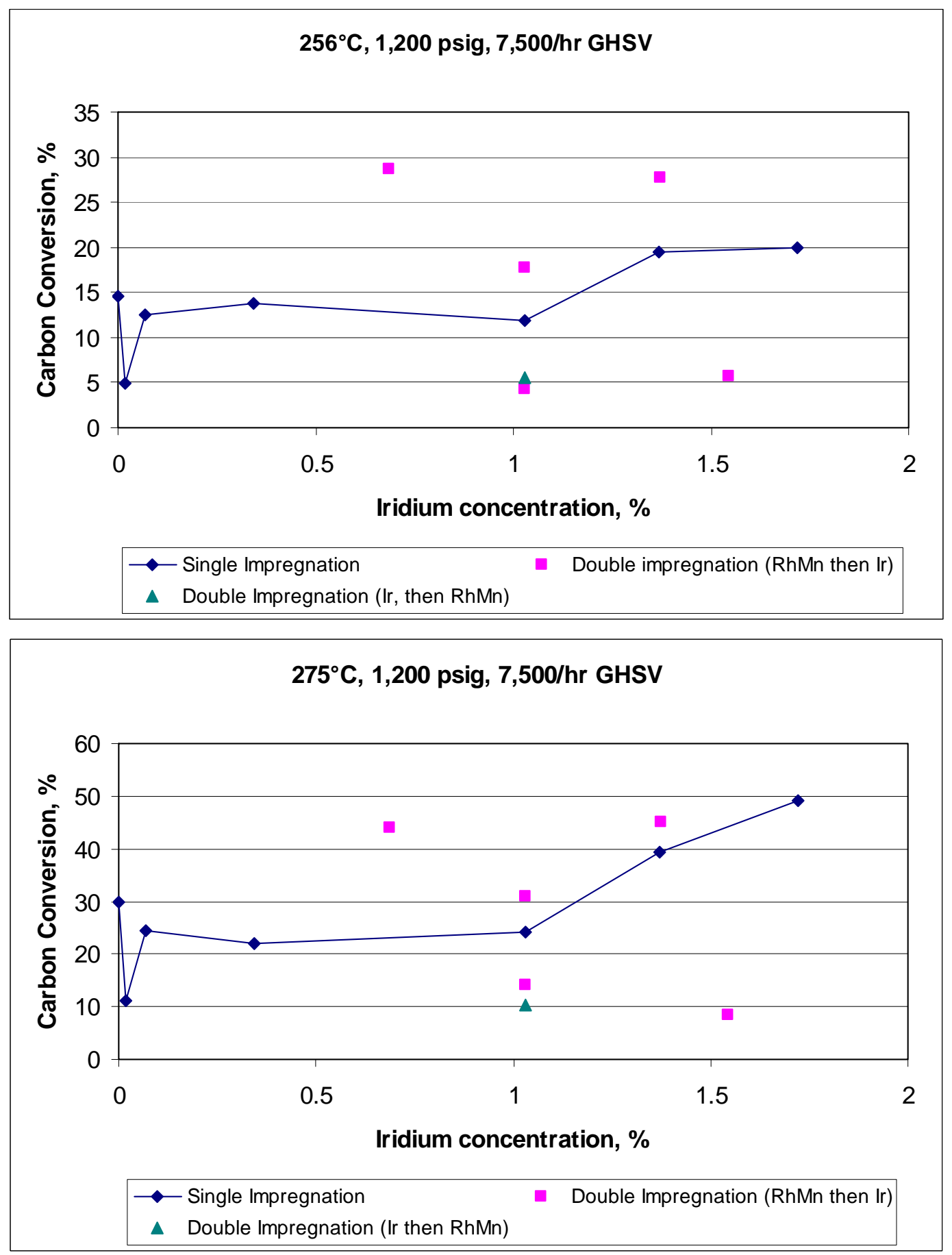

Figure 4.1. Effect of Ir Concentration on Carbon Conversion for the Davisil 645 Silica-Supported RhMn Catalysts at $256^{\circ} \mathrm{C}$ and $275^{\circ} \mathrm{C}$

Figure 4.1 compares the carbon conversions for different Ir concentrations for both sets of catalysts. Taken alone, data for the co-impregnated catalysts (single impregnation) suggest that there is a significant improvement in carbon conversion at Ir concentrations greater than 1\%, although there is some scatter in the data. There is too much scatter in the data for the double-impregnated catalysts to make any conclusions regarding carbon conversion. Clearly some catalysts prepared using two impregnations had 
carbon conversions substantially higher or substantially lower than those achieved with co-impregnated catalysts. When both sets of data are considered together, caution is given to the interpretation of the coimpregnated catalysts. Further tests, using co-impregnated catalysts both from the same catalyst batch as these tests and from freshly made catalysts, are required to ascertain what can be attributed to scatter in the data for catalysts with the same concentration and to determine whether there is an optimum Ir concentration for the double-impregnated catalysts.

Figure 4.2 compares the converted carbon selectivity to $\mathrm{C}_{2}+$ oxygenates for the different $\mathrm{Ir}$ concentrations for both sets of catalysts. It appears that there is a general downward trend in carbon selectivity with increasing Ir concentration for the co-impregnated (single impregnation) catalyst, but there is considerable scatter in the data, which may be masking any localized optimum concentration. It also appears that the converted carbon selectivity to $\mathrm{C}_{2}+$ oxygenates achieves a maximum at $4 / 3 \mathrm{X}$ baseline Ir concentration (1.37 wt\%) for double-impregnated catalysts ( $\mathrm{Rh}$ and $\mathrm{Mn}$ additions, followed by Ir addition). While the scatter in the data is not nearly as pronounced as it was for carbon conversion, this observation also must be made with caution. When Ir addition followed by $\mathrm{Rh}$ and $\mathrm{Mn}$ additions was used in a double-impregnated catalyst, the converted carbon selectivity to $\mathrm{C}_{2}+$ oxygenates was significantly lower than that for both the co-impregnated catalyst and the double-impregnated catalysts where $\mathrm{Rh}$ and $\mathrm{Mn}$ were added in the first impregnation as shown. This behavior also persisted at the higher operating temperatures.

Figure 4.3 compares the $\mathrm{C}_{2}+$ oxygenates STYs for the different Ir concentrations for both sets of catalysts. The data for both co-impregnated and double-impregnated catalysts closely follows the data for carbon conversion in terms of overall trends and scatter in the data, with similar conclusions being reached. Specifically, for the co-impregnated catalysts, there may be a small increase in the STY with increasing Ir concentration, but the data scatter is too great to draw any conclusions regarding doubleimpregnated catalysts on catalyst performance.

Figure 4.4 compares the selectivity of all oxygenates to $\mathrm{C}_{2}+$ alcohols. There does not appear to be any strong trend in selectivity with increasing Ir concentration for the co-impregnated catalysts, and it also appears that the double-impregnated catalysts ( $\mathrm{Rh}$ and $\mathrm{Mn}$ additions, followed by $\mathrm{Ir}$ addition) either maintain the same selectivity of all oxygenates to $\mathrm{C}_{2}+$ alcohols or achieve much higher selectivities. However, there is an excessive amount of scatter in the data, making definitive conclusions problematic regarding this parameter for the double-impregnated catalysts. The selectivity to alcohols for the doubleimpregnated catalyst when Ir is added in the first impregnation was consistently lower than the other two formulations as shown in Figure 4.4 as well as at higher tested temperatures. However, the validity of this observation could be questionable considering the scatter in the data for the other double-impregnated catalysts.

Overall, there may be a minor increasing trend in carbon conversion, a decreasing trend in converted carbon selectivity to $\mathrm{C}_{2}+$ oxygenates, and no trend in $\mathrm{C}_{2}+$ oxygenates STY with increasing Ir concentration for the co-impregnated catalysts. However, with the scatter in the data for these catalysts as well as that for the double-impregnated catalysts, these trends should be treated with caution. No clear trends could be ascertained for the double- impregnated catalysts because of the scatter in the data. Before any conclusions can be drawn, additional testing is needed to repeat tests with current catalyst samples and freshly made catalysts, and to investigate a greater range of Ir concentrations. 

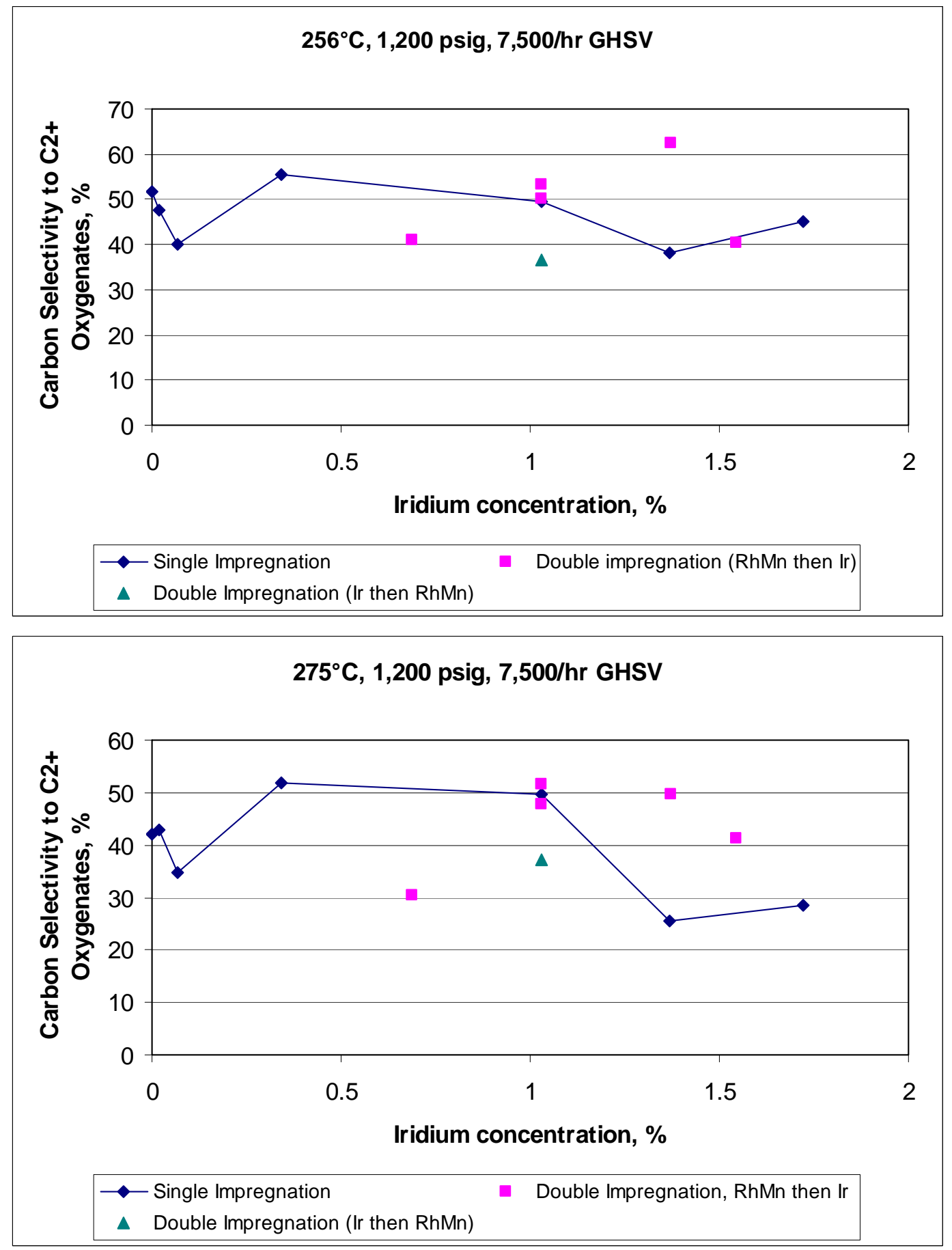

Figure 4.2. Effect of Ir Concentration on Carbon Selectivity to $\mathrm{C}_{2}+$ Oxygenates for the Davisil 645 Silica-Supported RhMn Catalysts at $256^{\circ} \mathrm{C}$ and $275^{\circ} \mathrm{C}$ 

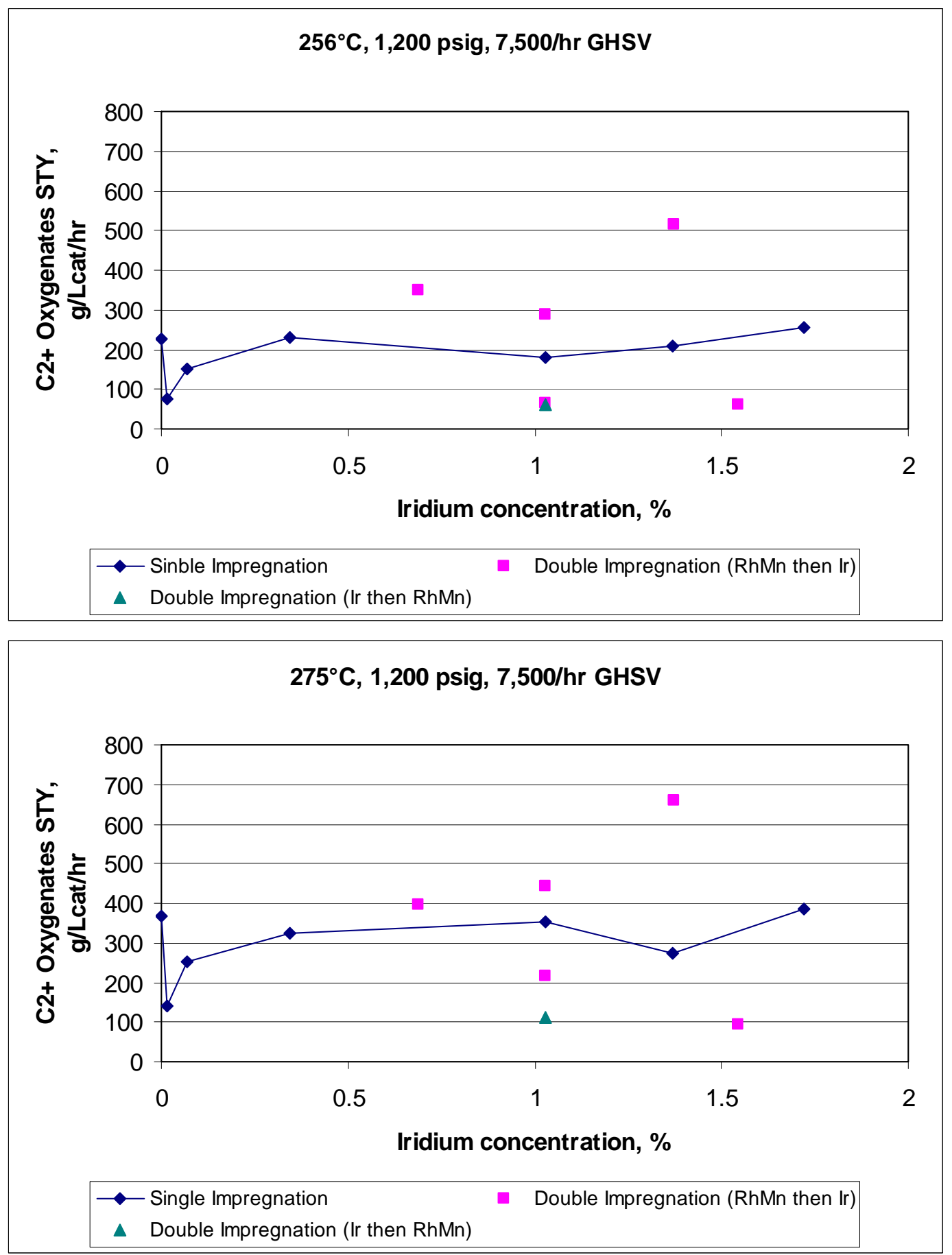

Figure 4.3. Effect of Ir Concentration on $\mathrm{C}_{2}+$ Oxygenates STY for the Davisil 645 Silica-Supported RhMn Catalysts at $256^{\circ} \mathrm{C}$ and $275^{\circ} \mathrm{C}$ 

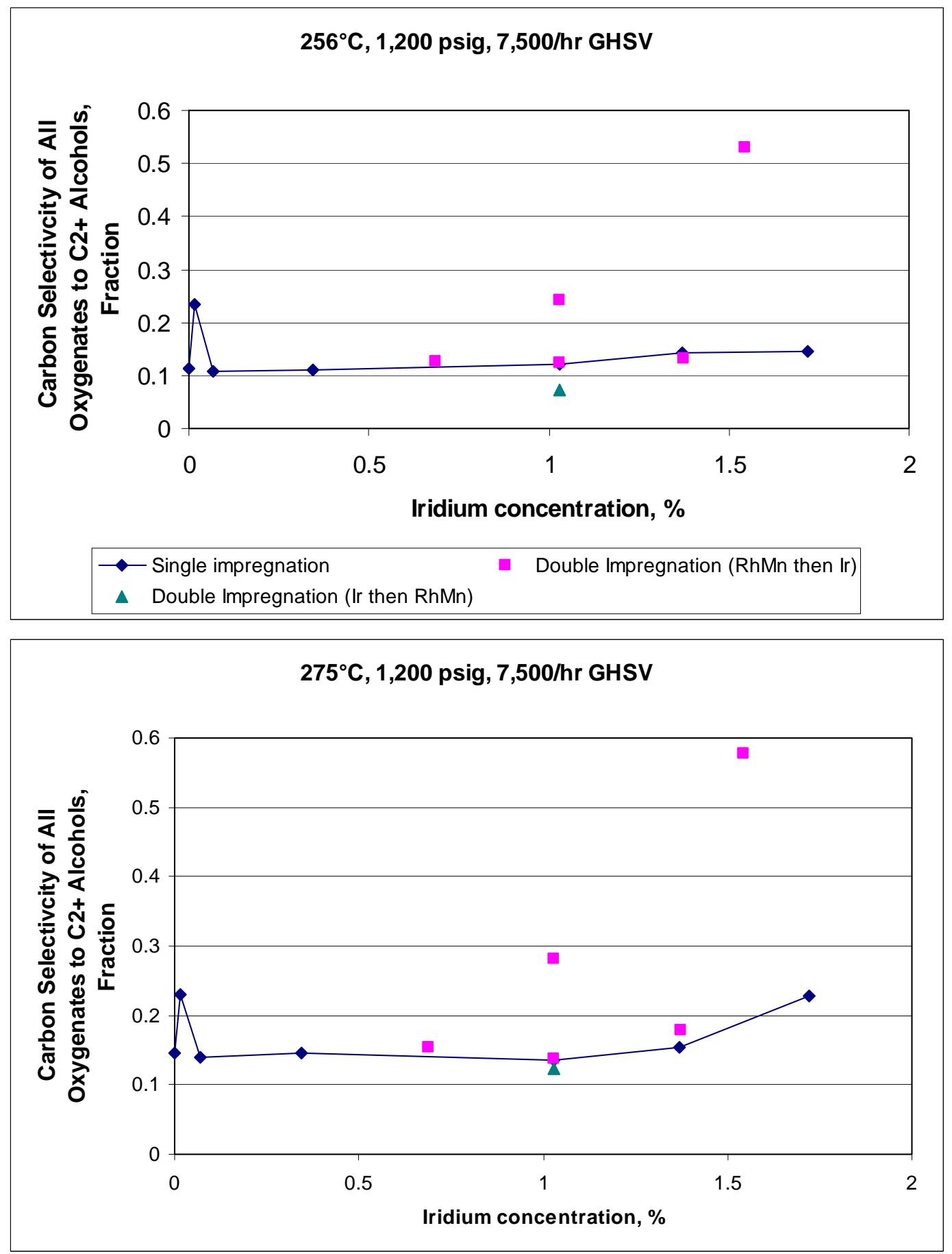

Figure 4.4. Effect of Ir Concentration on Carbon Selectivity of $\mathrm{C}_{2}+$ Oxygenates to Alcohols for the Davisil 645 Silica-Supported RhMn Catalysts at $256^{\circ} \mathrm{C}$ and $275^{\circ} \mathrm{C}$ 


\subsubsection{Effect of Platinum Concentration on Platinum-Promoted $\mathrm{Rh}-\mathrm{Mn} / \mathrm{SiO}_{2}$ Catalysts}

Five tests were conducted using different concentrations of Pt co-impregnated with the baseline concentrations of $\mathrm{Rh}(5.56 \% \mathrm{Rh})$ and $\mathrm{Mn}(1.69 \% \mathrm{Mn})$ using the Davisil 645 silica support to examine the effect of the Pt concentration on catalyst performance. The Pt concentrations investigated included:

- $0.00 \mathrm{wt} \%$ (no Pt)

- $0.35 \mathrm{wt} \%$ (1/3X baseline concentration)

- $0.69 \mathrm{wt} \%$ (2/3X baseline concentration)

- $1.05 \mathrm{wt} \%$ (3/3X baseline concentration)

- $1.40 \mathrm{wt} \%$ (4/3X baseline concentration).

The baseline Pt concentration (1.05\% Pt) corresponds to a 10:1 Rh:Pt atomic ratio.

Figures 4.5 through 4.6 provide comparative data for the following two test conditions: 1) $275^{\circ} \mathrm{C}$ and $7500 / \mathrm{hr}$ GHSV and 2) $315^{\circ} \mathrm{C}$ and $12,000 / \mathrm{hr}$ GHSV. These two conditions were chosen because they fairly well represented catalyst behavior below and above $300^{\circ} \mathrm{C}$ with catalysts tested at that temperature performing in a manner that was between to the two other temperatures. An earlier test is also included in the figures for a catalyst containing the same $1 \mathrm{X}$ baseline concentrations that was prepared by first coimpregnating $\mathrm{Rh}$ and $\mathrm{Mn}$ at their baseline concentrations on the silica support and then, after drying, impregnating the catalyst with the baseline concentration of $\mathrm{Pt}$ (double impregnation).

Figure 4.5 compares the carbon conversions for different Pt concentrations. Overall, there is a decreasing trend in carbon conversion with increasing Pt concentration at both temperatures for the coimpregnated catalysts, with very low carbon conversion at baseline and higher Pt concentrations. The double-impregnated catalyst had a slightly lower carbon conversion at $275^{\circ} \mathrm{C}$ than when the catalyst was not promoted with Pt. However, the carbon conversion was much greater than the co-impregnated catalysts with the same or higher Pt concentrations. At $315^{\circ} \mathrm{C}$, the double-impregnated catalyst had a higher conversion than the unpromoted $\mathrm{RhMn}$ catalyst, while at $300^{\circ} \mathrm{C}$ (not shown) the carbon conversion was nearly the same. Again, the carbon conversion on the double-impregnated catalyst was much greater than the co-impregnated catalysts with the same or higher Pt concentrations at the higher temperatures.

Figure 4.6 compares the converted carbon selectivity to $\mathrm{C}_{2}+$ oxygenates for the different $\mathrm{Pt}$ concentrations. Selectivities for the co-impregnated catalysts (single impregnation) with $\mathrm{Pt}$ concentrations at or above the baseline concentration of $1.05 \%$ at $275^{\circ} \mathrm{C}$ were not included because the carbon conversions were less than $1 \%$ resulting in hydrocarbon concentrations that were below the detection limit for the GC. In general, there appeared to be an increase in selectivity with increasing Pt concentration for the co-impregnated catalysts at temperatures at or above $275^{\circ} \mathrm{C}$, although there was considerable scatter in the data at $300^{\circ} \mathrm{C}$ or higher temperatures. At $256^{\circ} \mathrm{C}$ (not shown), the selectivity decreased with increasing Pt concentration. The double-impregnated catalyst at the baseline $\mathrm{Pt}$ concentration had a selectivity that was nearly the same as the unpromoted catalyst at $256^{\circ} \mathrm{C}$. That selectivity relative to the unpromoted catalyst gradually increased with increasing operating temperature throughout the testing range. Where comparisons could be made at $300^{\circ} \mathrm{C}$ and $315^{\circ} \mathrm{C}$, the selectivity of the double-impregnated catalyst was less than that for the co-impregnated catalyst at the same or higher concentration. 

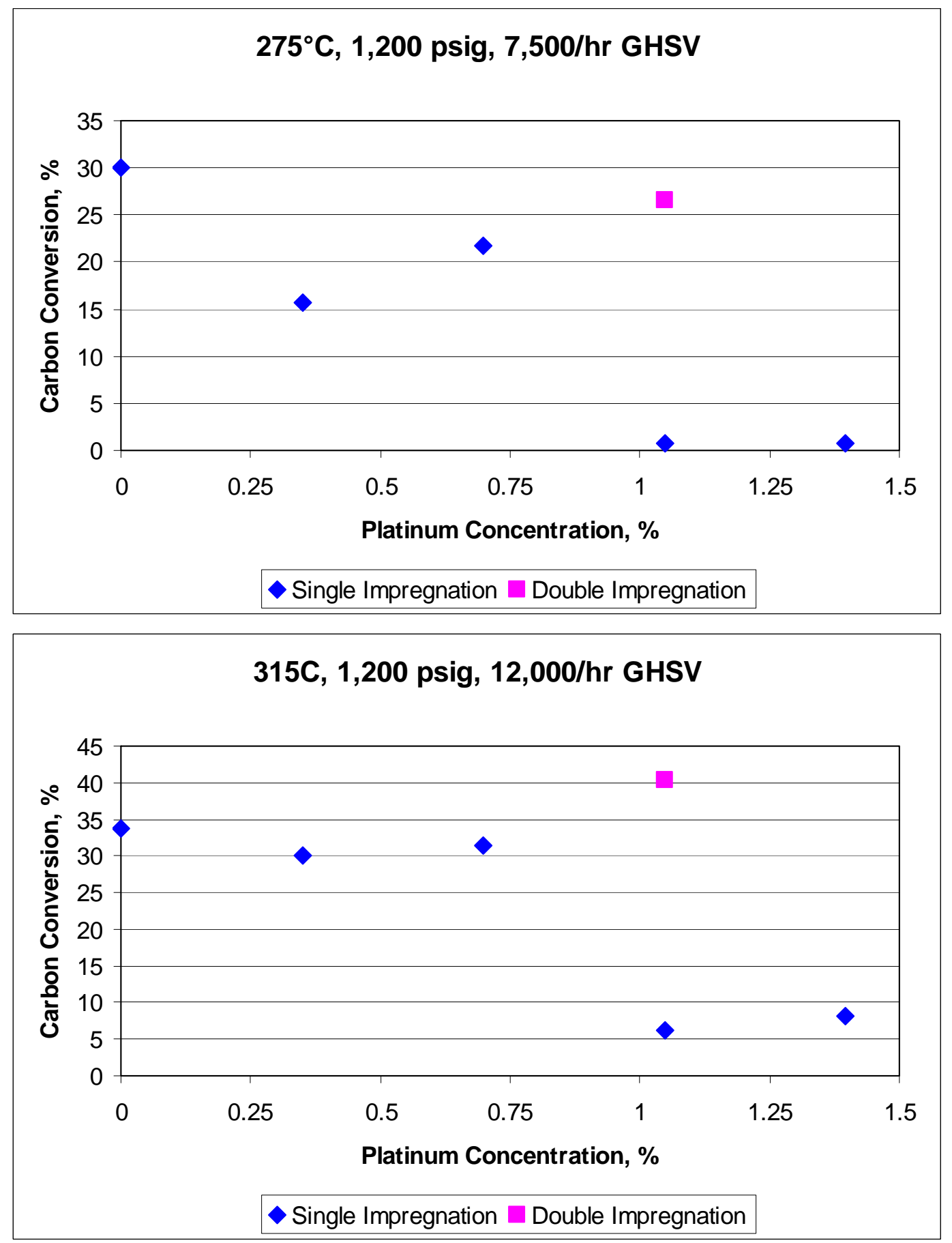

Figure 4.5. Effect of Pt Concentration on Carbon Conversion for the Davisil 645 Silica-Supported RhMn Catalysts at $275^{\circ} \mathrm{C}$ and $315^{\circ} \mathrm{C}$ 

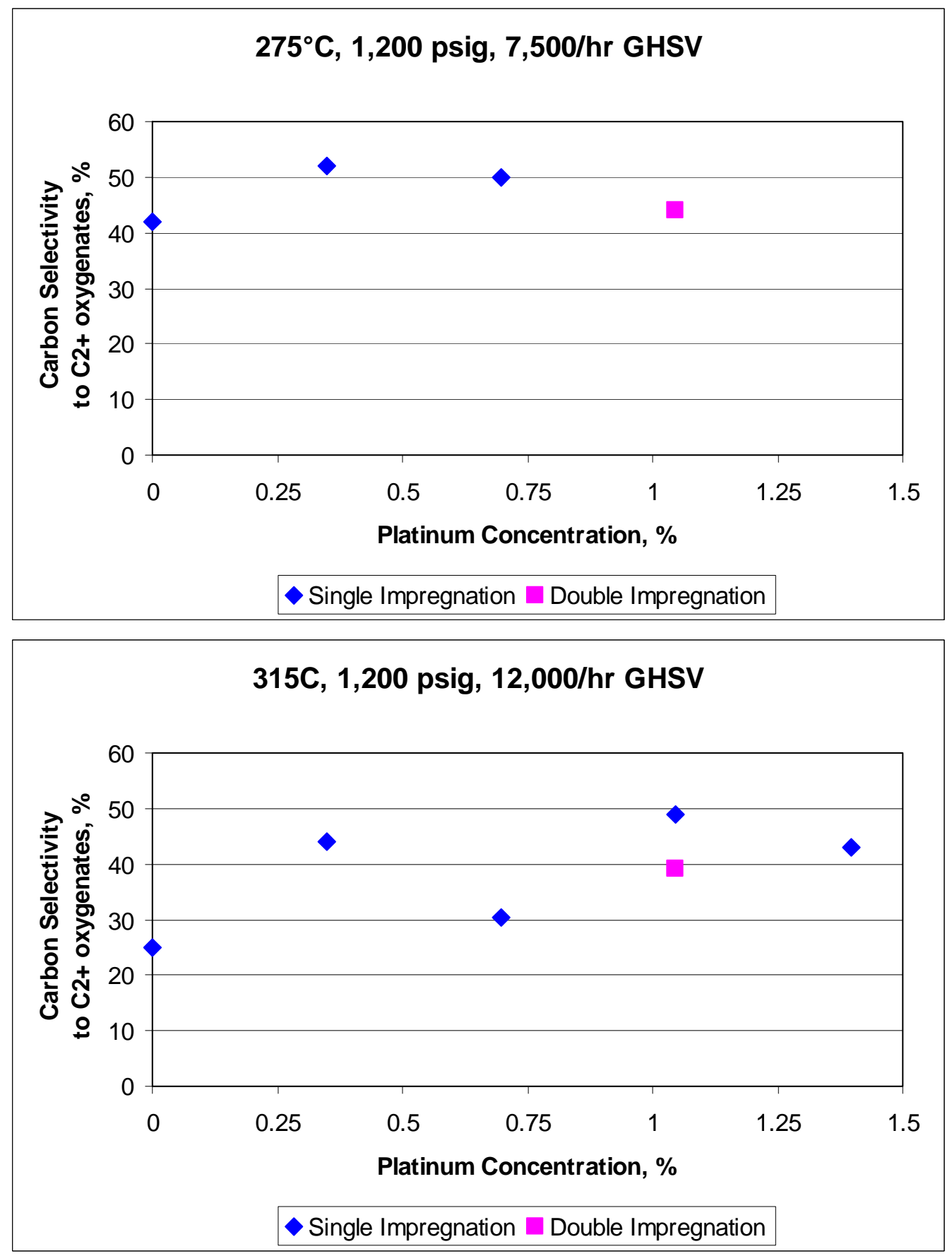

Figure 4.6. Effect of Pt Concentration on Carbon Selectivity to $\mathrm{C}_{2}+$ Oxygenates for the Davisil 645 Silica-Supported $\mathrm{RhMn}$ Catalysts at $275^{\circ} \mathrm{C}$ and $315^{\circ} \mathrm{C}$

Figure 4.7 compares the $\mathrm{C}_{2}+$ oxygenates STYs for the different Pt concentrations. In general, the STYs at the lower and higher temperatures behaved in a manner similar to the carbon conversion for both the co-impregnated and double-impregnated catalysts. The main difference was that, as the temperature increased, there was a trend towards higher STYs at the lower Pt concentrations for the co-impregnated catalysts than for the unpromoted RhMn catalyst. This trend suggests that it might be desirable to investigate Pt concentrations less than $1 / 3 \mathrm{X}$ of the baseline Pt concentration. 

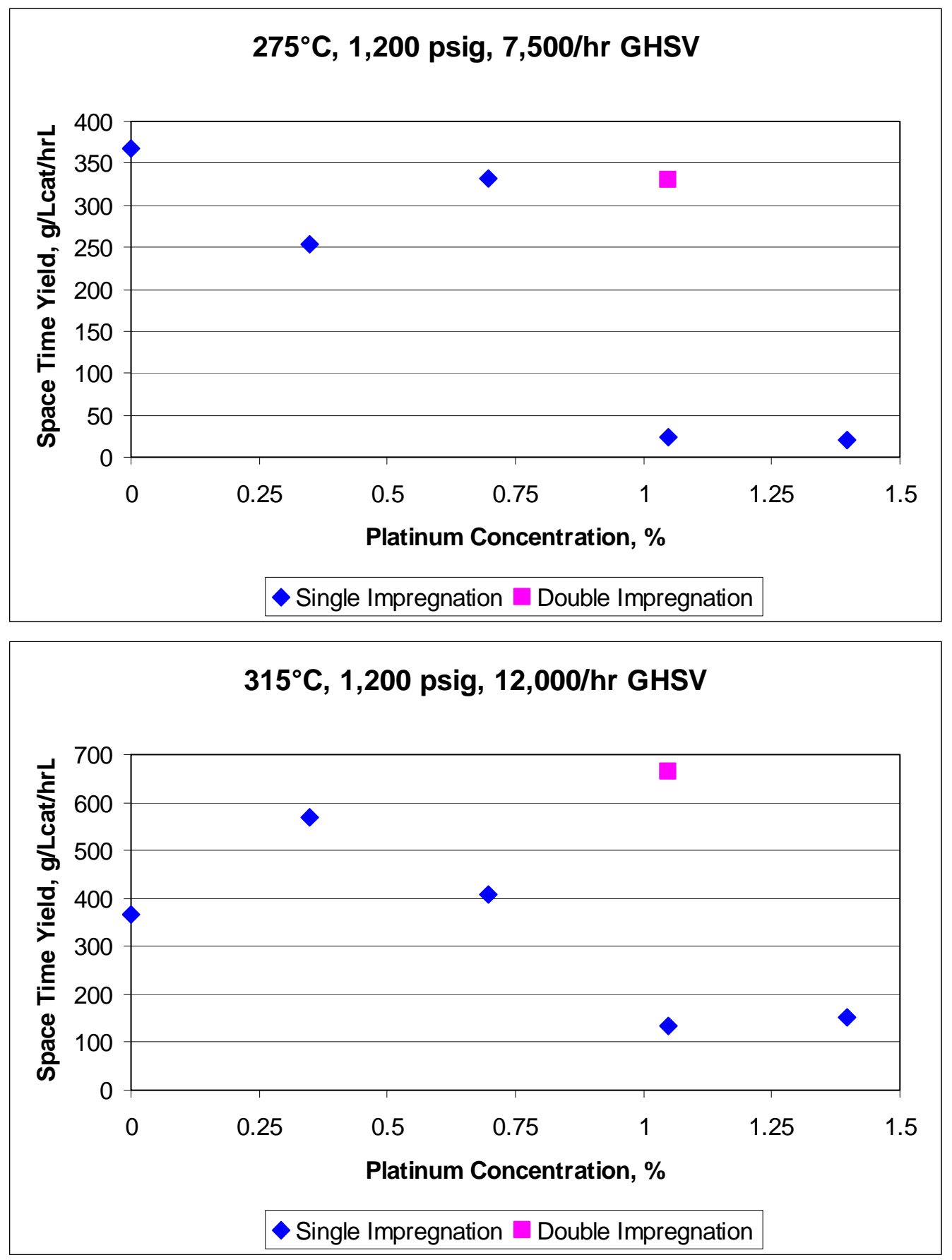

Figure 4.7. Effect of Pt Concentration on $\mathrm{C}_{2}+$ Oxygenates STY for the Davisil 645 Silica-Supported RhMn Catalysts at $275^{\circ} \mathrm{C}$ and $315^{\circ} \mathrm{C}$

Figure 4.8 compares the selectivity of all oxygenates to $\mathrm{C}_{2}+$ alcohols. In general, there is a consistent trend of increasing selectivity with increasing Pt concentration for the co-impregnated catalysts at all temperatures tested. However, the selectivity of the double-impregnated catalyst with a Pt concentration of $1 \mathrm{X}$ the baseline Pt concentration had a selectivity that trended from being approximately the same as that for the unpromoted catalyst at $256^{\circ} \mathrm{C}$ to progressively lower in selectivity than the unpromoted catalyst with increasing temperature. 

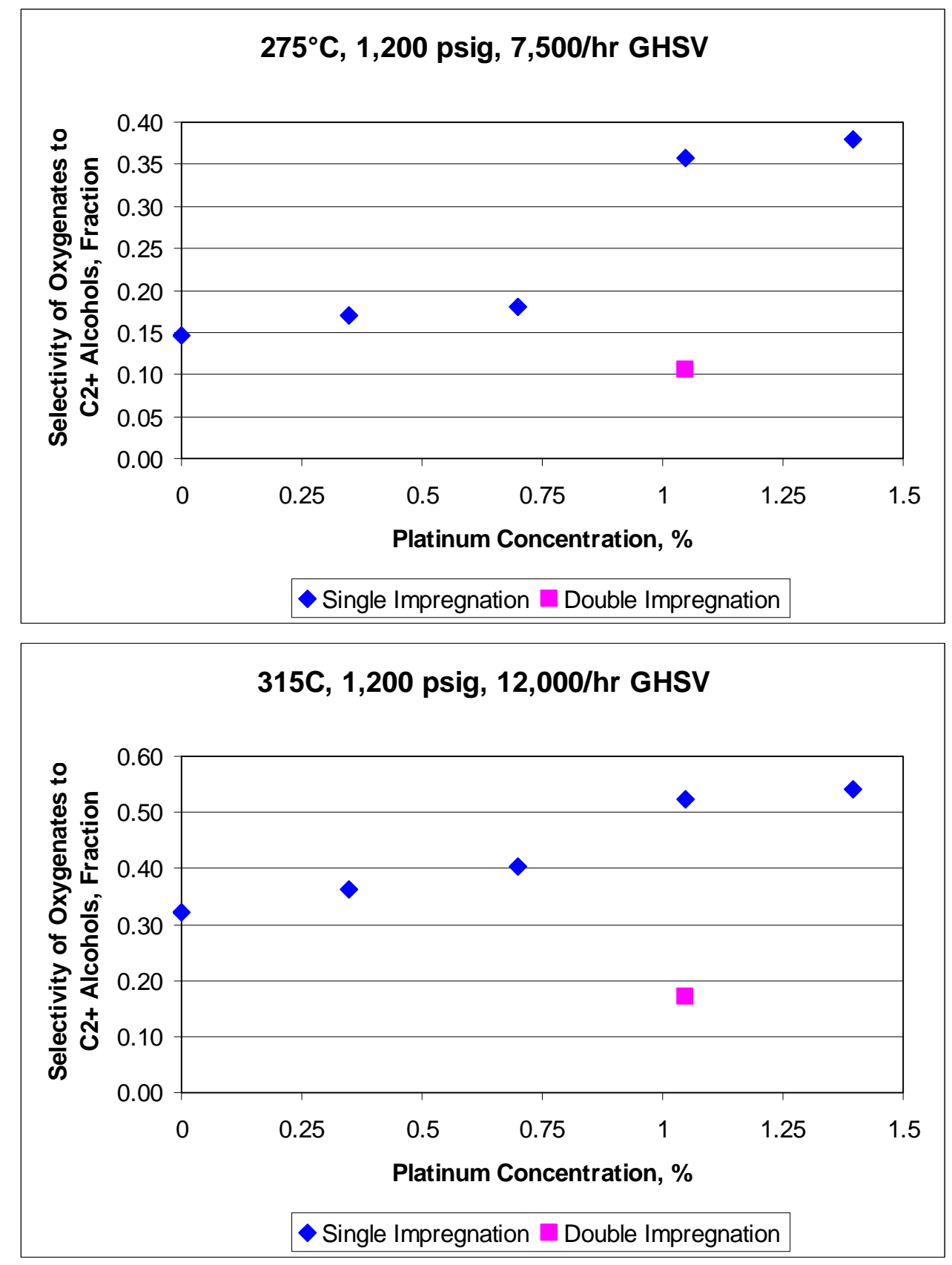

Figure 4.8. Effect of Pt Concentration on Carbon Selectivity of $\mathrm{C}_{2}+$ Oxygenates to Alcohols for the Davisil 645 Silica-Supported RhMn Catalysts at $275^{\circ} \mathrm{C}$ and $315 \mathrm{C}$

Overall, it appears that adding Pt to the $\mathrm{RhMn} / \mathrm{SiO}_{2}$ catalyst, via a single co-impregnation of all three metals, decreases the catalysts activity (carbon conversion) but increases the catalyst carbon selectivity to $\mathrm{C}_{2}+$ oxygenates. The net result is that there appears to be a maximum STY at the lower concentrations, possibly below a concentration of $1 / 3 \mathrm{X}$ of the baseline concentration of $1.05 \% \mathrm{Pt}$. Further testing would be required to confirm this hypothesis. It also appears that the double-impregnated catalyst, for which $\mathrm{Pt}$ is added in the second impregnation, is much more active, at least at the baseline Pt concentration with comparable or higher converted carbon selectivity to $\mathrm{C}_{2}+$ oxygenates, depending on the temperature. Further testing is needed to optimize the Pt concentration for the double-impregnated catalysts. 


\subsubsection{Effect of Gallium Concentration on Gallium-Promoted Rh-Mn/SiO 2 Catalysts}

Five tests were conducted using different concentrations of Ga co-impregnated with the baseline concentrations of $\mathrm{Rh}(5.56 \% \mathrm{Rh})$ and $\mathrm{Mn}(1.69 \% \mathrm{Mn})$ using the Davisil 645 silica support to examine the effect of the Ga concentration on catalyst performance. The Ga concentrations investigated included:

- $0.00 \mathrm{wt} \%$ (no Ga)

- $0.00234 \mathrm{wt} \%(0.00625 \mathrm{X}$ baseline concentration $)$

- $0.00468 \mathrm{wt} \%(0.0125 \mathrm{X}$ baseline concentration $)$

- $0.00935 \mathrm{wt} \%$ (0.025X baseline concentration)

- $0.187 \mathrm{wt} \%(0.5 \mathrm{X}$ baseline concentration $)$

The baseline Ga concentration $(0.374 \% \mathrm{Ga})$ corresponds to a 10:1 Rh:Ga atomic ratio.

Figures 4.9 through 4.12 provide comparative data for the following two test conditions: 1) $275^{\circ} \mathrm{C}$ and $7500 / \mathrm{hr}$ GHSV and 2) $315^{\circ} \mathrm{C}$ and $12,000 / \mathrm{hr} \mathrm{GHSV}$. The latter condition was chosen because the $\mathrm{C}_{2}+$ oxygenates STYs was at a maximum for the Ga impregnated catalysts, while the former condition illustrates the trends in catalyst behavior at lower temperatures.

Figure 4.9 compares the carbon conversions for different Ga concentrations. It can be seen that addition of even very small concentrations of Ga produced significantly reduced carbon conversions, which further decrease with increasing concentration. This behavior was more pronounced at lower temperatures.

Figure 4.10 compares the converted carbon selectivities to $\mathrm{C}_{2}+$ oxygenates for different $\mathrm{Ga}$ concentrations. In general, there is a trend towards increasing selectivity with increasing $\mathrm{Ga}$ concentration. However, this trend is very diminished at concentrations $0.00468 \mathrm{wt} \% \mathrm{Ga}$ or lower at the lower temperatures, but very pronounced at $300^{\circ} \mathrm{C}$ and higher temperatures.

Figure 4.11 compares the $\mathrm{C}_{2}+$ oxygenates STYs for different Ga concentrations. It can be seen that the effect of concentration depends on the temperature of the catalyst for Ga concentrations of $0.00468 \%$ or lower. At lower temperatures, at which there is very little effect of concentration in this range on the converted carbon selectivity to $\mathrm{C}_{2}+$ oxygenates, the STY decreases very significantly and then continues to decrease at lower rates for higher $\mathrm{Ga}$ concentrations. However, at $300^{\circ} \mathrm{C}$ or higher, there is a very significant increase in the converted carbon selectivity to $\mathrm{C}_{2}+$ oxygenates with increasing $\mathrm{Ga}$ concentrations up to $0.00468 \%$. The result is that there is a maximum in the STY between zero and $0.00468 \% \mathrm{Ga}$ concentrations. This maximum is significantly higher than that for the unpromoted catalyst.

Figure 4.12 compares the selectivity of all oxygenates to $\mathrm{C}_{2}+$ alcohols. The general trend at all temperatures is a relatively rapid increase in selectivity with concentration at the lower concentrations. This increase in selectivity continues but at a lower rate at higher concentrations.

Overall, there appears to be a concentration at or below $0.00468 \% \mathrm{Ga}$ where there is an optimum combination of higher converted carbon selectivity to $\mathrm{C}_{2}+$ oxygenates and $\mathrm{C}_{2}+$ oxygenates STY that is significantly higher than that of the unpromoted $\mathrm{RhMn} / \mathrm{SiO}_{2}$ catalyst. This optimum appears to occur when the catalyst is heated to about $300^{\circ} \mathrm{C}$, suggesting some change in the catalyst at this temperature. 

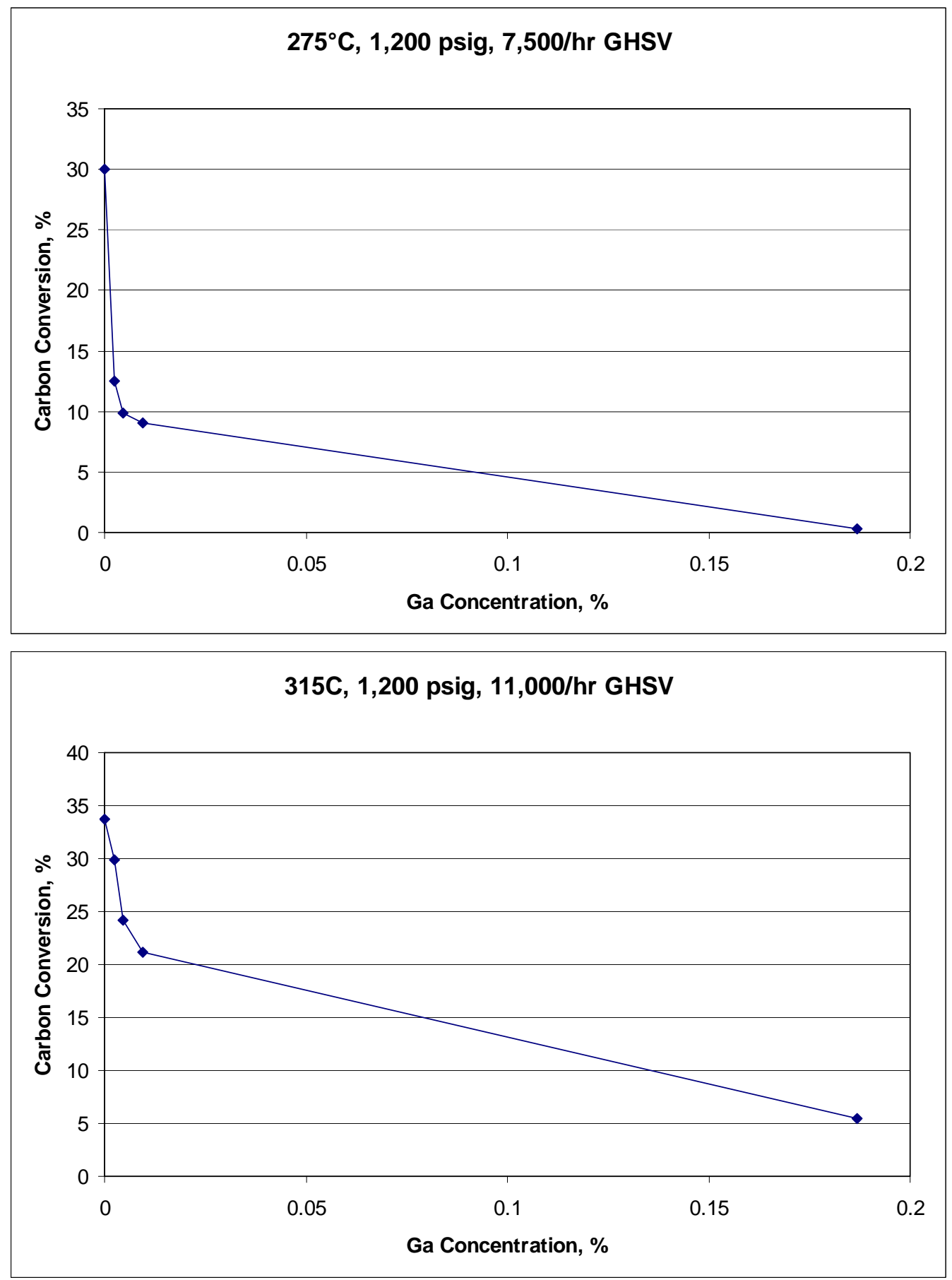

Figure 4.9. Effect of Ga Concentration on Carbon Conversion for the Davisil 645 Silica-Supported RhMn Catalysts at $275^{\circ} \mathrm{C}$ and $315^{\circ} \mathrm{C}$ 

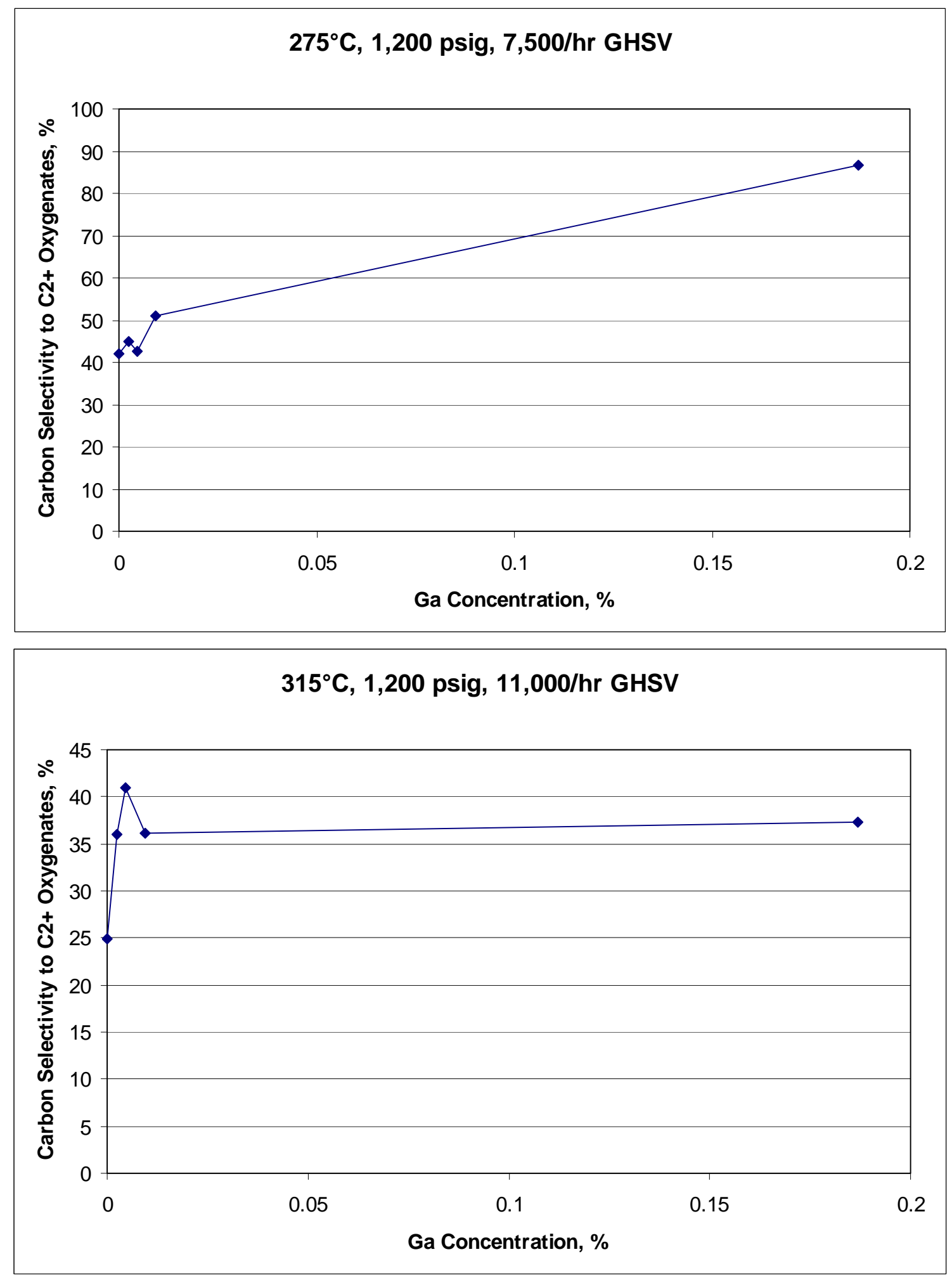

Figure 4.10. Effect of Ga Concentration on Carbon Selectivity to $\mathrm{C}_{2}+$ Oxygenates for the Davisil 645 Silica-Supported RhMn Catalysts at $275^{\circ} \mathrm{C}$ and $315^{\circ} \mathrm{C}$ 

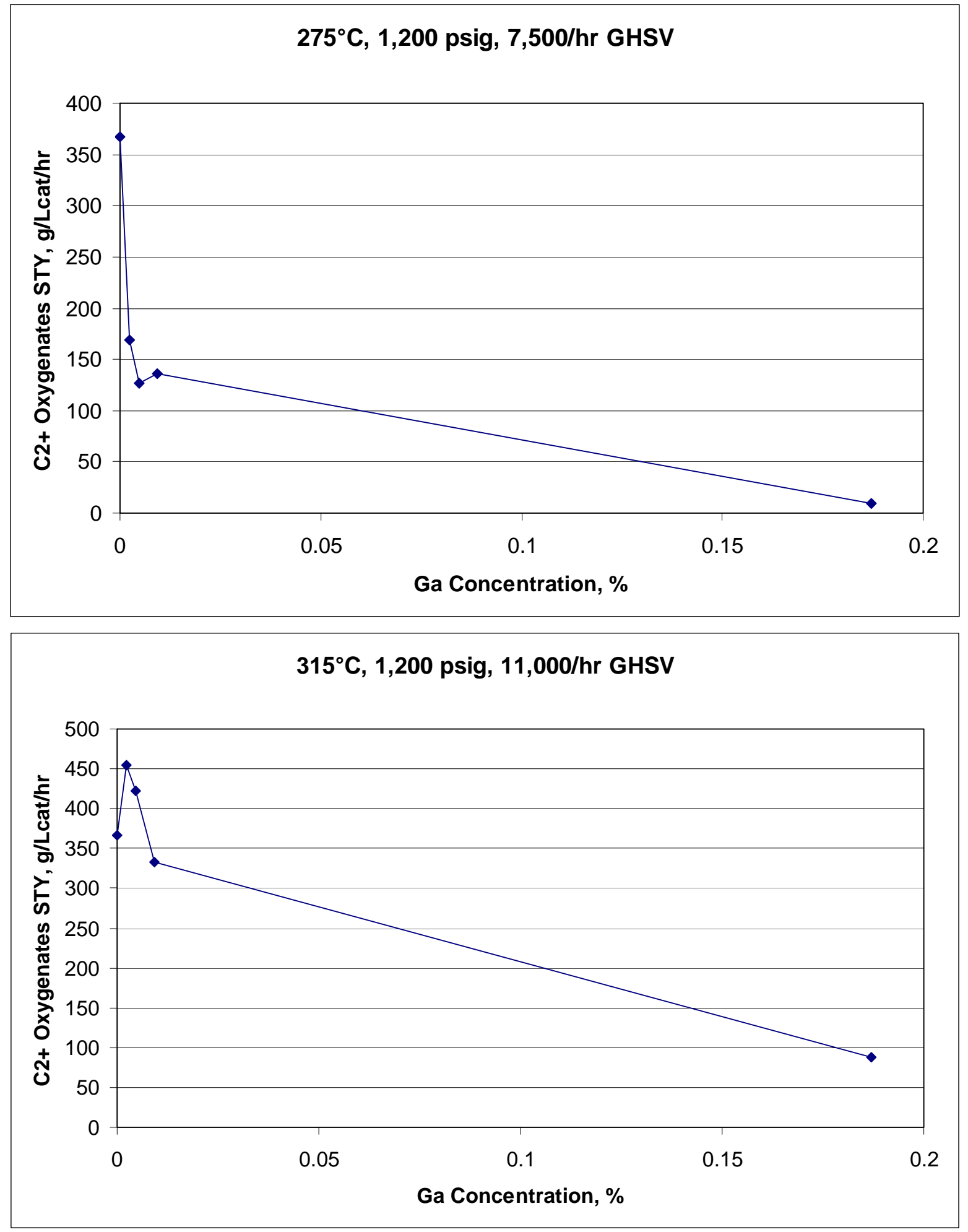

Figure 4.11. Effect of $\mathrm{Ga}$ Concentration on $\mathrm{C}_{2}+$ Oxygenates STY for the Davisil 645 Silica-Supported RhMn Catalysts at $275^{\circ} \mathrm{C}$ and $315^{\circ} \mathrm{C}$ 

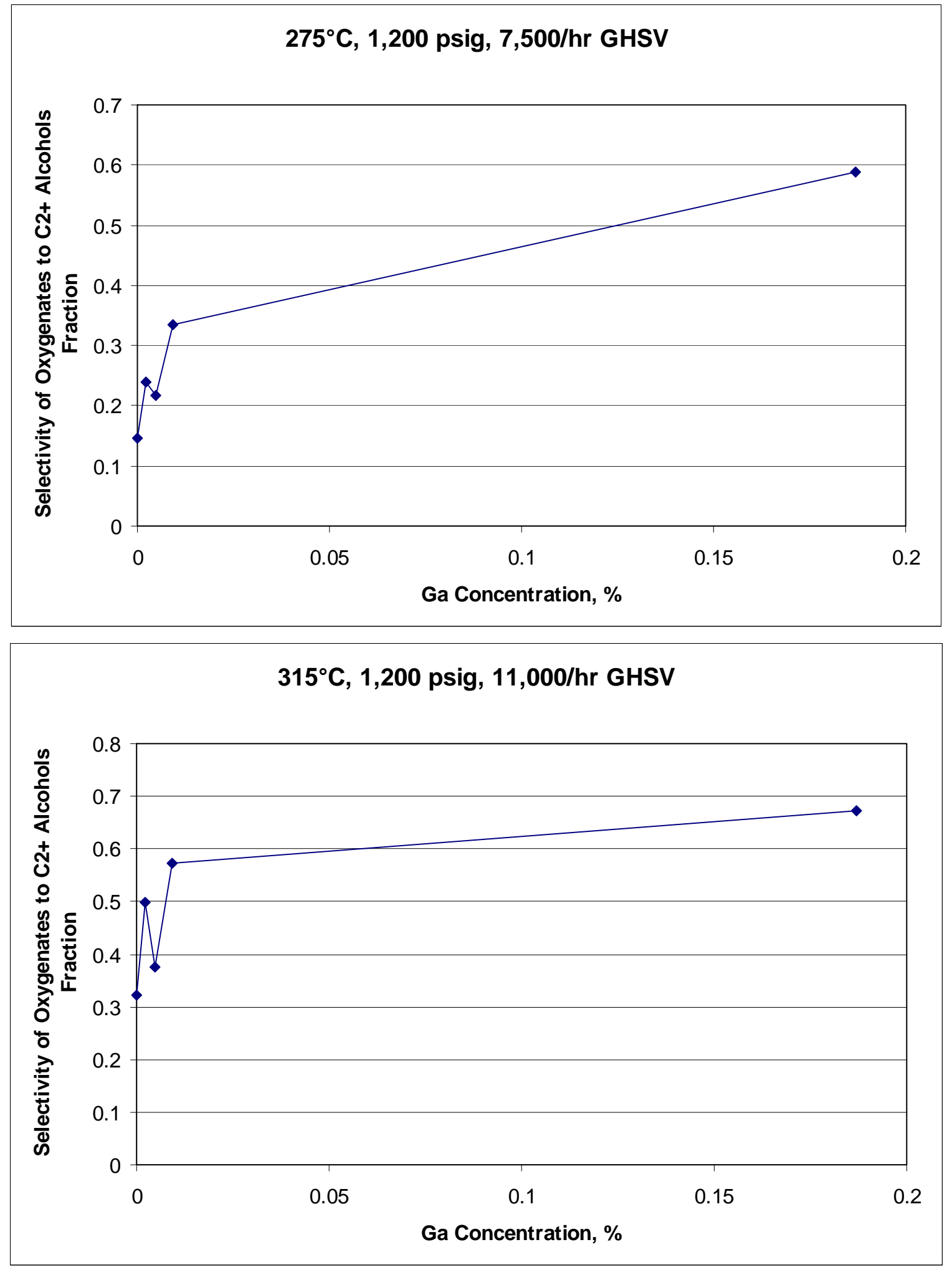

Figure 4.12. Effect of Ga Concentration on Carbon Selectivity of $\mathrm{C}_{2}+$ Oxygenates to Alcohols for the Davisil 645 Silica-Supported RhMn Catalysts at $275^{\circ} \mathrm{C}$ and $315^{\circ} \mathrm{C}$ 


\subsubsection{Effect of the Order of Metal Addition for Unpromoted $\mathrm{Rh}-\mathrm{Mn} / \mathrm{SiO}_{2}$ Catalysts}

The following three tests were conducted to compare the method of impregnating $\mathrm{Rh}$ and $\mathrm{Mn}$ on the Davisil 645 silica:

- Single co-impregnation of both metals simultaneously

- Double impregnation, adding $\mathrm{Rh}$ in the first impregnation and $\mathrm{Mn}$ in the second, with drying between impregnations

- Double impregnation, adding $\mathrm{Mn}$ in the first impregnation and $\mathrm{Rh}$ in the second, with drying between impregnations.

All three catalysts were evaluated at $256^{\circ} \mathrm{C}$, and $275^{\circ} \mathrm{C}$ at $1200 \mathrm{psig}$ and a GHSV of $7500 \mathrm{~L} / \mathrm{L}_{\text {cat }} / \mathrm{hr}$, and at $300^{\circ} \mathrm{C}$ at $1200 \mathrm{psig}$ and a GHSV of $12,000 \mathrm{~L} / \mathrm{L}_{\text {cat }} / \mathrm{hr}$. However, both the co-impregnated catalyst and the double-impregnated catalyst with Rh added in the first impregnation experienced difficulty establishing a stable catalyst temperature of $300^{\circ} \mathrm{C}$. The co-impregnated catalyst began experiencing instability at about $290^{\circ} \mathrm{C}$ and continued to experience temperature fluctuations at $300^{\circ} \mathrm{C}$ during the first sample period. A second sample was collected during a period when the catalyst temperature was stable.

The double-impregnated sample with Rh added in the first impregnation also lost stability at about $290^{\circ} \mathrm{C}$, and experienced temperature spikes as high as $325^{\circ} \mathrm{C}$ that lasted about an hour on four occasions during the sample period (in a typical excursion, after the temperature finally decreased to about $285^{\circ} \mathrm{C}$, it slowly reheated to $\sim 300^{\circ} \mathrm{C}$, and then underwent another temperature excursion). A second sample period experienced a single temperature excursion to about $325^{\circ} \mathrm{C}$ that lasted 8 hours before decreasing to about $285^{\circ} \mathrm{C}$. A third sample period continued to have three similar temperature excursions of about 1.5 hours each. Finally, an attempt to purposely deactivate and stabilize the catalyst was made by trying to heat the catalyst to $315^{\circ} \mathrm{C}$. Instead, the catalyst temperature increased to $339^{\circ} \mathrm{C}$ where it remained steady overnight. Subsequent stable conditions were evaluated at $325^{\circ} \mathrm{C}$ and $\sim 300^{\circ} \mathrm{C}$.

The double-impregnated catalyst with Mn added in the first impregnation was more stable than the other two catalysts with stable conditions achieved on the first try at $300^{\circ} \mathrm{C}$ (a repeat sample was taken), while a single temperature excursion lasting 2 hours occurred when testing at $\sim 315^{\circ} \mathrm{C}$. Subsequent tests at 325 and a repeat $300^{\circ} \mathrm{C}$ were stable also.

Figures 4.13 through 4.16 compare the three catalysts for carbon conversion, converted carbon selectivity to $\mathrm{C}_{2}+$ oxygenates, $\mathrm{C}_{2}+$ oxygenates STYs, and the fraction of the oxygenates that were $\mathrm{C}_{2}+$ alcohols. Only data from the tests at $256^{\circ} \mathrm{C}, 275^{\circ} \mathrm{C}$, and $300^{\circ} \mathrm{C}$ are shown in the figures because the catalysts underwent distinctly different testing histories at the higher temperatures, thus making direct comparisons difficult. Even comparisons at $300^{\circ} \mathrm{C}$ must be made with caution, considering that two of the catalysts were undergoing periodic temperature excursions during tests at that temperature, and some accelerated deactivation was likely occurring at the higher temperatures during these tests.

Figure 4.13 compares the carbon conversion for the three catalysts. The double-impregnated catalyst with $\mathrm{Rh}$ added during the first impregnation was the most active catalyst measured by the carbon conversion at $256^{\circ} \mathrm{C}$ and $275^{\circ} \mathrm{C}$, followed by the co-impregnated catalyst. The double-impregnated catalyst with $\mathrm{Mn}$ added during the first impregnation was the least active. At $300^{\circ} \mathrm{C}$, the doubleimpregnated catalyst with $\mathrm{Rh}$ added first clearly lost more of its activity than the other two catalysts 
during the temperature excursions as indicated by its relatively lower carbon conversion at the higher temperature. The co-impregnated catalyst also appeared to deactivate at $300^{\circ} \mathrm{C}$ because carbon conversion at that temperature is only slightly higher than that at $275^{\circ} \mathrm{C}$. The double-impregnated catalyst where $\mathrm{Mn}$ was added first did not show evidence of significant deactivation at $300^{\circ} \mathrm{C}$ because its activity continued to increase significantly between $275^{\circ} \mathrm{C}$ and $300^{\circ} \mathrm{C}$.

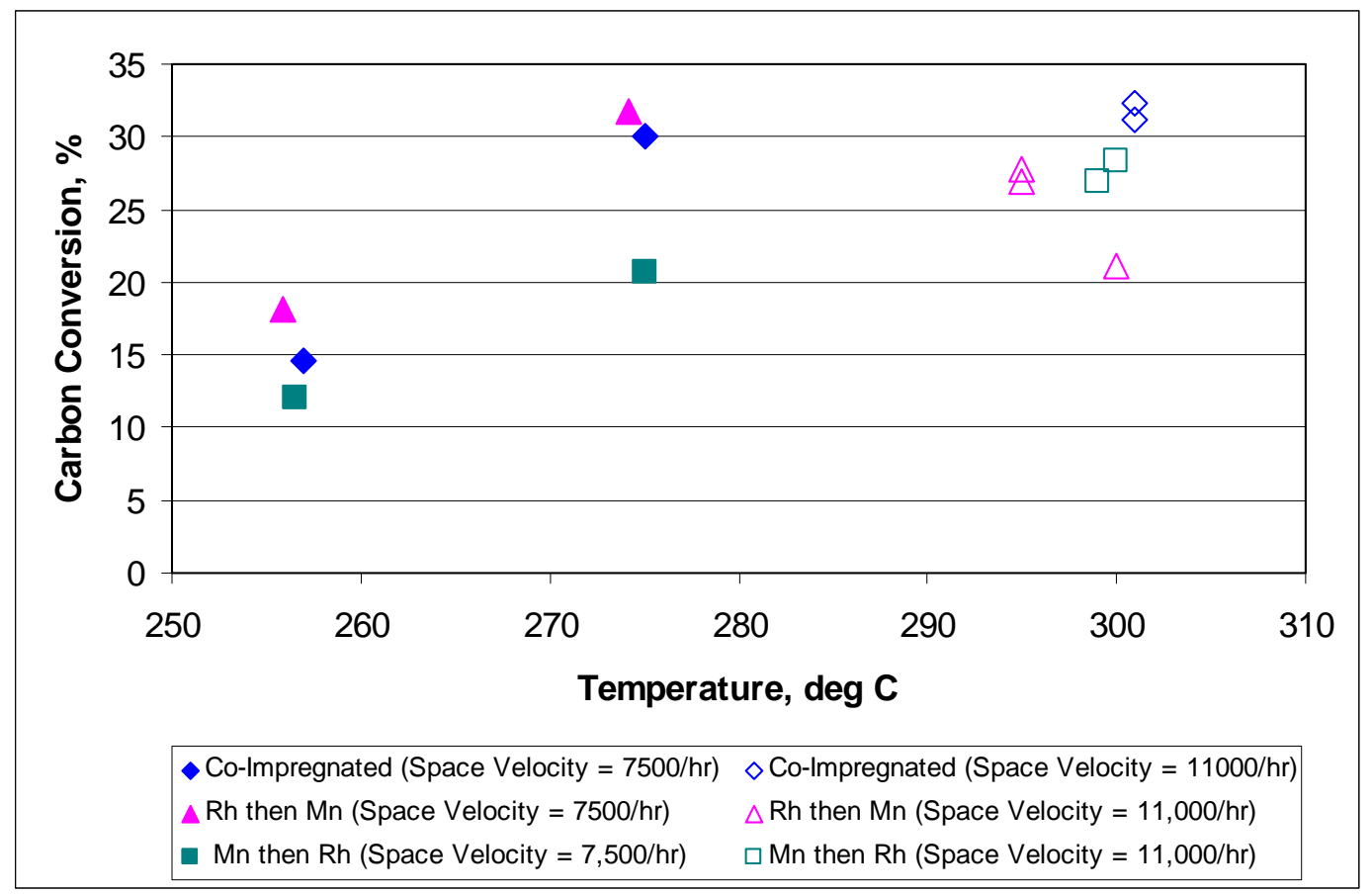

Figure 4.13. Comparison of Carbon Conversions for $\mathrm{RhMn} / \mathrm{SiO}_{2}$ Catalyst Prepared Using Different Orders of Metal Additions to the Support

Figure 4.14 compares the converted carbon selectivity to $\mathrm{C}_{2}+$ oxygenates. The selectivities of all three catalysts decreased with increasing catalyst temperature, which is consistent with other tests containing $\mathrm{Rh}$ and $\mathrm{Mn}$. The co-impregnated and double-impregnated catalyst with $\mathrm{Mn}$ added first had nearly the same selectivities at $256^{\circ} \mathrm{C}$ and $275^{\circ} \mathrm{C}$, while the double-impregnated catalyst with $\mathrm{Rh}$ added first had a selectivity that was significantly lower. At $300^{\circ} \mathrm{C}$, the selectivity of both the co-impregnated catalyst and the double-impregnated catalyst with $\mathrm{Rh}$ added first were about the same and were significantly lower than the double-impregnated catalyst with Mn added first. This behavior suggests that significant changes occur in the catalyst undergoing temperature excursions at $300^{\circ} \mathrm{C}$.

Figure 4.15 compares the $\mathrm{C}_{2}+$ oxygenates STYs. The co-impregnated catalyst performed better than either of the double-impregnated catalysts at $256^{\circ} \mathrm{C}$ and $275^{\circ} \mathrm{C}$. At $300^{\circ} \mathrm{C}$, the double-impregnated catalyst with Mn added first had the highest STY. This is attributed to the temperature excursions of the other two catalysts at this temperature that appeared to adversely affect their activity and selectivity to $\mathrm{C}_{2}+$ oxygenates. 


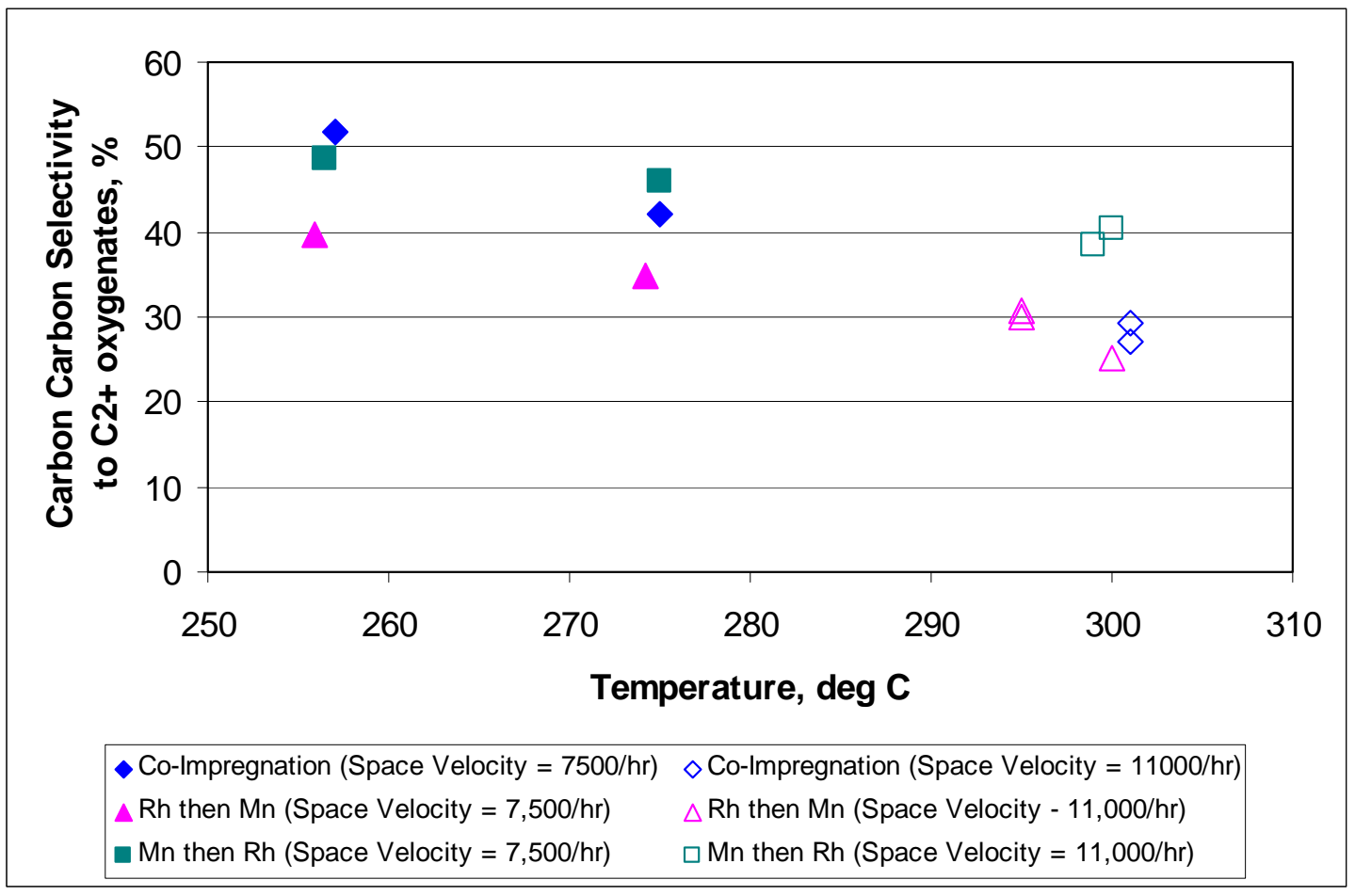

Figure 4.14. Comparison of Carbon Selectivities to $\mathrm{C}_{2}+$ Oyxgenates for $\mathrm{RhMn} / \mathrm{SiO}_{2}$ Catalyst Prepared Using Different Orders of Metal Additions to the Support

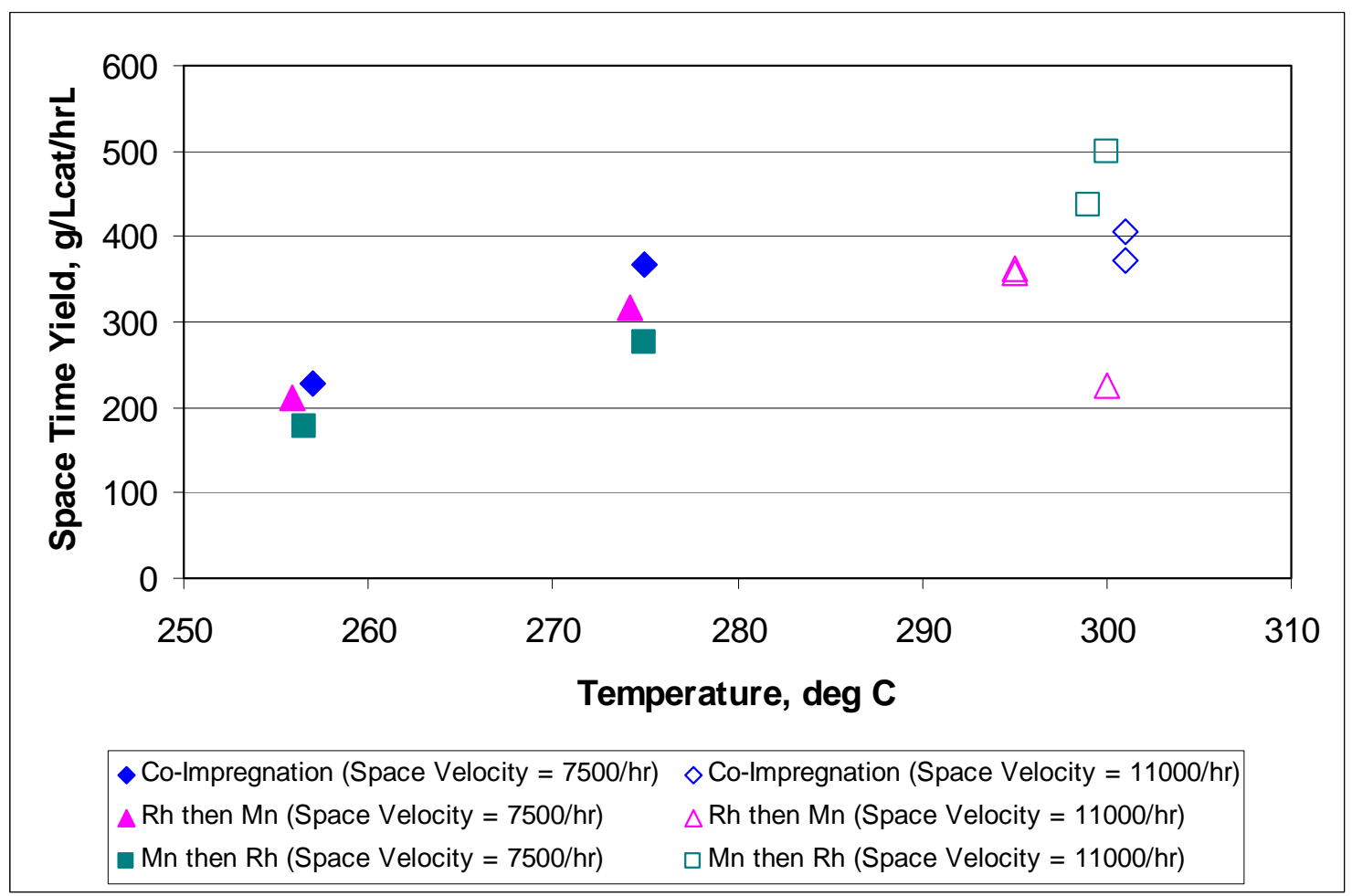

Figure 4.15. Comparison of $\mathrm{C}_{2}+$ Oyxgenates $\mathrm{STYs}$ for $\mathrm{RhMn} / \mathrm{SiO}_{2}$ Catalyst Prepared Using Different Orders of Metal Additions to the Support 
Figure 4.16, compares the selectivity of all oxygenates to $\mathrm{C}_{2}+$ alcohols. As expected, the selectivities of all three catalysts increased with increasing temperature. Furthermore, all three catalysts had about the same selectivities at $256^{\circ} \mathrm{C}$ and $275^{\circ} \mathrm{C}$, while only the double-impregnated catalyst with $\mathrm{Rh}$ added first had a significantly lower selectivity at $300^{\circ} \mathrm{C}$. More importantly, none of the catalysts had selectivities greater than $25 \%$ at any of the temperatures. This level of selectivity is considered to be relatively low.

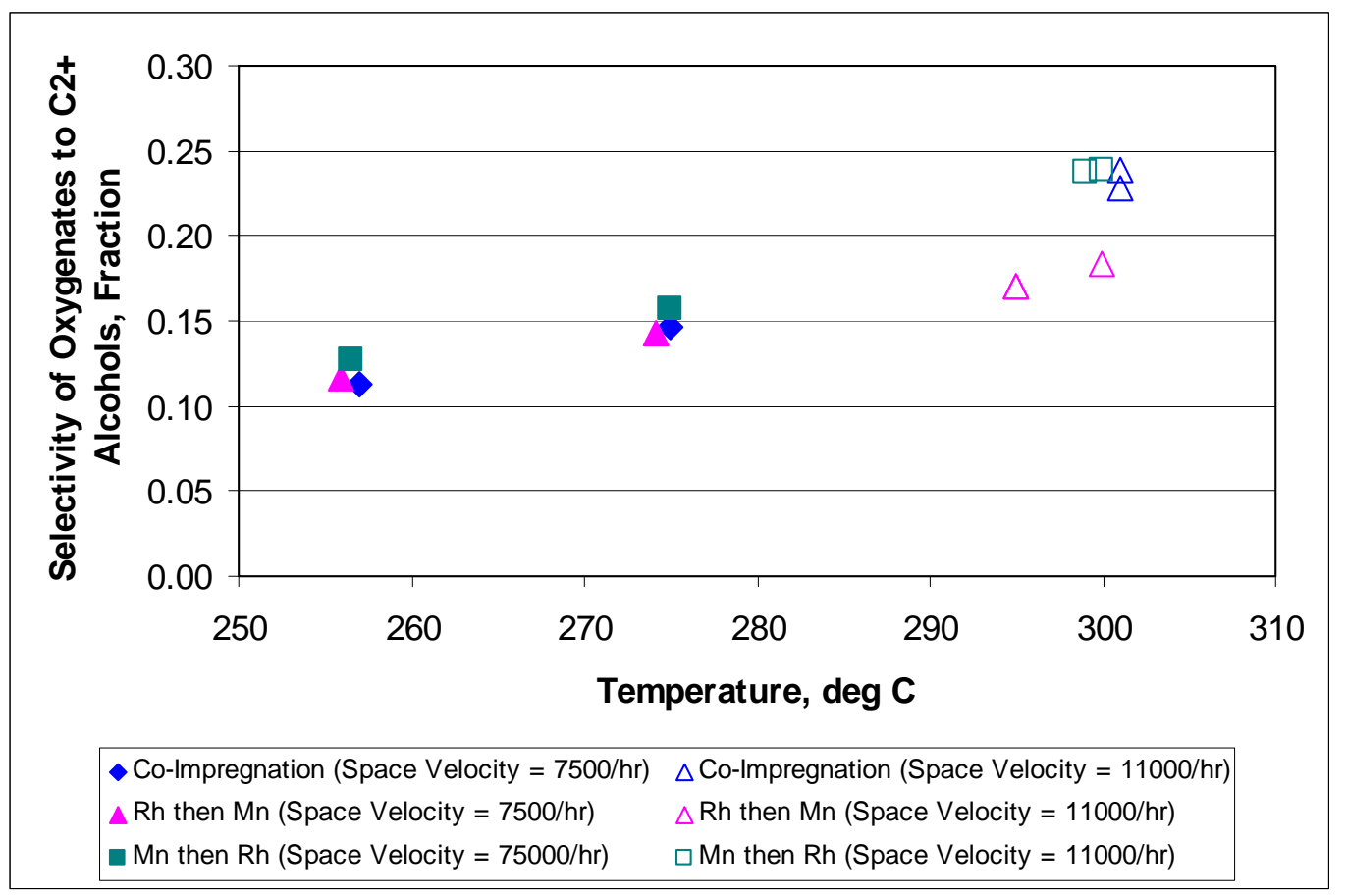

Figure 4.16. Comparison of the Selectivities of all Oxygenates to $\mathrm{C}_{2}+$ Alcohols for $\mathrm{RhMn} / \mathrm{SiO}_{2} \mathrm{Catalyst}$ Prepared Using Different Orders of Metal Additions to the Support

Overall, it appears that the co-impregnated catalyst has the best overall performance combination with a higher $\mathrm{C}_{2}+$ oxygenates STY and converted carbon selectivity to $\mathrm{C}_{2}+$ oxygenates at the lower temperatures. The double-impregnated catalyst with Mn added first had a significantly lower STY, while the double-impregnated catalyst with $\mathrm{Rh}$ added first had a significantly lower selectivity. At $300^{\circ} \mathrm{C}$, the double-impregnated catalyst had the best overall performance in terms of these parameters, but that is attributed to the fact that it did not undergo temperature excursions at this temperature and apparently partially deactivated the other two catalysts. If heat management was better for all three catalysts, the other two catalysts may have behaved better at this temperature.

\subsection{Carbon-Supported Catalysts}

Several tests were conducted to examine a number of variables that could affect the RhMn and the RhMnIr catalyst performances on the Hyperion CS-02C-063 carbon support. The variables tested included total metals loading, the catalyst reducing temperature, and the order of metals addition. 


\subsubsection{RhMn Total Metal Loadings}

Four tests were conducted using different multiples of the baseline concentrations of $\mathrm{Rh}(5.56 \% \mathrm{Rh})$ and $\mathrm{Mn}(1.69 \% \mathrm{Mn})$ using the Hyperion CS-02C-063 carbon nanotube support to examine the effect of the total metal concentration on the catalyst performance. The concentrations investigated included:

- $0.75 \mathrm{X}$ baseline concentrations of $\mathrm{Rh}$ and $\mathrm{Mn}$ )

- 1.00X baseline concentration of $\mathrm{Rh}$ and $\mathrm{Mn}$ )

- 1.5X baseline concentration of $\mathrm{Rh}$ and $\mathrm{Mn}$ )

- 2.11X baseline concentration of Rh and Mn)

Figures 4.17 through 4.20 provide comparative data for the following two test conditions: 1) $275^{\circ} \mathrm{C}$ and $7500 / \mathrm{hr}$ GHSV and 2) $300^{\circ} \mathrm{C}$ and $11,000 / \mathrm{hr}$ GHSV. The latter condition was the maximum temperature at which the catalysts were tested, while the former condition illustrates the trends in catalyst behavior at lower temperatures. Note, some initial difficulty in establishing a stable feed gas flow rate for the $1.5 \mathrm{X}$ baseline concentration catalyst at $275^{\circ} \mathrm{C}$ may have resulted in a higher than expected activity.

Figure 4.17 and 4.18 compares the carbon conversions and the converted carbon selectivities to $\mathrm{C}_{2}+$ oxygenates for different multiples of the $\mathrm{Rh}$ and $\mathrm{Mn}$ concentrations. There appears to be a regular increase in both parameters with increasing concentrations, although there is a fair amount of scatter for the latter parameter. It is noteworthy that the increase in the carbon conversion increases by a much greater multiple than the increase in concentration. The $\mathrm{C}_{2}+$ oxygenate STYs generally follow the same trend as the carbon conversion shown in Figure 4.19 but with an even greater leveraging of the STY with increasing concentration. For example, increasing the concentration from $1 \mathrm{X}$ to $2.11 \mathrm{X}$ of the baseline RhMn concentration produces a $5.7 \mathrm{X}$ increase in the $\mathrm{STY}$ at $275^{\circ} \mathrm{C}$ and a $2.9 \mathrm{X}$ increase at $300^{\circ} \mathrm{C}$. Figure 4.20 compares the selectivity of all oxygenates to $\mathrm{C}_{2}+$ alcohols. The general trend at both temperatures is a decrease in selectivity with increasing concentration.

Overall, it appears that increasing the total metal loading of $\mathrm{Rh}$ and $\mathrm{Mn}$ at a constant $\mathrm{Rh}: \mathrm{Mn}$ atomic ratio results in improved performance with respect to carbon conversion, $\mathrm{C}_{2}+$ oxygenate STYs, and selectivity to $\mathrm{C}_{2}+$ oxygenates. This improved performance comes at the expense of a lower selectivity to $\mathrm{C}_{2}+$ alcohols, but this parameter is of secondary importance relative to the overall selectivity to $\mathrm{C}_{2}+$ oxygenates. 

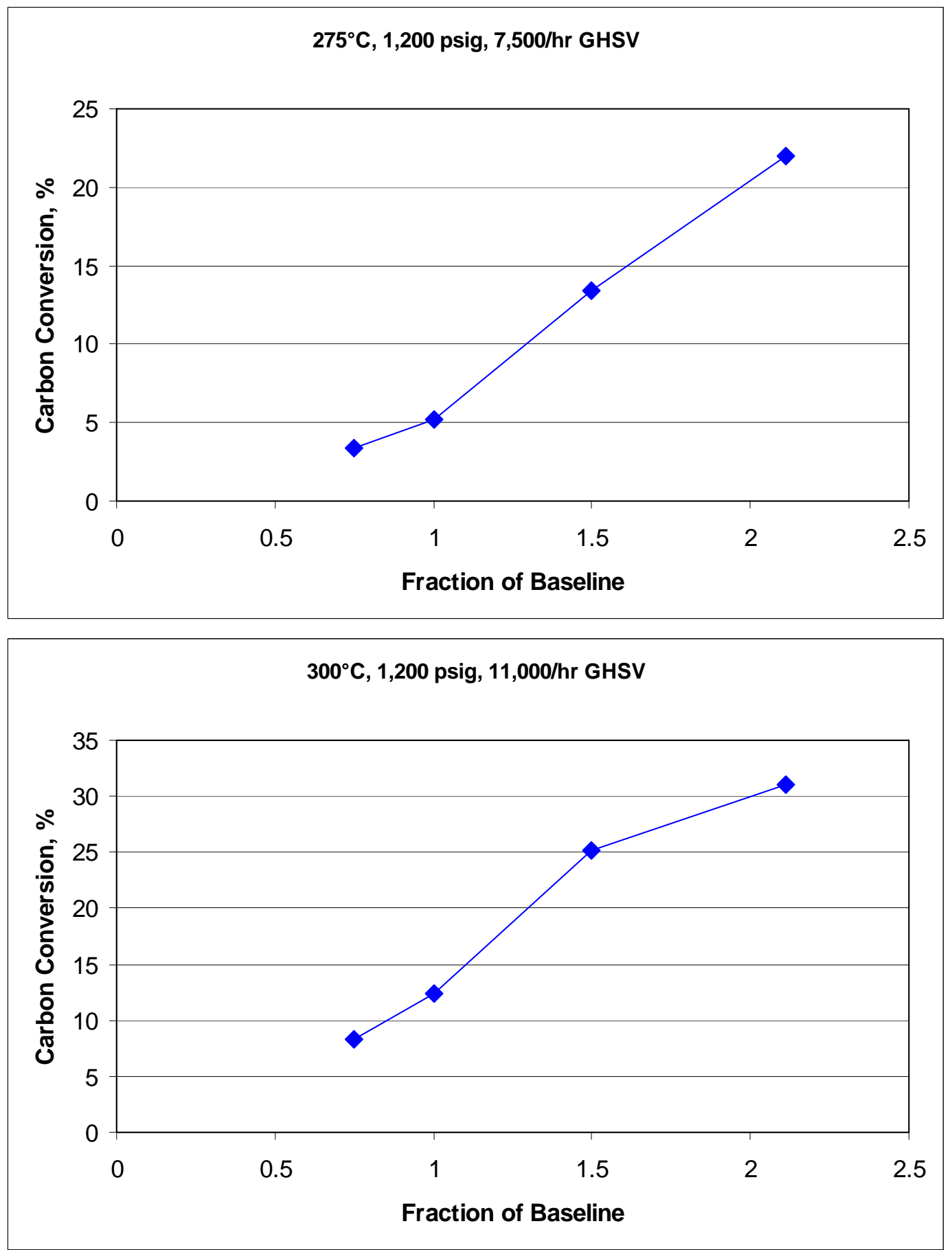

Figure 4.17. Effect of Total $\mathrm{Rh}+\mathrm{Mn}$ Metal Concentration on Carbon Conversion for the Hyperion CS-02C-063-Supported RhMn Catalysts at $275^{\circ} \mathrm{C}$ and $300^{\circ} \mathrm{C}$ 

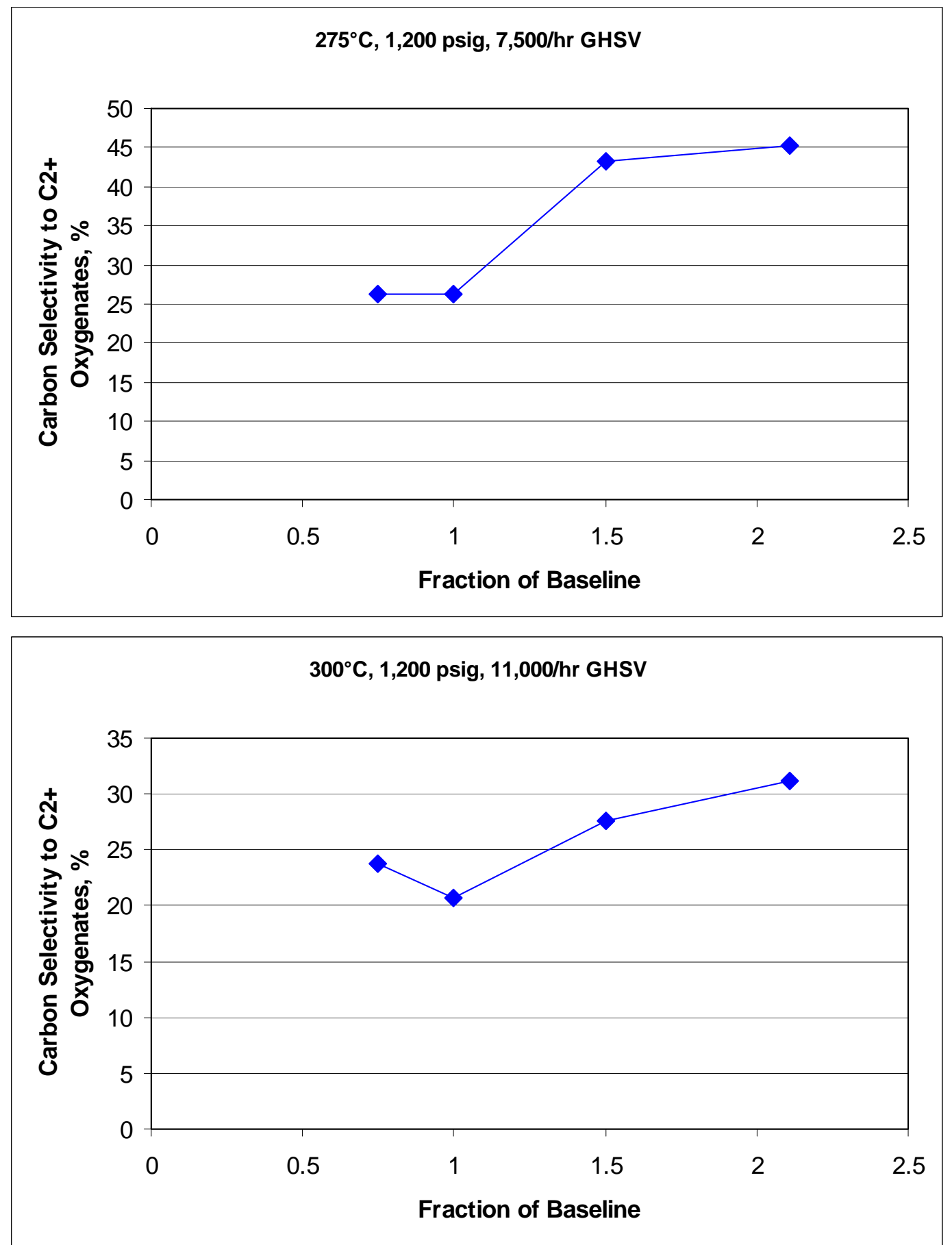

Figure 4.18. Effect of Total $\mathrm{Rh}+\mathrm{Mn}$ Metal Concentration on Converted Carbon Selectivity to $\mathrm{C} 2+$ Oxygenates for the Hyperion CS-02C-063-Supported RhMn Catalysts at $275^{\circ} \mathrm{C}$ and $300^{\circ} \mathrm{C}$ 

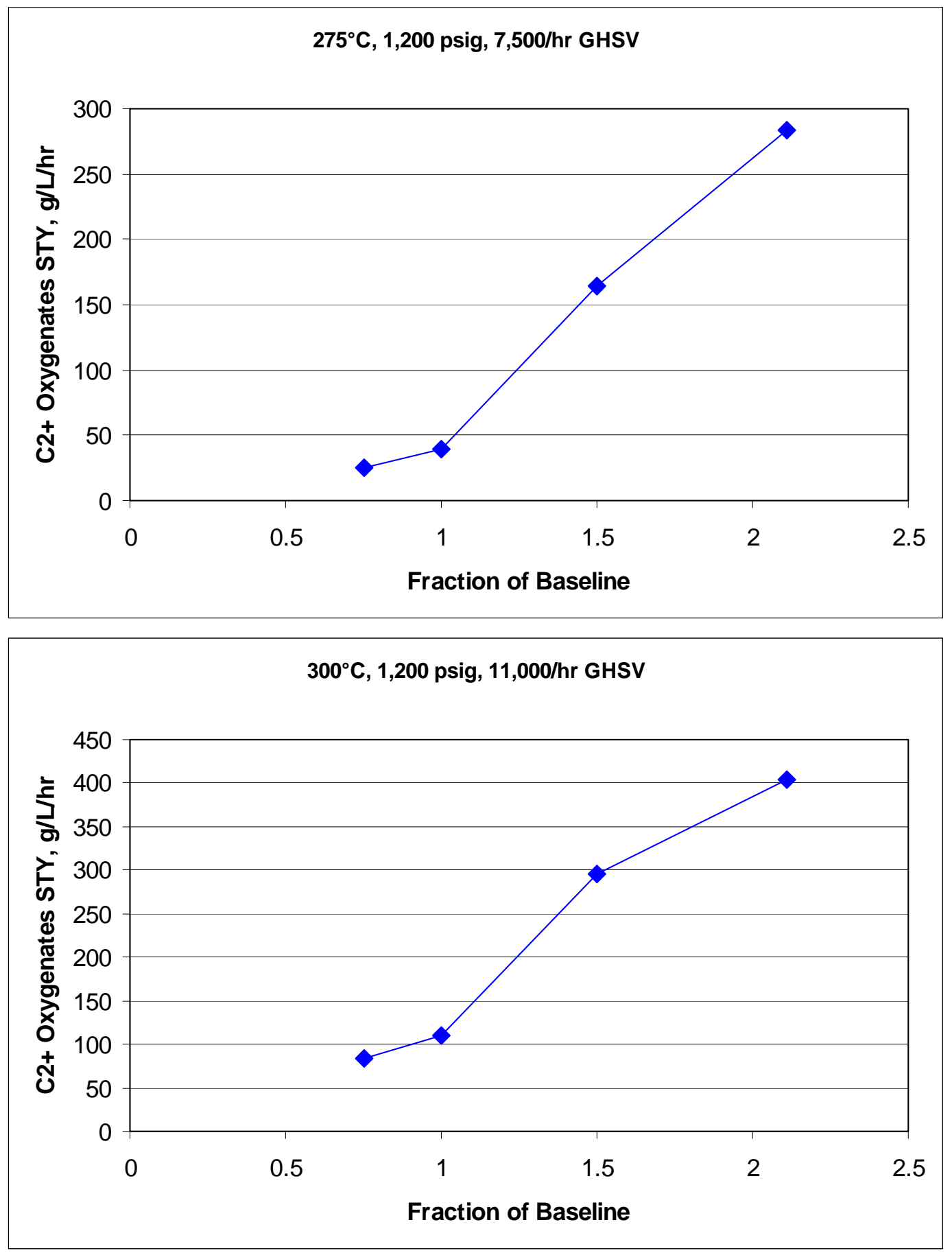

Figure 4.19. Effect of Total $\mathrm{Rh}+\mathrm{Mn}$ Metal Concentration on $\mathrm{C}_{2}+$ Oxygenates Stys for the Hyperion CS-02C-063-Supported RhMn Catalysts at $275^{\circ} \mathrm{C}$ and $300^{\circ} \mathrm{C}$ 

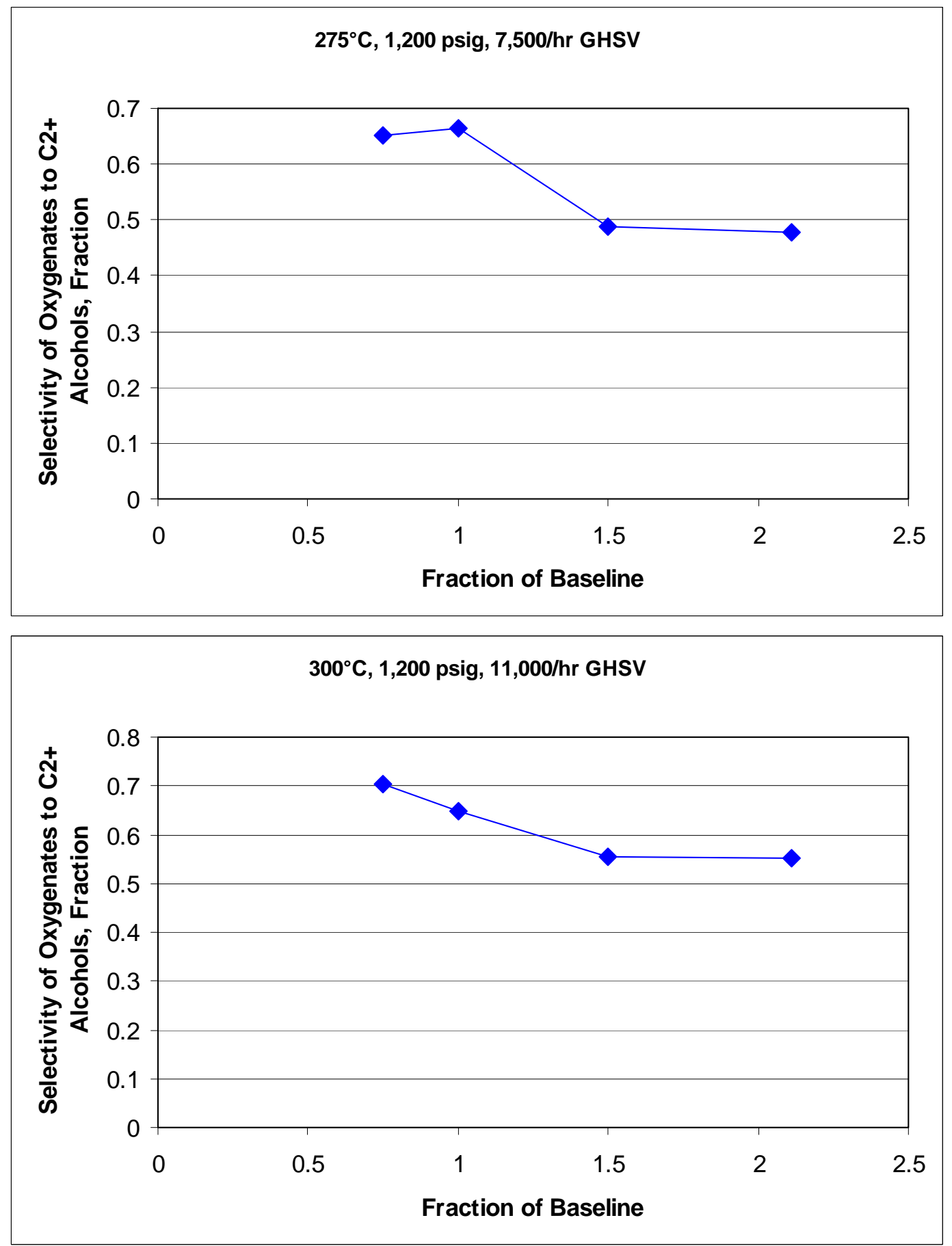

Figure 4.20. Effect of Total $\mathrm{Rh}+\mathrm{Mn}$ metals Concentration on Selectivities of all Oxygenates to $\mathrm{C}_{2}+$ Alcohols for the Hyperion CS-02C-063-Supported RhMn Catalysts at $275^{\circ} \mathrm{C}$ and $300^{\circ} \mathrm{C}$

\subsubsection{Effect of the Order of Metal Addition for Unpromoted Rh-Mn/Carbon Catalysts}

The following three tests were conducted to compare the method of impregnating $\mathrm{Rh}$ and $\mathrm{Mn}$ on the Hyperion CS-02C-063 carbon support: 
- Single co-impregnation of both metals at once

- Double impregnation, adding $\mathrm{Rh}$ in the first impregnation and $\mathrm{Mn}$ in the second, with drying between impregnations

- Double impregnation, adding $\mathrm{Mn}$ in the first impregnation and $\mathrm{Rh}$ in the second, with drying between impregnations.

All three catalysts were evaluated at $256^{\circ} \mathrm{C}, 275^{\circ} \mathrm{C}$ at $1200 \mathrm{psig}$ and a $7500 \mathrm{~L} / \mathrm{L}_{\text {cat }} / \mathrm{hr} \mathrm{GHSV}$, and at $300^{\circ} \mathrm{C}$ at $1200 \mathrm{psig}$ and a $12,000 \mathrm{~L} / \mathrm{L}_{\text {cat }} / \mathrm{hr}$ GHSV. However, the co-impregnated catalyst initially had difficulty in establishing a stable feed gas flow rate at $275^{\circ} \mathrm{C}$. This problem may have resulted in a higher than expected activity, evidenced by a higher catalyst temperature than before the interruption of flow for the same hot oil temperature.

Figure 4.21 compares the carbon conversion for the three catalysts. All three catalysts exhibited nearly the same conversion at $256^{\circ} \mathrm{C}$. Both double-impregnated catalysts also had the same carbon conversions at $275^{\circ} \mathrm{C}$, although the conversion for the double-impregnated catalyst in which Mn was added first was slightly higher at $300^{\circ} \mathrm{C}$. At $275^{\circ} \mathrm{C}$ and $300^{\circ} \mathrm{C}$, the co-impregnated catalyst had a significantly higher conversion that either of the double-impregnated catalysts. However, it is possible that the initial interruption of flow for the co-impregnated catalyst at $275^{\circ} \mathrm{C}$ may have resulted in a higher activity and may account for its higher carbon conversions at both $275^{\circ} \mathrm{C}$ and $300^{\circ} \mathrm{C}$.

Figure 4.22 compares the converted carbon selectivity to $\mathrm{C}_{2}+$ oxygenates. With one exception, the selectivities of all three catalysts decreased with increasing catalyst temperature, which is consistent with other tests with catalysts containing $\mathrm{Rh}$ and $\mathrm{Mn}$. However, at $256^{\circ} \mathrm{C}$, the selectivity of the doubleimpregnated catalyst, with $\mathrm{Rh}$ added first, was significantly lower than its selectivity at $275^{\circ} \mathrm{C}$. This behavior may be associated with the apparently higher activity than expected at $275^{\circ} \mathrm{C}$. If the anomaly at $256^{\circ} \mathrm{C}$ is ignored then there is a consistent trend among the catalysts where the co-impregnated catalyst had a greater selectivity to $\mathrm{C}_{2}+$ oxygenates than the double-impregnated catalyst with $\mathrm{Rh}$ added in the first impregnation, and both of those catalysts had higher selectivities than the double-impregnated catalyst with $\mathrm{Mn}$ added in the first impregnation.

Figure 4.23 compares the $\mathrm{C}_{2}+$ oxygenate STYs for the three catalysts. The $\mathrm{C}_{2}+$ oxygenates STYs for both double-impregnated catalysts were essentially the same at all three temperatures. The STYs for the co-impregnated catalyst was the same as the other two at $256^{\circ} \mathrm{C}$ and were much higher at $275^{\circ} \mathrm{C}$ and $300^{\circ} \mathrm{C}$. This behavior is consistent with the higher activity and selectivity of the catalysts to $\mathrm{C} 2+$ oxygenates of the co-impregnated catalyst at the higher temperatures relative to the other two catalysts.

Figure 4.24 compares the selectivity of oxygenates to $\mathrm{C}_{2}+$ alcohols. The selectivities of oxygenates to $\mathrm{C}_{2}+$ alcohols did not behave in a consistent manner. The double-impregnated catalyst with $\mathrm{Mn}$ added in the first impregnation decreased in selectivity with increasing temperature which is opposite to what is typically observed with the silica-supported RhMn catalysts. However, the selectivities are very high $\left(76 \%\right.$ at $256^{\circ} \mathrm{C}$, then decreasing to $63 \%$ at $300^{\circ} \mathrm{C}$ ) compared to the more typical $\sim 12 \%$ at $256^{\circ} \mathrm{C}$ to $\sim 24 \%$ at $300^{\circ} \mathrm{C}$ for the silica-supported catalysts (see Figure 4.16). The double-impregnated catalyst with $\mathrm{Rh}$ added in the first impregnation, had a relatively constant selectivity between $62 \%$ and $66 \%$ over the temperature range. The selectivity for the co-impregnated catalyst generally decreased with increasing temperature, but there was considerable scatter in the data compared to the other two catalysts. It is noteworthy that the selectivities of all three catalysts more or less converged at $300^{\circ} \mathrm{C}$. 


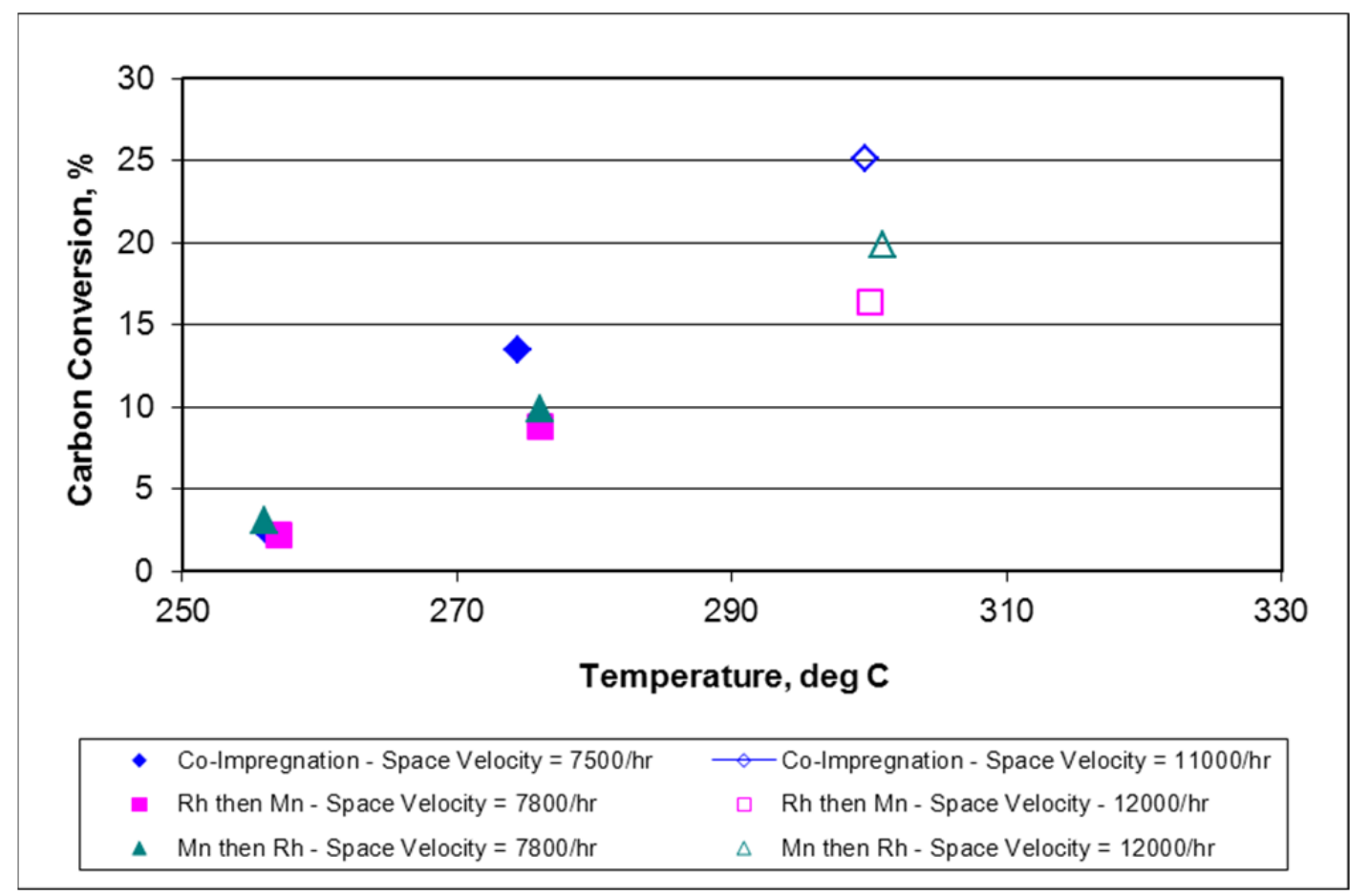

Figure 4.21. Comparison of Carbon Conversions for Hyperion CS-02C-063-Supported RhMn Catalysts Prepared Using Different Orders of Metal Additions to the Support

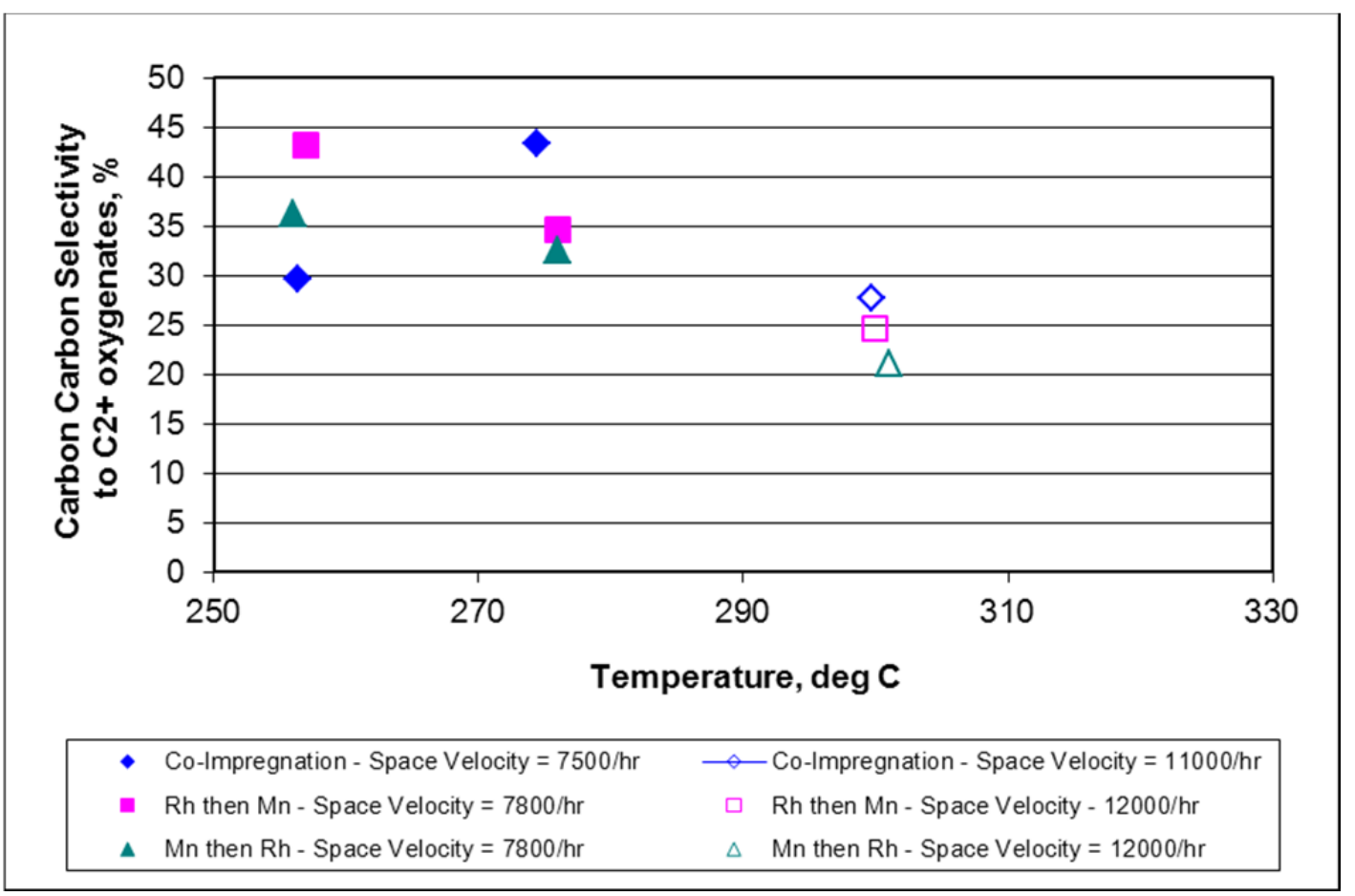

Figure 4.22. Comparison of Carbon Selectivities to $\mathrm{C}_{2}+$ Oyxgenates for the Hyperion CS-02C-063Supported RhMn Prepared Using Different Orders of Metal Additions to the Support 


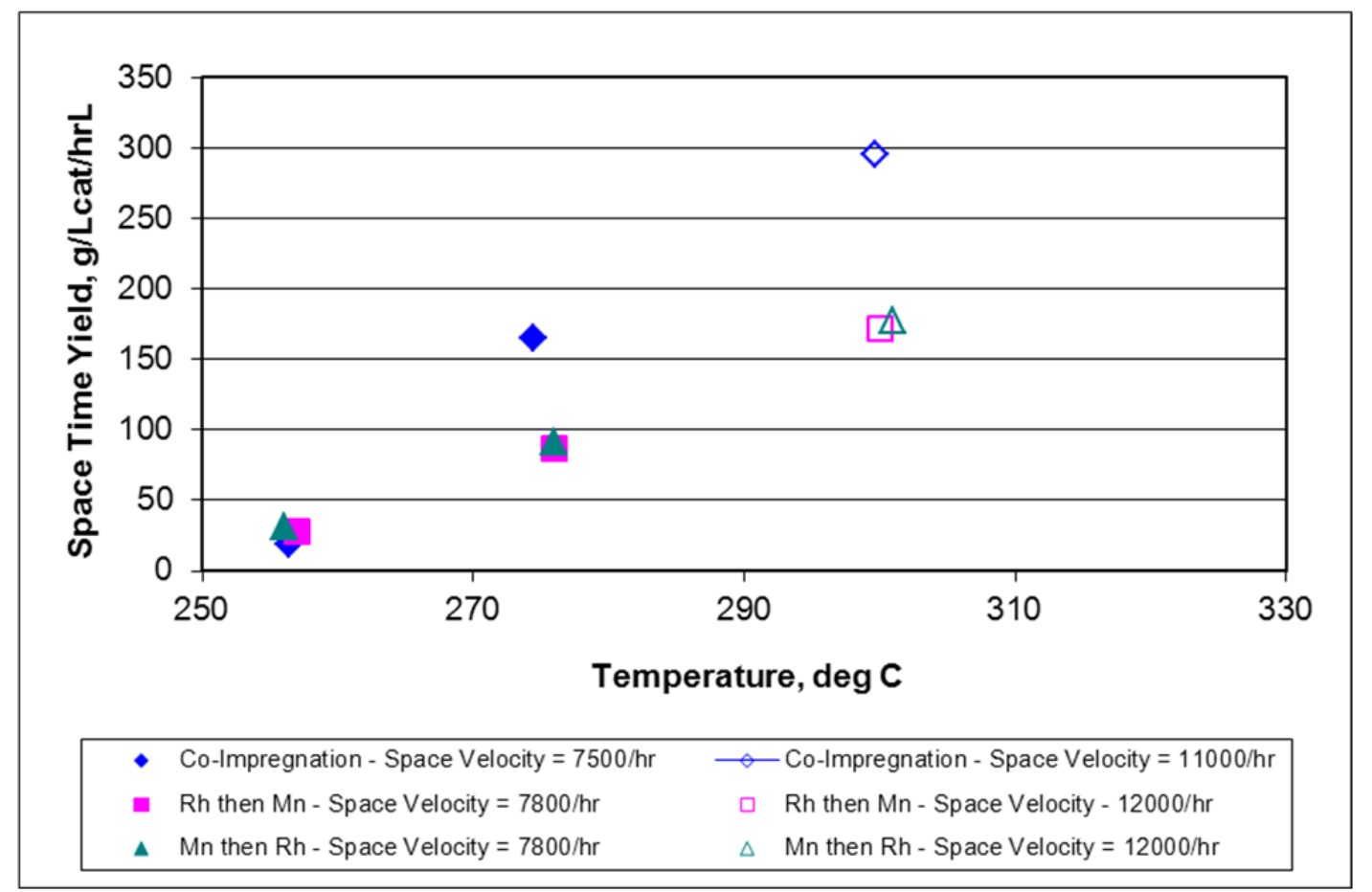

Figure 4.23. Comparison of $\mathrm{C}_{2}+$ Oyxgenate STYs for the Hyperion CS-02C-063-Supported RhMn Catalyst Prepared Using Different Orders of Metal Additions to the Support

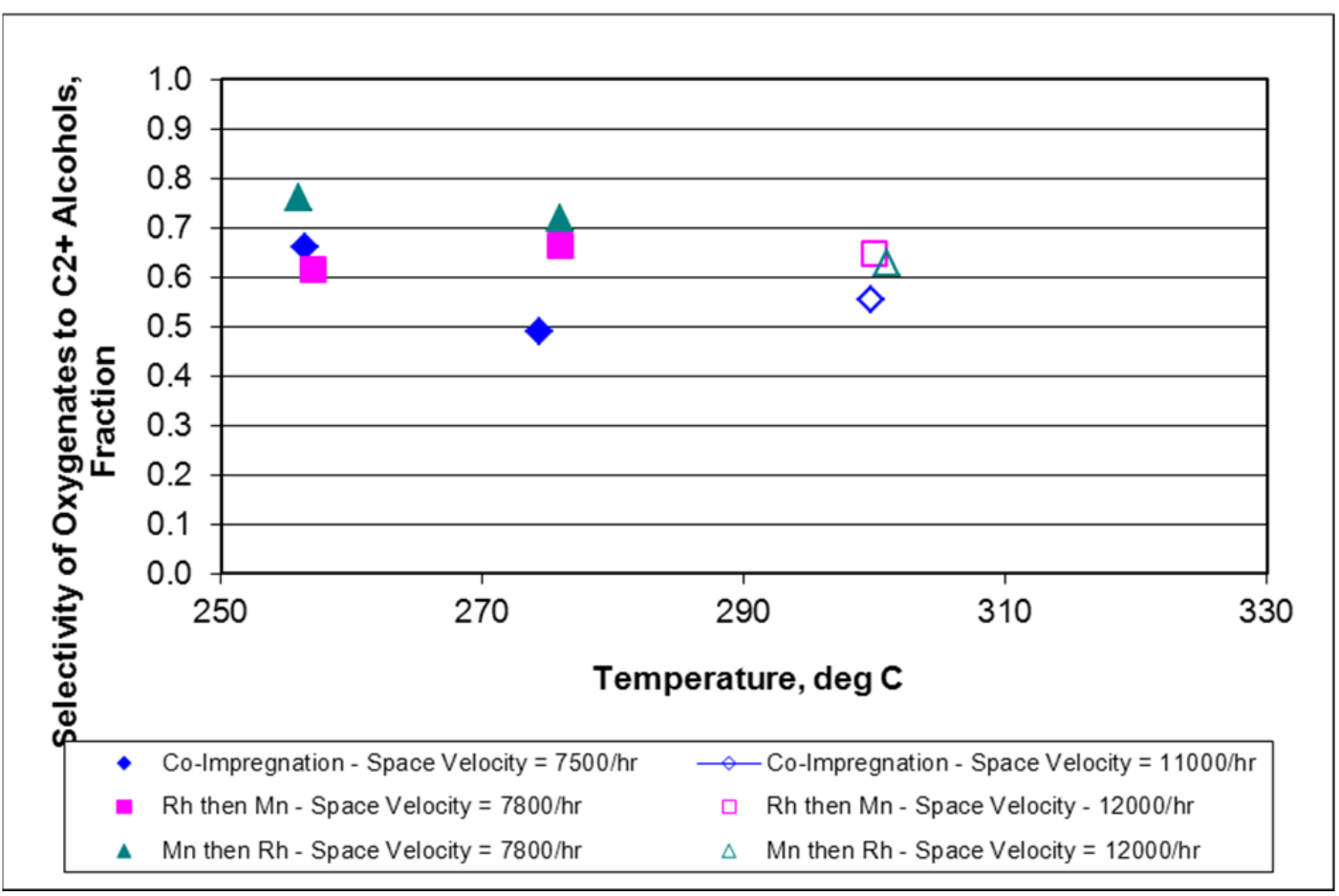

Figure 4.24. Comparison of the Selectivities of All Oxygenates to $\mathrm{C}_{2}+$ Alcohols for the Hyperion CS-02C-063-Supported RhMn Catalyst Prepared Using Different Orders Of Metal Additions to the Support 
It appears that the co-impregnated catalyst had the best overall performance in terms of carbon selectivity to $\mathrm{C}_{2}+$ oxygenates and $\mathrm{C}_{2}+$ oxygenates STYs at $275^{\circ} \mathrm{C}$ or higher temperatures. However, this performance may be attributed to the interruption of flow at this temperature for the co-impregnated catalyst that appeared to increase both its activity and its converted carbon selectivity to $\mathrm{C}_{2}+$ oxygenates at the higher temperatures. Conversely, while it is possible that it would have had performance characteristics more comparable to the other two catalysts if it had not experienced the flow interruption, it is unlikely that the catalyst would have been less active or selective than the other two catalysts.

\subsubsection{Effect of Manganese Concentration on Catalyst Performance Unpromoted Rh-Mn/Carbon Catalysts}

Four tests were conducted to examine the effect of the Mn concentration when it was co-impregnated with the $1.5 \mathrm{X}$ baseline concentration of $\mathrm{Rh}(8.34 \% \mathrm{Rh})$ using the Hyperion CS-02C-063 support. The Mn concentrations investigated included:

- $0.00 \mathrm{wt} \%$ (no Mn)

- $1.69 \mathrm{wt} \%$ (1X baseline concentration)

- $2.53 \mathrm{wt} \%$ (3/2X baseline concentration)

- $3.38 \mathrm{wt} \%$ (2X baseline concentration)

Figures 4.25 through 4.28 provide comparative data for the following two test conditions: 1) $275^{\circ} \mathrm{C}$ and $7500 / \mathrm{hr} \mathrm{GHSV}$ and 2) $300^{\circ} \mathrm{C}$ and $12,000 / \mathrm{hr}$ GHSV. These two conditions were chosen because they represent fairly well catalyst behavior at temperatures of interest.

Figure 4.25 compares the carbon conversions for different $\mathrm{Mn}$ concentrations at $275^{\circ} \mathrm{C}$ and $300^{\circ} \mathrm{C}$. Although there is some scatter in the data, there is consistent increase in the carbon conversion with increasing Mn concentration at both temperatures.

Figure 4.26 compares the converted carbon selectivity to $\mathrm{C}_{2}+$ oxygenates for the different $\mathrm{Mn}$ concentrations at $275^{\circ} \mathrm{C}$ and $300^{\circ} \mathrm{C}$. Again there appears to be a general trend of increasing selectivity with increasing Mn concentration at both temperatures.

Figure 4.27 compares the $\mathrm{C}_{2}+$ oxygenates STYs for the different $\mathrm{Mn}$ concentrations at $275^{\circ} \mathrm{C}$ and $300^{\circ} \mathrm{C}$. In general the STYs follow the same trends as carbon conversion and converted carbon selectivity to $\mathrm{C}_{2}+$ oxygenates where the STYs increase with increasing Mn concentration.

Figure 4.28 compares the selectivity of all oxygenates to $\mathrm{C}_{2}+$ alcohols for different $\mathrm{Mn}$ concentration levels. There appears to be an overall trend of increasing selectivity with increasing Mn concentration. However, with the scatter in the data, it is not possible to determine whether the increase is gradual over the entire concentration range or rapid to a concentration of $1.69 \% \mathrm{Mn}$ followed by a leveling-off or gradual decline at the higher concentrations. Overall, it appears that increasing the Mn concentration in the $\mathrm{RhMn} / \mathrm{SiO}_{2}$ catalyst results in improvements in all of the performance parameters over the entire range of concentrations examined. Further testing at even higher temperatures is warranted to determine the optimum concentration. 

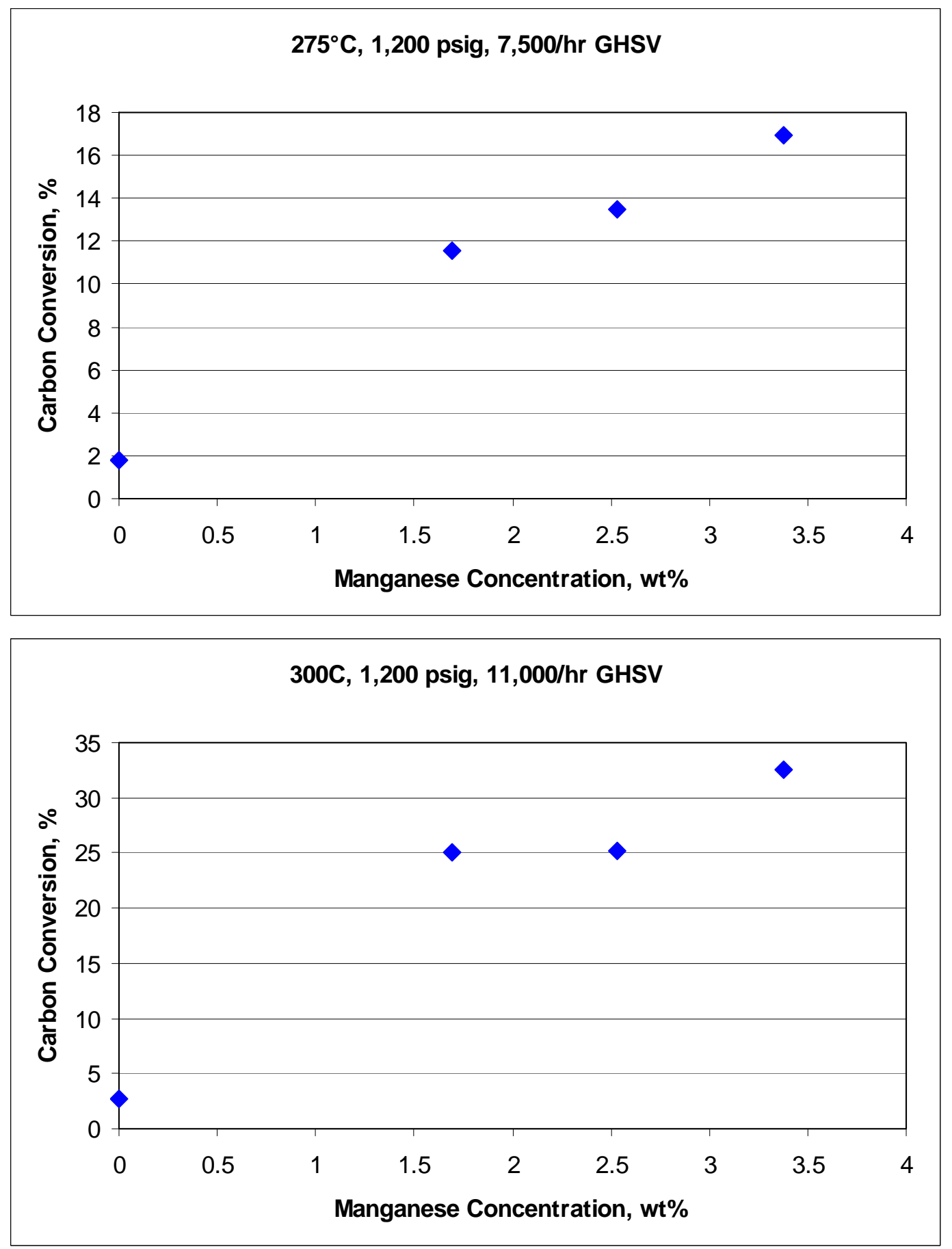

Figure 4.25. Comparison of Carbon Conversions for the Hyperion CS-02C-063 Supported RhMn Catalysts Prepared Using Different Concentrations of $\mathrm{Mn}$ at $275^{\circ} \mathrm{C}$ and $300^{\circ} \mathrm{C}$ 

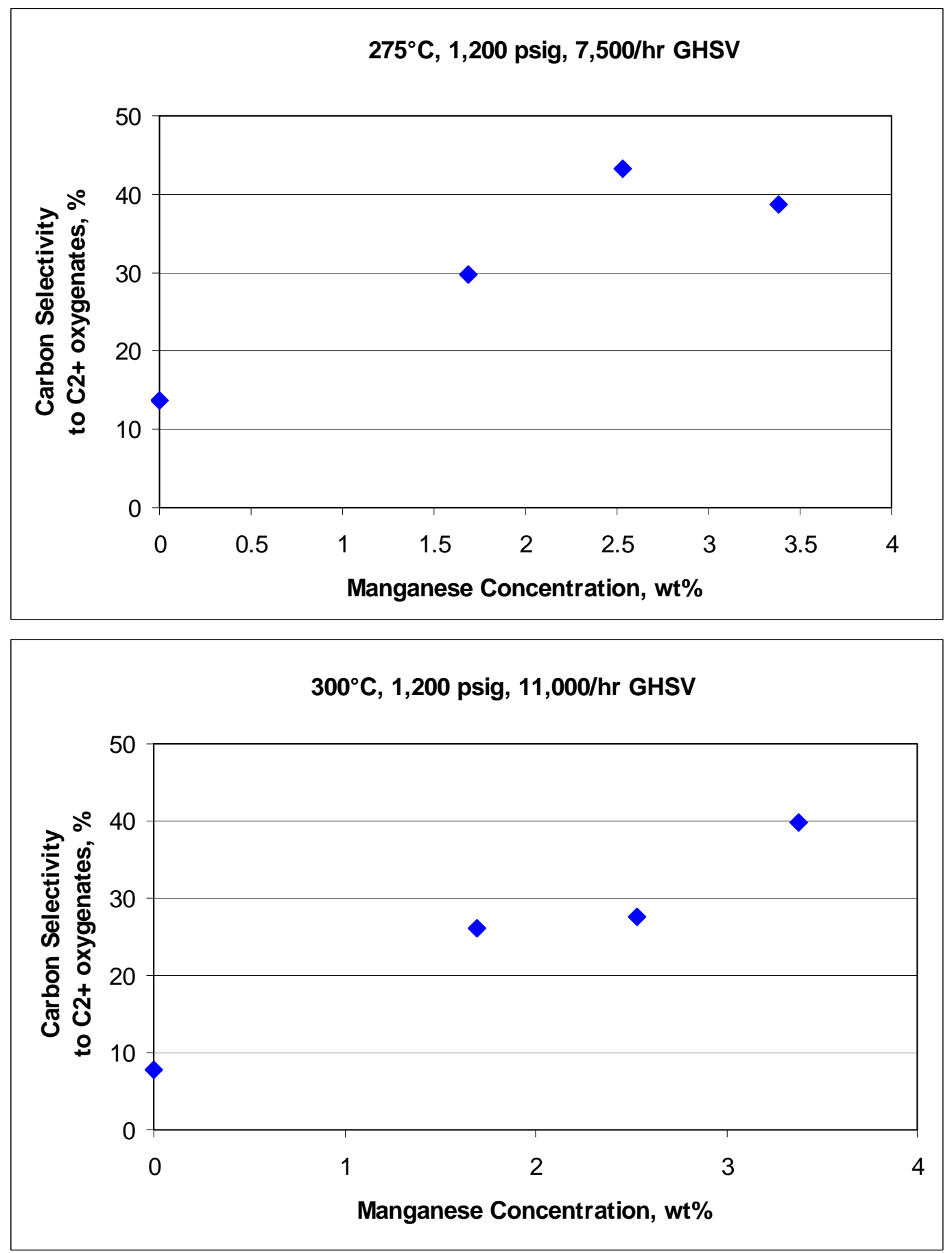

Figure 4.26. Comparison of Converted Carbon Selectivity to $\mathrm{C}_{2}+$ Oxygenates for the Hyperion CS-02C-063 Supported RhMn Catalysts Prepared Using Different Concentrations of Mn at $275^{\circ} \mathrm{C}$ and $300^{\circ} \mathrm{C}$ 

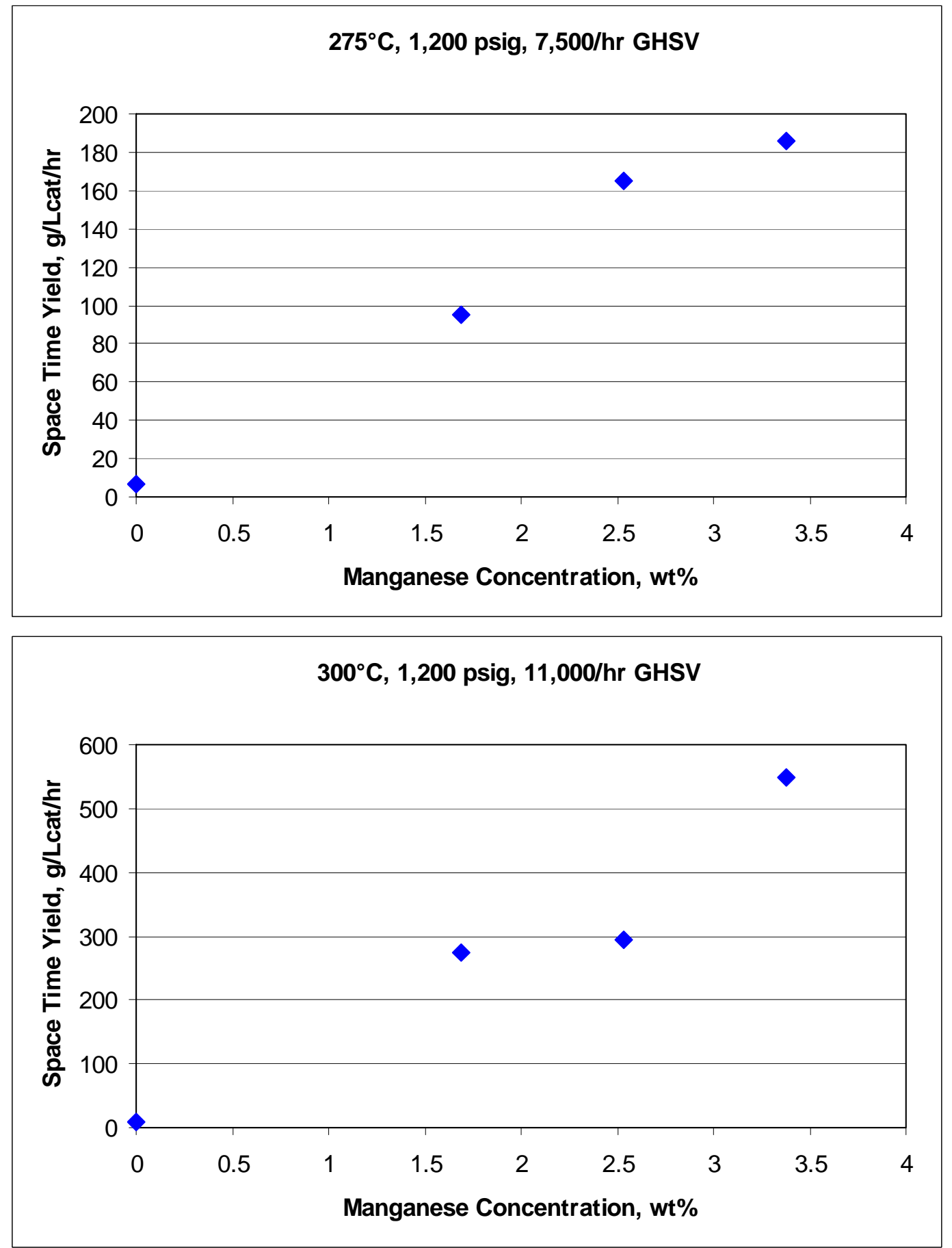

Figure 4.27. Comparison of $\mathrm{C}_{2}+$ Oxygenates STYs for the Hyperion CS-02C-063-Supported RhMn Catalysts Prepared Using Different Concentrations of $\mathrm{Mn}$ at $275^{\circ} \mathrm{C}$ and $300^{\circ} \mathrm{C}$ 

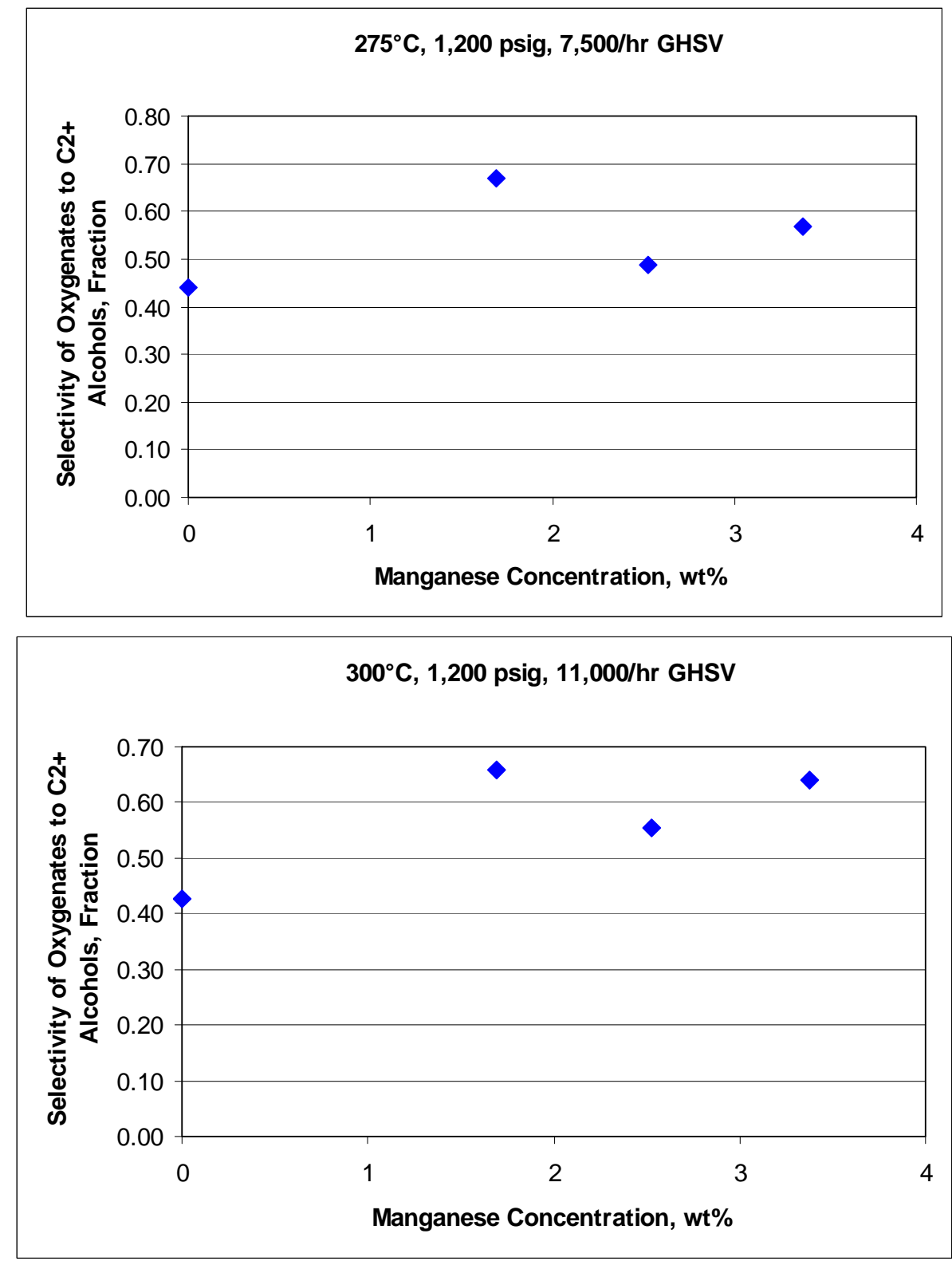

Figure 4.28. Comparison of Selectivities of All Oxygenates to $\mathrm{C}_{2}+$ Alcohols for the Hyperion CS-02C-063-Supported RhMn Catalyst Prepared Using Different Mn Concentrations at $275^{\circ} \mathrm{C}$ and $300^{\circ} \mathrm{C}$

\subsubsection{Effect of Iridium Concentration on Iridium-Promoted RhMn/Carbon Catalyst Performance}

Five tests were conducted to examine the effect of the Ir concentration when it was co-impregnated with the $1.5 \mathrm{X}$ baseline concentrations of $\mathrm{Rh}$ and $\mathrm{Mn}(5.56 \% \mathrm{Rh}$ and $2.69 \% \mathrm{Mn}$ baseline concentrations) using the Hyperion CS-02C-063 support. The Ir concentrations investigated included:

- $0.00 \mathrm{wt} \%$ (no Ir)

- $1.28 \mathrm{wt} \%$ (1.25X baseline concentration) 
- $1.55 \mathrm{wt} \%$ (1.5X baseline concentration)

- $1.80 \mathrm{wt} \%$ (1.75X baseline concentration)

- $2.06 \mathrm{wt} \%$ (2.0X baseline concentration).

The baseline concentration of Ir corresponds to a 10:1 Rh:Ir atomic ratio at the baseline $\mathrm{Rh}$ concentration.

Figures 4.29 through 4.32 provide comparative data for the following two test conditions: 1) $256^{\circ} \mathrm{C}$ at $1200 \mathrm{psig}$ and a GHSV of $7500 \mathrm{~L} / \mathrm{L}_{\text {cat }} / \mathrm{hr}$, and 2) $300^{\circ} \mathrm{C}$ at $1200 \mathrm{psig}$ and a GHSV of $12,000 \mathrm{~L} / \mathrm{L}_{\mathrm{cat}} / \mathrm{hr}$. These conditions generally bracket the performance of the catalysts at $276^{\circ} \mathrm{C}$ at $1200 \mathrm{psig}$ and a GHSV of $7500 \mathrm{~L} / \mathrm{L}_{\text {cat }} / \mathrm{hr}$, except for the catalyst containing no Ir. During the test with this catalyst at this temperature, the catalyst initially had difficulty establishing a stable flow. This condition appeared to have resulted in a higher than expected activity, evidenced by a higher catalyst temperature than before the interruption of flow for the same hot oil temperature.

Figure 4.29 compares the carbon conversions for different Ir concentrations. Although there is considerable scatter in the data at the higher concentrations, it appears that carbon conversion is higher for Ir concentrations at and above $1.8 \%$ at $275^{\circ} \mathrm{C}$. At $300^{\circ} \mathrm{C}$, it appears that the carbon conversion initially drops as the Ir concentration increases from zero to $1.55 \%$ and then increases at higher concentrations. Again the scatter in the data at the higher concentrations makes it difficult to determine the magnitude of the trend of this increase. Furthermore, during the test with the catalyst containing no Ir, gas flow to the reactor was interrupted for a period of time, and the catalyst appeared to be more active (the temperature of the circulating oil had to be reduced to maintain the desired temperature). Thus, it is likely that the carbon conversion for this catalyst would have been lower if the gas flow had not been interrupted, and there would have been a more regular trend of increasing conversion with increasing Ir concentration.

Figure 4.30 compares the converted carbon selectivity to $\mathrm{C}_{2}+$ oxygenates for the different Ir concentrations. In general, the selectivity increases significantly as the Ir concentration increases from zero to $1.28 \%$ (at $300^{\circ} \mathrm{C}$ ) or $1.55 \%\left(\right.$ at $256^{\circ} \mathrm{C}$ ), and then remains constant at higher concentrations.

Figure 4.31 compares the $\mathrm{C}_{2}+$ oxygenates STYs for the different Ir concentrations. In general, the STYs increase and then followed the same trends as carbon conversion, with a pronounced increase in the STYs as the Ir concentration increased to $1.8 \%$ or higher.

Figure 4.32 compares the selectivity of all oxygenates to $\mathrm{C}_{2}+$ alcohols for different Ir concentration levels. In general, it appears that the selectivity is not affected by the $\mathrm{Ir}$ concentration, at least at $256^{\circ} \mathrm{C}$. Again, the problems with gas flow at $275^{\circ} \mathrm{C}$, may account for the lower selectivity for the catalyst containing $0 \% \mathrm{Ir}$, at $275^{\circ} \mathrm{C}$ and higher temperatures.

Overall, it appears that increasing the Ir concentration above $1.55 \%$ significantly improves the performance of the catalyst in terms of carbon conversion, $\mathrm{C}_{2}+$ oxygenates STYs and the converted carbon selectivity to $\mathrm{C}_{2}+$ oxygenates, without adversely affecting the selectivity of the oxygenates to $\mathrm{C}_{2}+$ alcohols. Additional testing at concentrations above $2.06 \%$ is needed to determine an upper limit for the beneficial effects of higher Ir concentrations. 

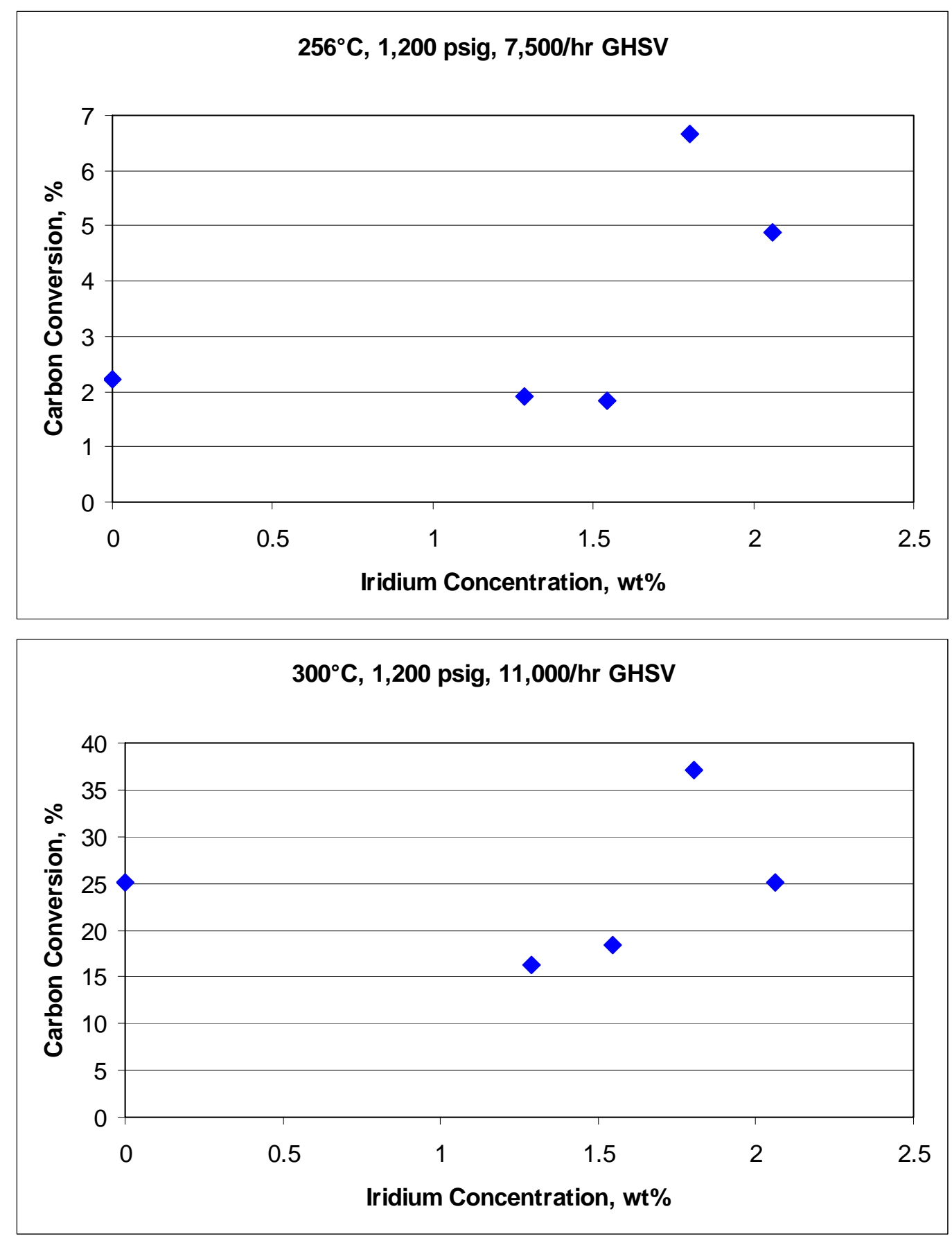

Figure 4.29. Comparison of Carbon Conversions for the Hyperion CS-02C-063-Supported Co-Impregnated RhMnIr Catalysts Prepared Using Different Concentrations of Ir at $256^{\circ} \mathrm{C}$ and $300^{\circ} \mathrm{C}$ 

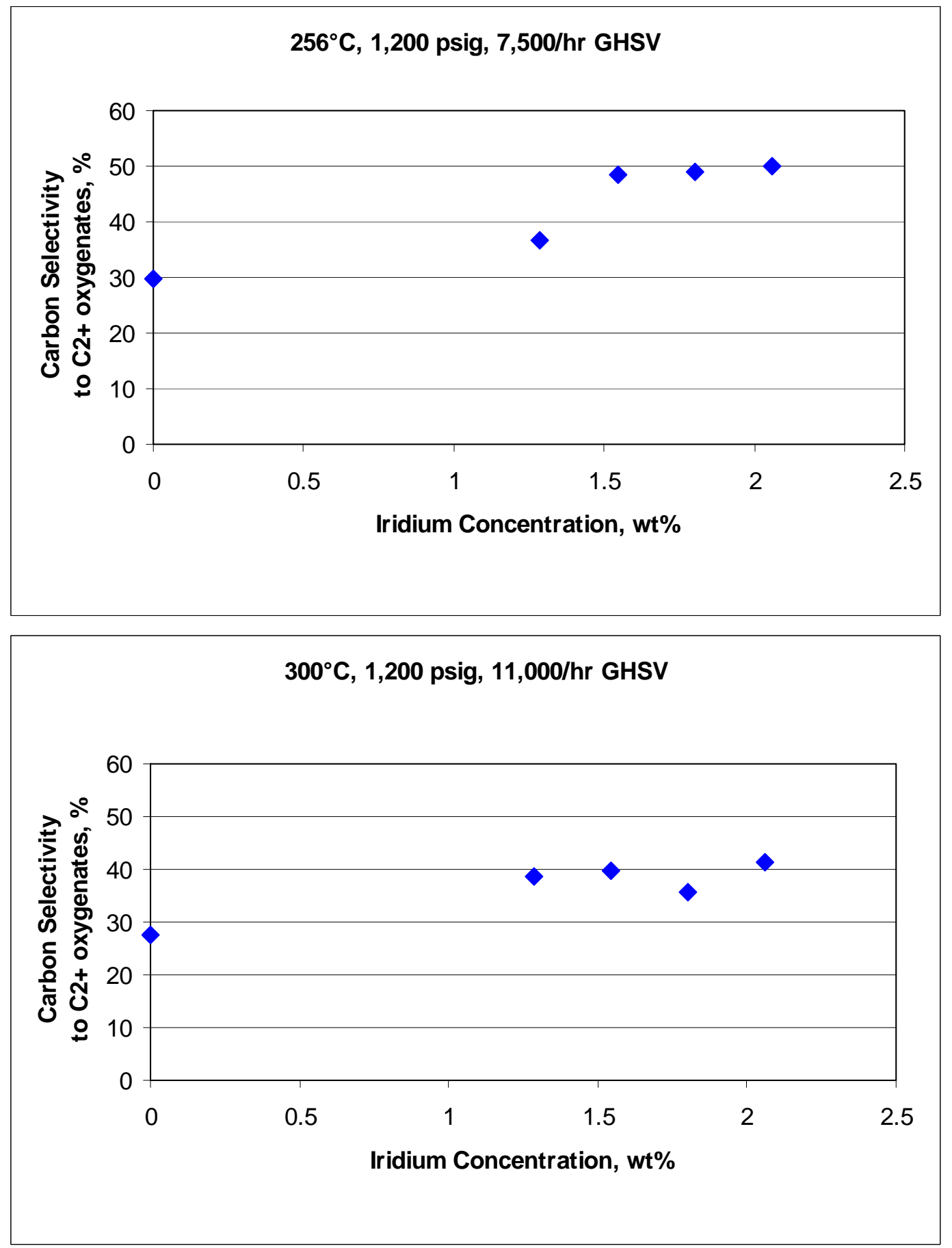

Figure 4.30. Comparison of Converted Carbon Selectivity to $\mathrm{C}_{2}+$ Oxygenates for the Hyperion CS-02C-063-Supported Co-Impregnated RhMnIr Catalysts Prepared Using Different Concentrations of $\mathrm{Ir}$ at $256^{\circ} \mathrm{C}$ and $300^{\circ} \mathrm{C}$ 

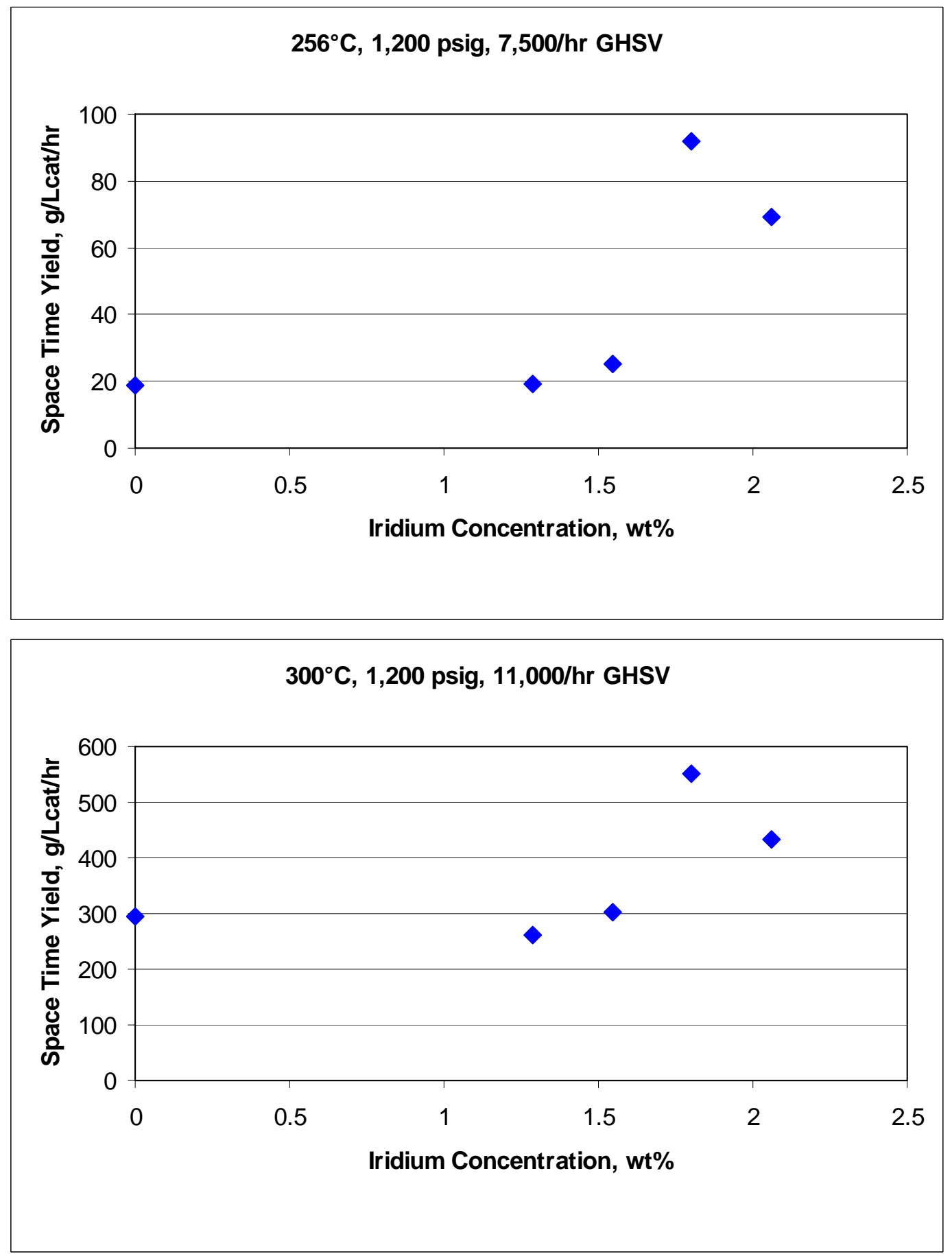

Figure 4.31. Comparison of $\mathrm{C}_{2}+$ Oxygenates STYs for the Hyperion CS-02C-063-Supported Co-Impregnated RhMnIr Catalysts Prepared Using Different Concentrations of Ir at $265^{\circ} \mathrm{C}$ and $300^{\circ} \mathrm{C}$ 

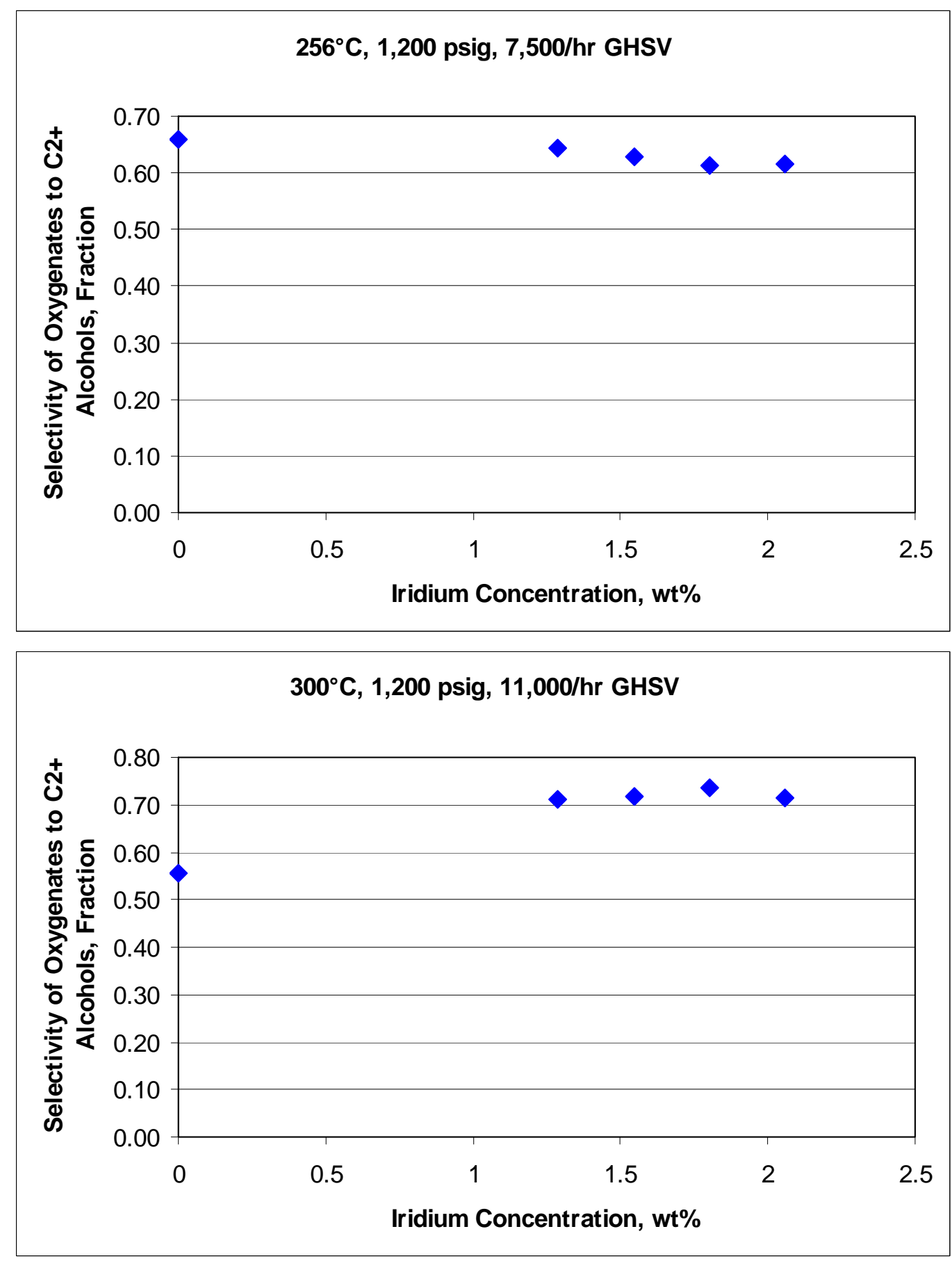

Figure 4.32. Comparison of the Selectivities of All Oxygenates to $\mathrm{C}_{2}+$ Alcohols for the Hyperion CS-02C-063-Supported Rh-Mn-Ir Catalysts Prepared Using Different Concentrations of Ir at $256^{\circ} \mathrm{C}$ and $300^{\circ} \mathrm{C}$ 


\subsubsection{Effect of Total Metal Concentration and the Method of Ir Addition on Catalyst Performance for RhMnIr/Carbon Catalysts}

Five tests were conducted to examine the effect of the total metals concentration and the method of Ir addition on catalyst performance. The metals concentrations are based on $1 \mathrm{X}$ baseline concentrations of $5.56 \% \mathrm{Rh}, 1.69 \% \mathrm{Mn}$, and 1.03\% Ir corresponding to Rh:Mn:Ir atomic ratios of 1.00:0.57:0.10. The metal loadings investigated included:

- $1.5 \mathrm{X}$ baseline concentrations

- $2.11 \mathrm{X}$ baseline concentrations

Ir was either co-impregnated with the $\mathrm{Rh}$ and $\mathrm{Mn}$ or it was added by first co-impregnating $\mathrm{Rh}$ and Mn, drying the catalyst, and then impregnating Ir.

Figures 4.33 through 4.36 provide comparative data for the following two test conditions: 1) $275^{\circ} \mathrm{C}$, at $1,200 \mathrm{psig}$ and a GHSV of 7,500 L/L $/ \mathrm{L}_{\text {cat }} / \mathrm{hr}$, and 2) $300^{\circ} \mathrm{C}$ at $1200 \mathrm{psig}$ and a GHSV of $12,000 \mathrm{~L} / \mathrm{L}_{\text {cat }} / \mathrm{hr}$. Figure 4.33 compares the carbon conversions for different catalyst loadings. As might be expected, there is a significant increase in carbon conversion with increasing catalyst concentration. Because of the scatter of the data for both temperatures, it is less clear how the method of Ir addition affected performance.

Figure 4.34 compares the converted carbon selectivity to $\mathrm{C}_{2}+$ oxygenates for the different loadings. Because of the scatter of the data, there does not appear to be any clear trend in selectivity with respect to the metals loading or the method of Ir addition.

Figure 4.35 compares the $\mathrm{C}_{2}+$ oxygenates STYs for the different metal loads. In general the STYs increase followed the same trends as carbon conversion, with respect to both the effect of metals loading and the method of Ir addition.

Figure 4.36 compares the selectivity of all oxygenates to $\mathrm{C}_{2}+$ alcohols for different metals loadings. While there was much less scatter in the data, it appears that there is no significant effect of either the metals loading or the method of Ir addition on the selectivity.

Overall, it appears that, as would be expected, increasing the metal loading significantly increases the carbon conversion and $\mathrm{C}_{2}+$ oxygenates STYs, but it does not significantly affect the selectivity of the converted carbon to $\mathrm{C}_{2}+$ oxygenates or the selectivity of the oxygenates to alcohols. There is no clear effect on the method of impregnating the catalyst support on catalyst performance, mainly because of scatter in the data. 

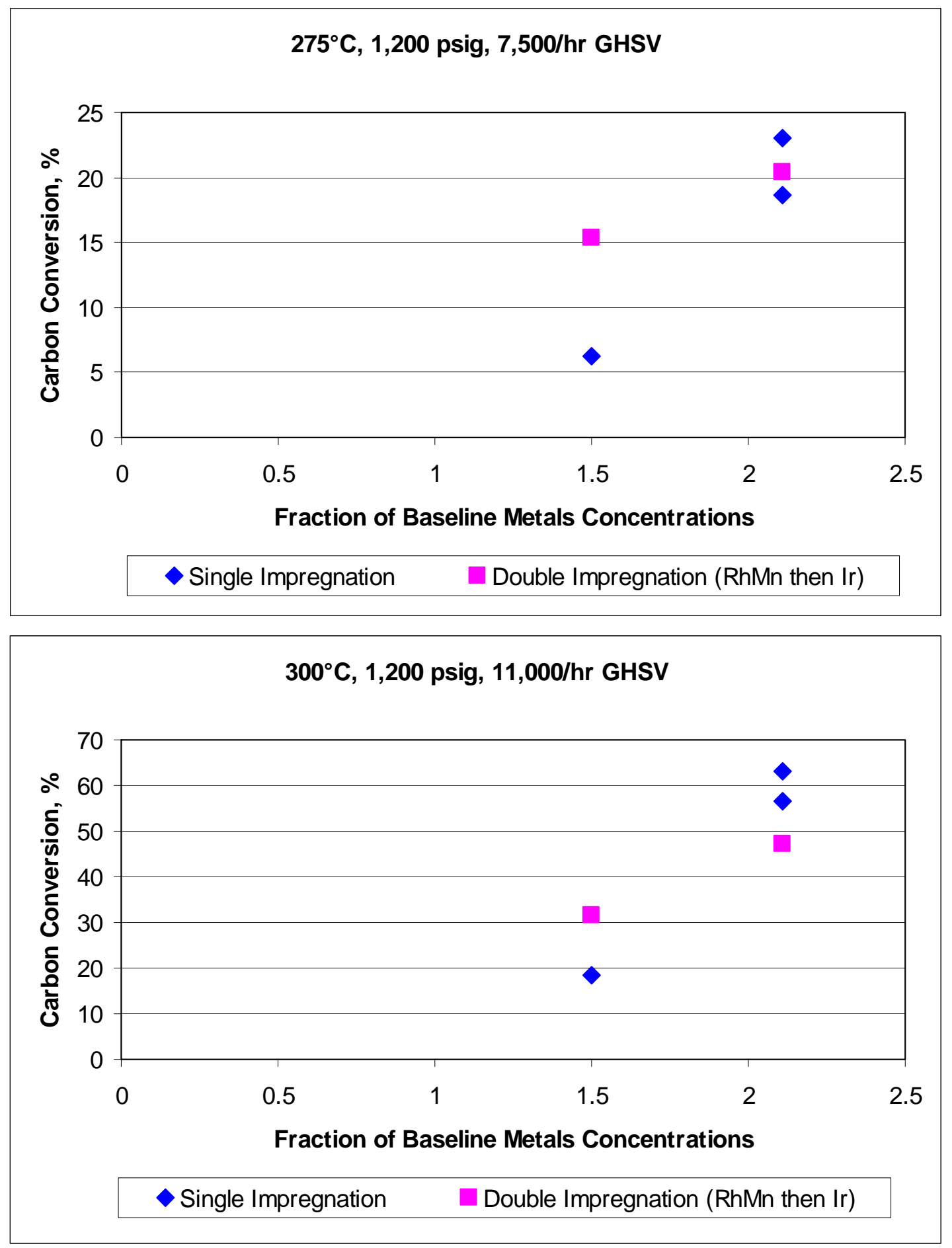

Figure 4.33. Comparison of Carbon Conversions for the Hyperion CS-02C-063-Supported RhMnI Catalysts Prepared Using Different Total Metal Loadings at $275^{\circ} \mathrm{C}$ and $300^{\circ} \mathrm{C}$ 

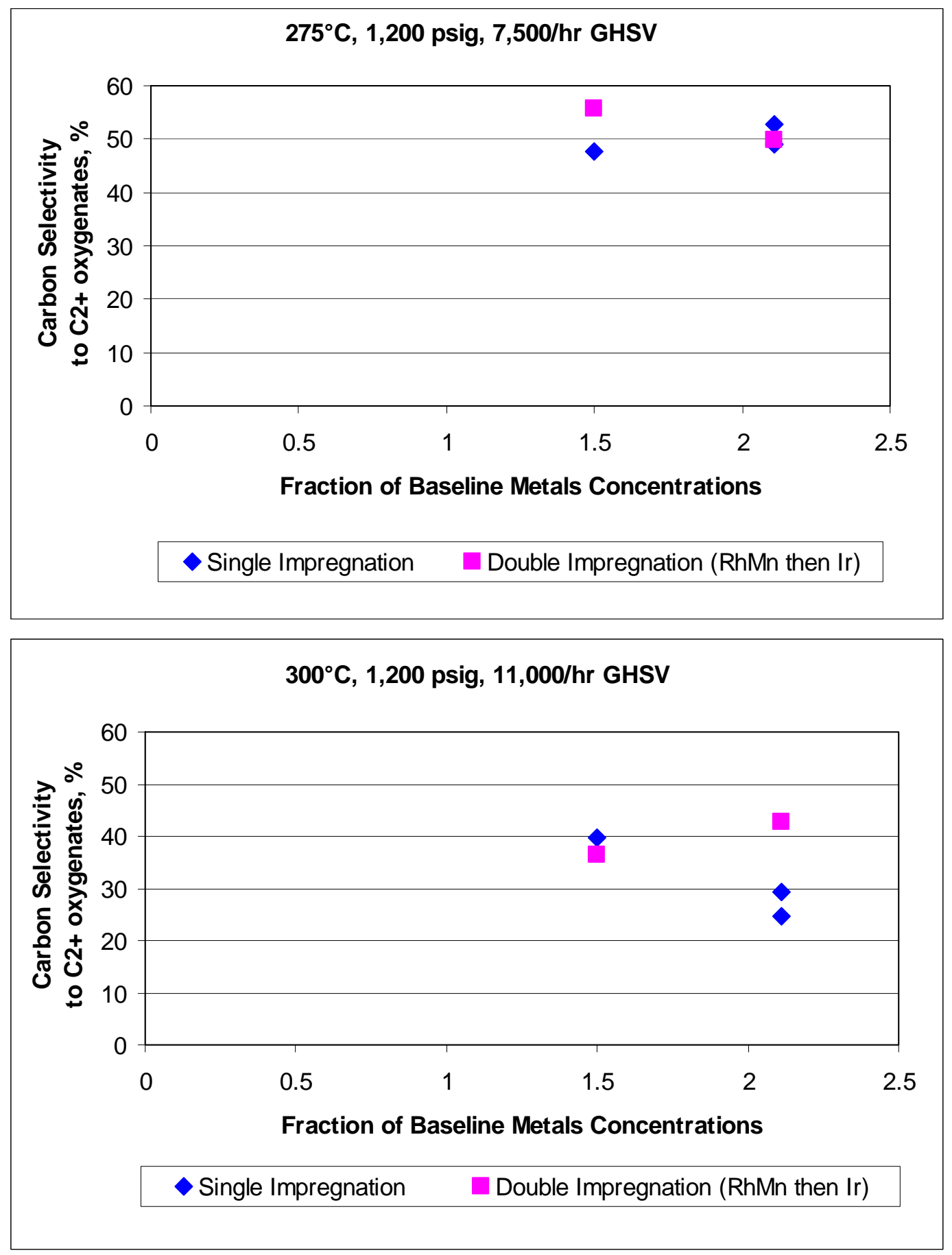

Figure 4.34. Comparison of Converted Carbon Selectivities to $\mathrm{C}_{2}+$ Oxygenates for the Hyperion CS-02C-063-Supported Co-Impregnated RhMnIr Catalysts Prepared Using Different Total Metal Loadings at $275^{\circ} \mathrm{C}$ and $300^{\circ} \mathrm{C}$ 

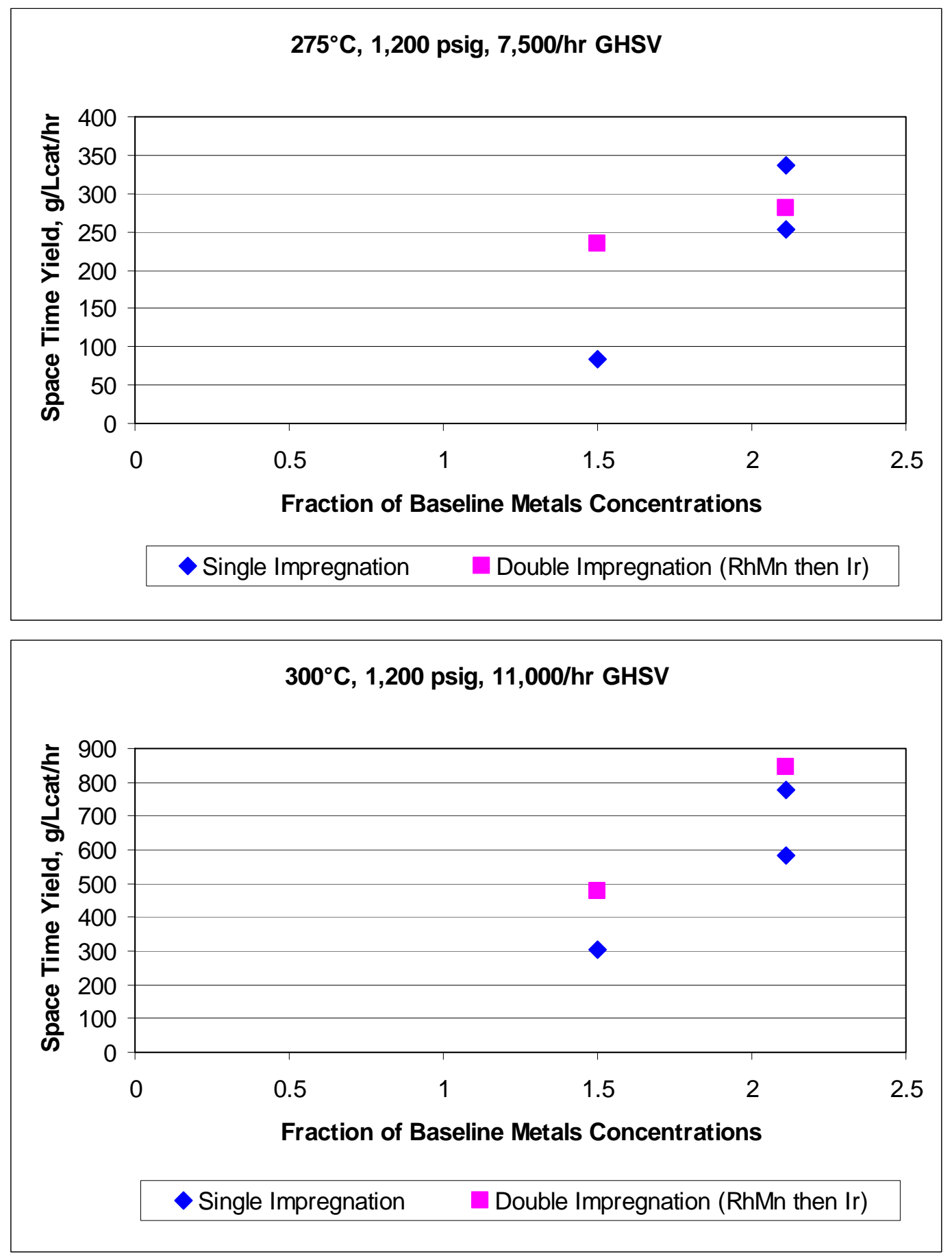

Figure 4.35. Comparison of $\mathrm{C}_{2}+$ Oxygenates STYs for the Hyperion CS-02C-063-Supported Co-Impregnated RhMnIr Catalysts Prepared Using Different Total Metal Loadings at $275^{\circ} \mathrm{C}$ and $300^{\circ} \mathrm{C}$ 

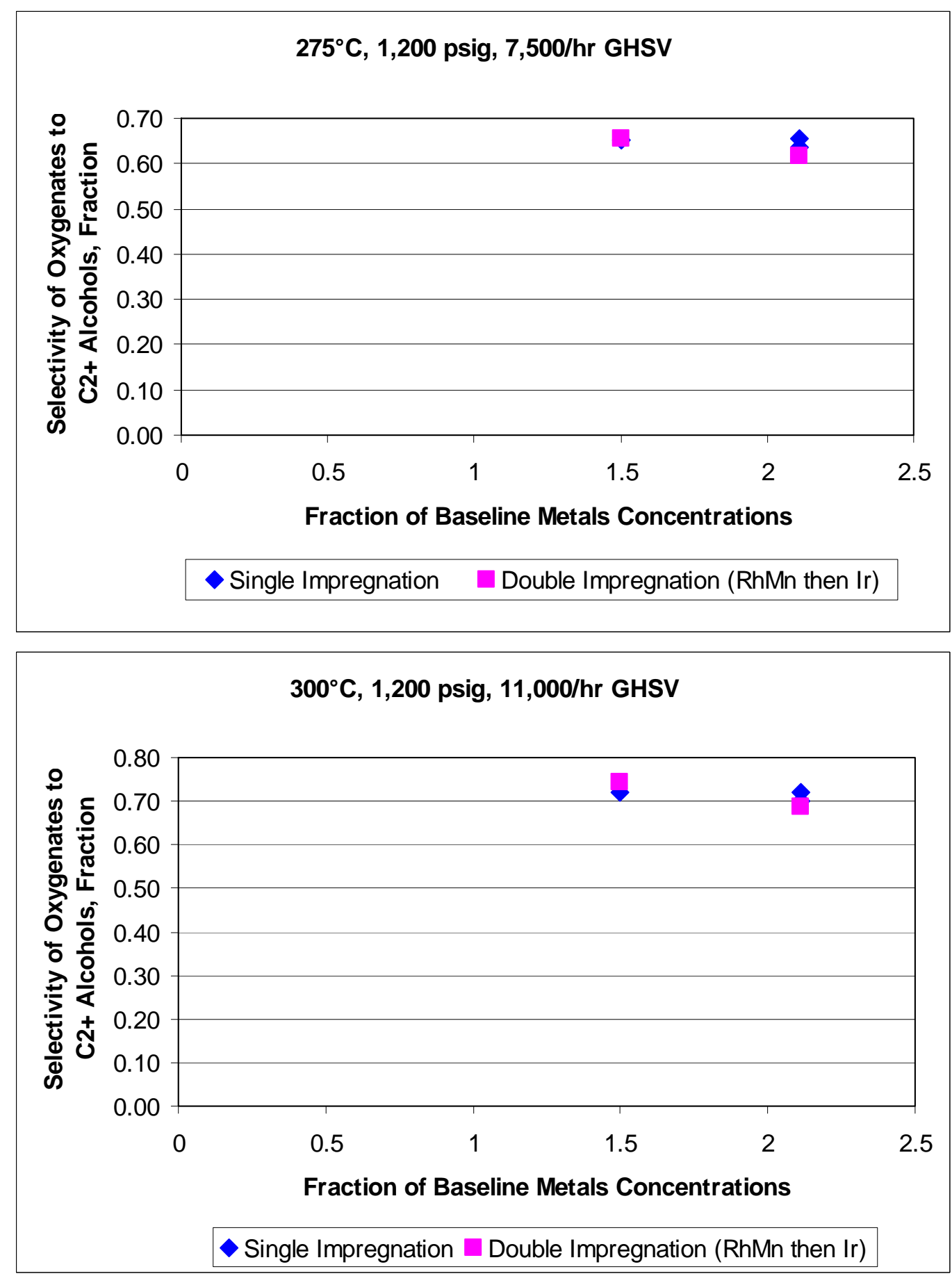

Figure 4.36. Comparison of the Selectivities of All Oxygenates to $\mathrm{C}_{2}+$ Alcohols for the Hyperion CS-02C-063-Supported RhMn Catalyst Prepared Using Different Total Metal Loadings at $275^{\circ} \mathrm{C}$ and $300^{\circ} \mathrm{C}$

\subsubsection{Effect of Reducing Conditions on Catalyst Performance}

Using an RhMnIr catalyst supported on the Hyperion CS-02C-063 support, three tests were conducted to investigate the effect of the maximum reducing temperature on catalyst performance. 
The catalyst contained $2.11 \mathrm{X}$ the baseline concentrations of $5.56 \% \mathrm{Rh}, 1.69 \% \mathrm{Mn}$, and $1.03 \% \mathrm{Ir}$, which corresponded to Rh:Mn:Ir atomic ratios of 1.00:0.57:0.10. All catalysts were obtained from the same master batch of catalyst and were reduced using a mixture that contained $10 \%$ hydrogen in nitrogen. The following reducing conditions were performed in the tests:

- Catalyst heated at $2^{\circ} \mathrm{C} / \mathrm{min}$ to $200^{\circ} \mathrm{C}$ and held there for 12 hours

- Catalyst heated at $2^{\circ} \mathrm{C} / \mathrm{min}$ to $220^{\circ} \mathrm{C}$ and held there for 1 hour; heated at $2^{\circ} \mathrm{C} / \mathrm{min}$ to $260^{\circ} \mathrm{C}$ and held there for 12 hours

- Catalyst heated at $2.5^{\circ} \mathrm{C} / \mathrm{min}$ to $220^{\circ} \mathrm{C}$ and held there for 1 hour; heated at $2^{\circ} \mathrm{C} / \mathrm{min}$ to $260^{\circ} \mathrm{C}$ and held there for 8 hours heated at $1.5^{\circ} \mathrm{C} / \mathrm{min}$ to $360^{\circ} \mathrm{C}$ and held there for 4 hours.

All catalysts were cooled to ambient temperature in the reducing gas after the reduction procedure was completed.

Figures 4.37 through 4.40 compare the performance of the three catalysts over a temperature range from $240^{\circ} \mathrm{C}$ to $275^{\circ} \mathrm{C}$, at $1200 \mathrm{psig}$ and a GHSV of $7500 \mathrm{~L} / \mathrm{L}_{\text {cat }} / \mathrm{hr}$. Data for the catalysts reduced at $360^{\circ} \mathrm{C}$ include the results from two different tests using the same catalyst preparation.

Comparing the catalyst reduced at $200^{\circ} \mathrm{C}$ to the catalyst reduced at $360^{\circ} \mathrm{C}$, it appears that both have very similar activities in term of carbon conversion at all temperatures as shown in Figure 4.37, but the catalyst reduced at $360^{\circ} \mathrm{C}$ has a significantly higher selectivity to $\mathrm{C}_{2}+$ oxygenates at temperatures up to $256^{\circ} \mathrm{C}$ as shown in Figure 4.38 . At $275^{\circ} \mathrm{C}$, both catalysts have very similar activities and converted carbon selectivities to $\mathrm{C}_{2}+$ oxygenates. The $\mathrm{C}_{2}+$ oxygenates STYs were higher for the catalysts reduced at $360^{\circ} \mathrm{C}$ than the catalyst reduced at $200^{\circ} \mathrm{Cas}$ shown in Figure 4.39 , while both catalysts had very similar selectivities of the oxygenates to $\mathrm{C}_{2}+$ alcohols as shown in Figure 4.40.

Comparing the catalyst reduced at $260^{\circ} \mathrm{C}$ to the other two reduced catalysts is more difficult because this catalyst behaved very differently in terms of carbon conversion and converted carbon selectivity to $\mathrm{C}_{2}+$ oxygenates. It appears that the catalyst reduced at $260^{\circ} \mathrm{C}$ had carbon conversions similar to the other two catalysts at temperatures up to $256^{\circ} \mathrm{C}$ but had a much lower carbon conversion than either of the other catalysts at $275^{\circ} \mathrm{C}$. On the other hand, the catalyst reduced at $260^{\circ} \mathrm{C}$ had converted carbon selectivities to $\mathrm{C}_{2}+$ oxygenates at the $240^{\circ} \mathrm{C}$ and $275^{\circ} \mathrm{C}$ test conditions that were similar to the catalyst reduced at $360^{\circ} \mathrm{C}$, but had a much higher selectivity than either of the other two catalysts at $256^{\circ} \mathrm{C}$. The $\mathrm{C}_{2}+$ oxygenates STYs for this catalyst followed the same trends observed for carbon conversion, while the selectivity of oxygenates to $\mathrm{C}_{2}+$ alcohols was essentially the same as the catalysts reduced at the other two temperatures. There were no significant differences in how these catalysts were tested in this temperature range, so the differences in carbon conversion at $275^{\circ} \mathrm{C}$ and converted carbon selectivity at $256^{\circ} \mathrm{C}$ for the catalyst reduced at $260^{\circ} \mathrm{C}$ could be a result of scatter in the data resulting from an as yet unknown reason, or they may accurately represent a significant difference in the catalyst reduced at $260^{\circ} \mathrm{C}$.

Overall it appears that the catalyst reduced at $200^{\circ} \mathrm{C}$ had inferior performance compared to the other two catalysts mainly in terms of the converted carbon selectivity to $\mathrm{C}_{2}+$ oxygenates. It is possible, however, that the catalyst reduced at $260^{\circ} \mathrm{C}$ had performance that was comparable to that of the catalyst reduced at $360^{\circ} \mathrm{C}$, provided that the previously described anomalies can be explained. With the unusually high converted carbon selectivity obtained at $256^{\circ} \mathrm{C}$ for the catalyst reduced at $260^{\circ} \mathrm{C}$, additional tests are warranted to determine whether this performance can be reproduced. 


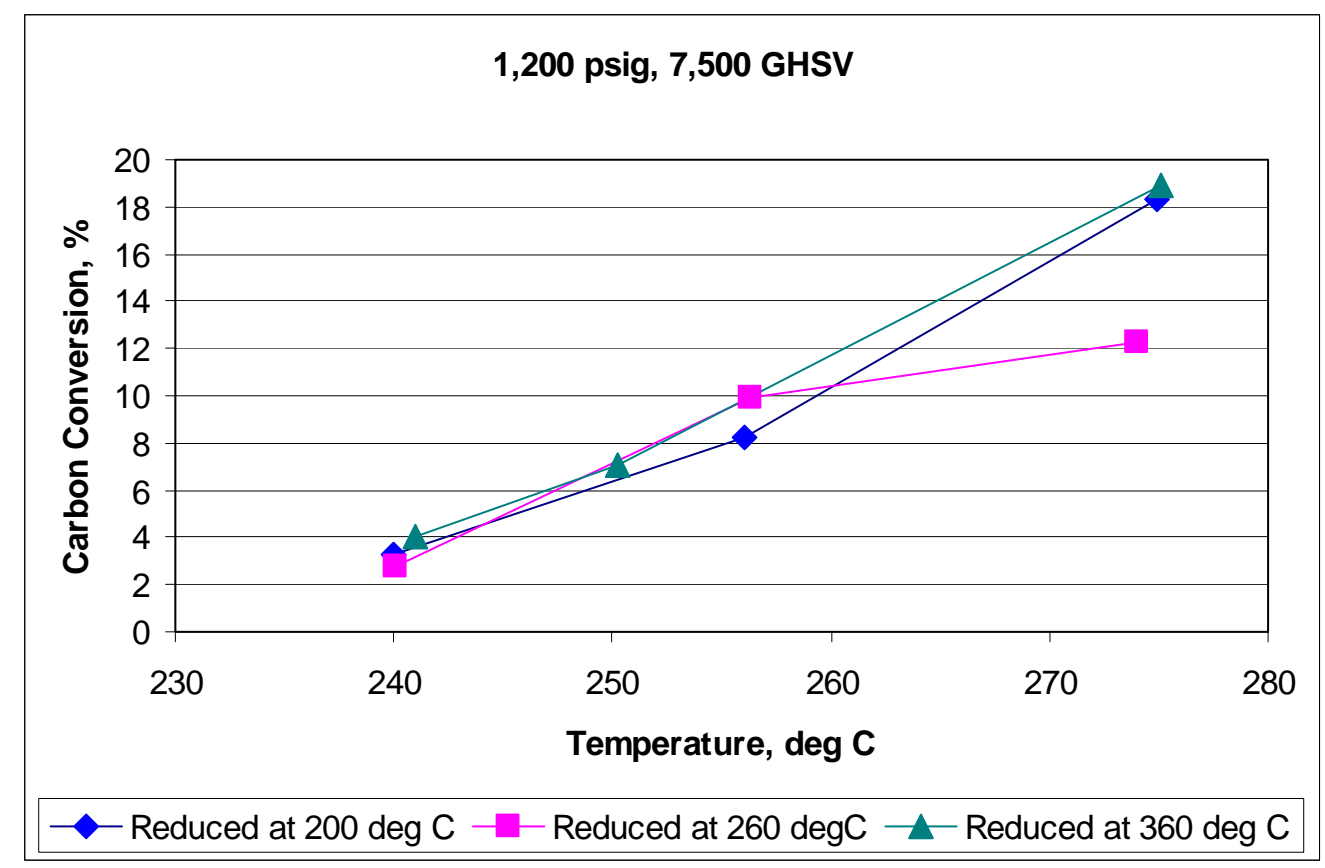

Figure 4.37. Effect of Catalyst Reduction Temperature on Carbon Conversion for Hyperion CS-02C-063-Supported 2.11X Baseline RhMnIr Catalysts

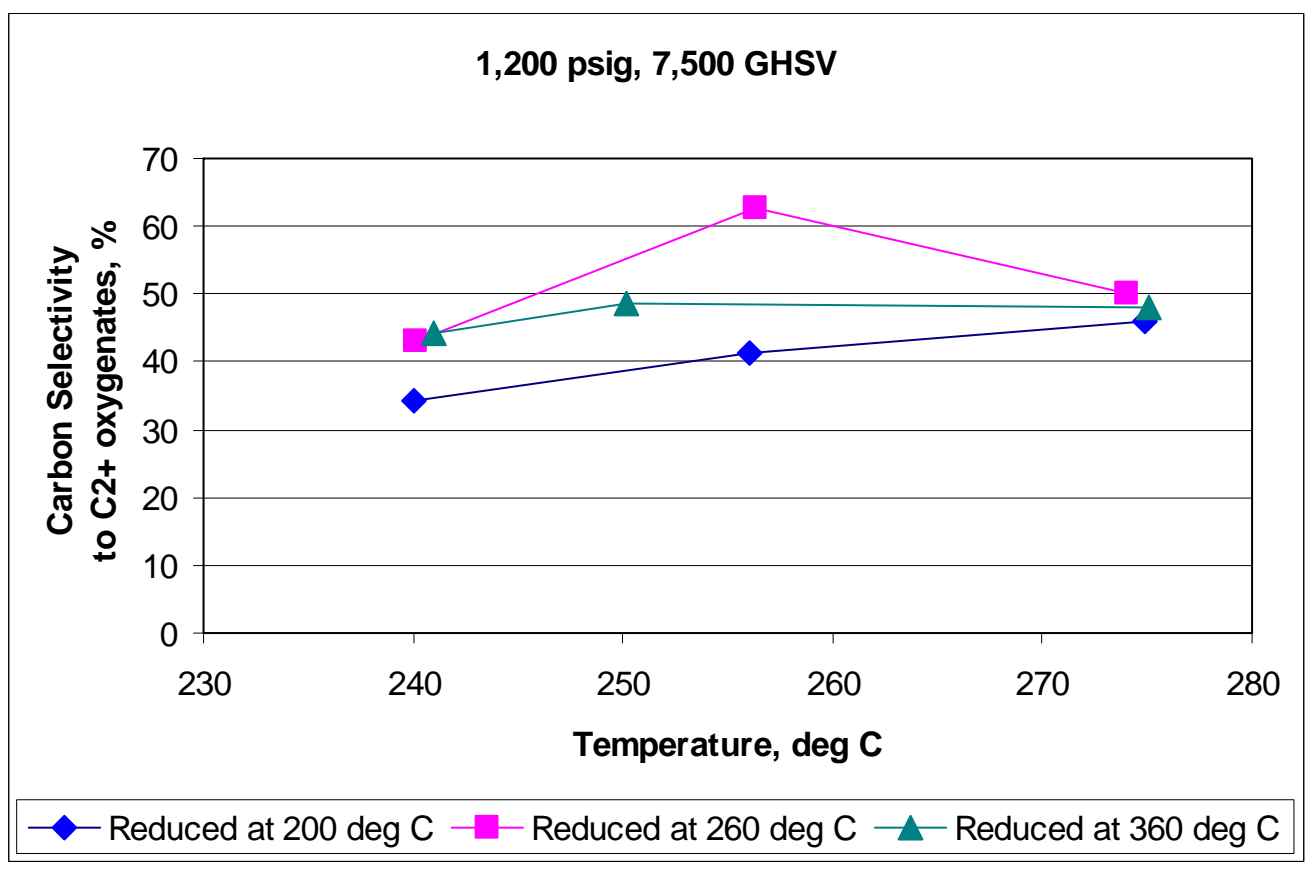

Figure 4.38. Effect of Catalyst Reduction Temperature on Converted Carbon Selectivity to $\mathrm{C}_{2}+$ Oxygenates for Hyperion CS-02C-063-Supported 2.11X Baseline RhMnIr Catalysts 


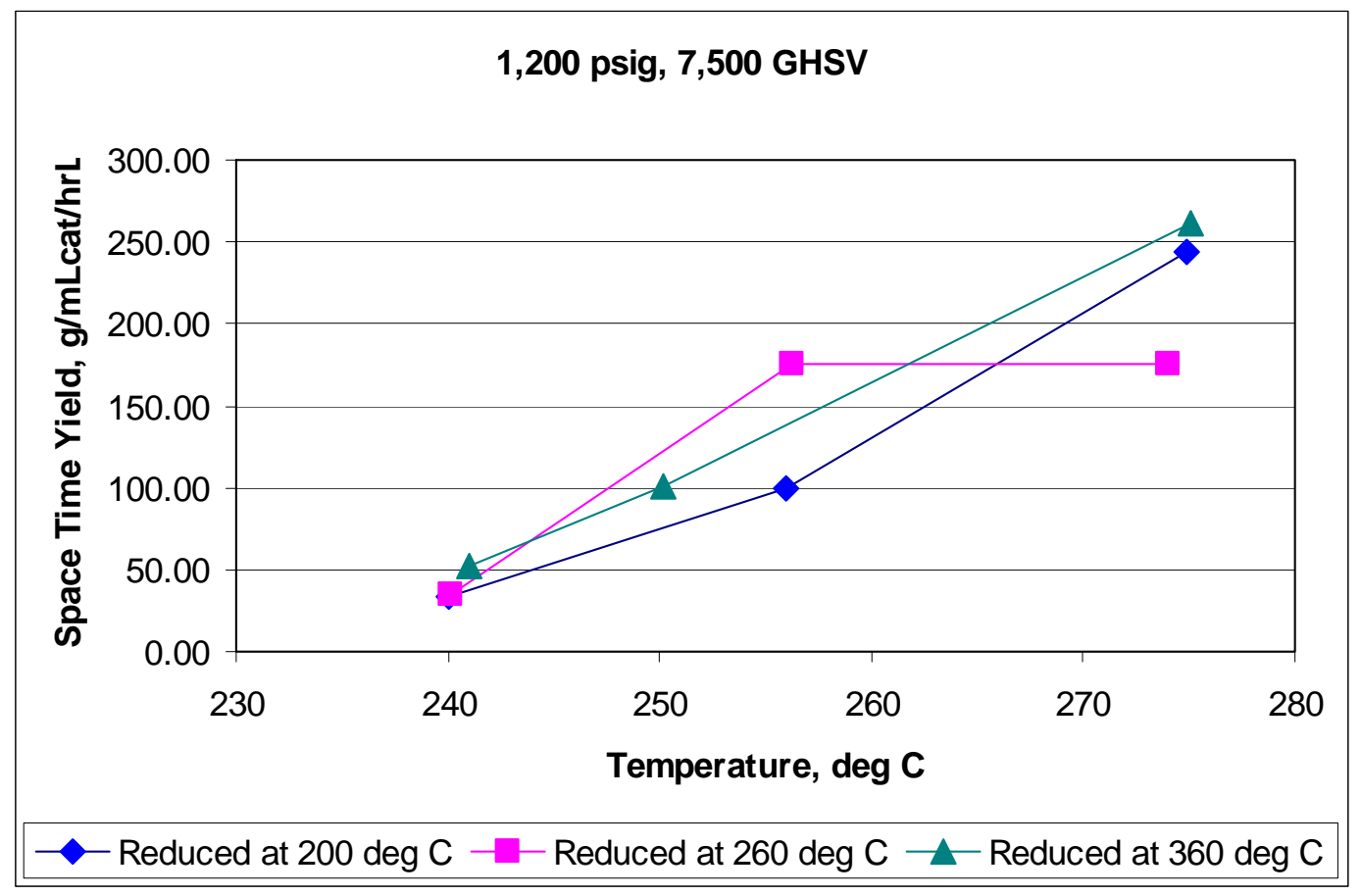

Figure 4.39. Effect of Catalyst Reduction Temperature on $\mathrm{C}_{2}+$ Oxygenates STYs for Hyperion CS-02C-063-Supported 2.11X Baseline RhMnIr Catalysts

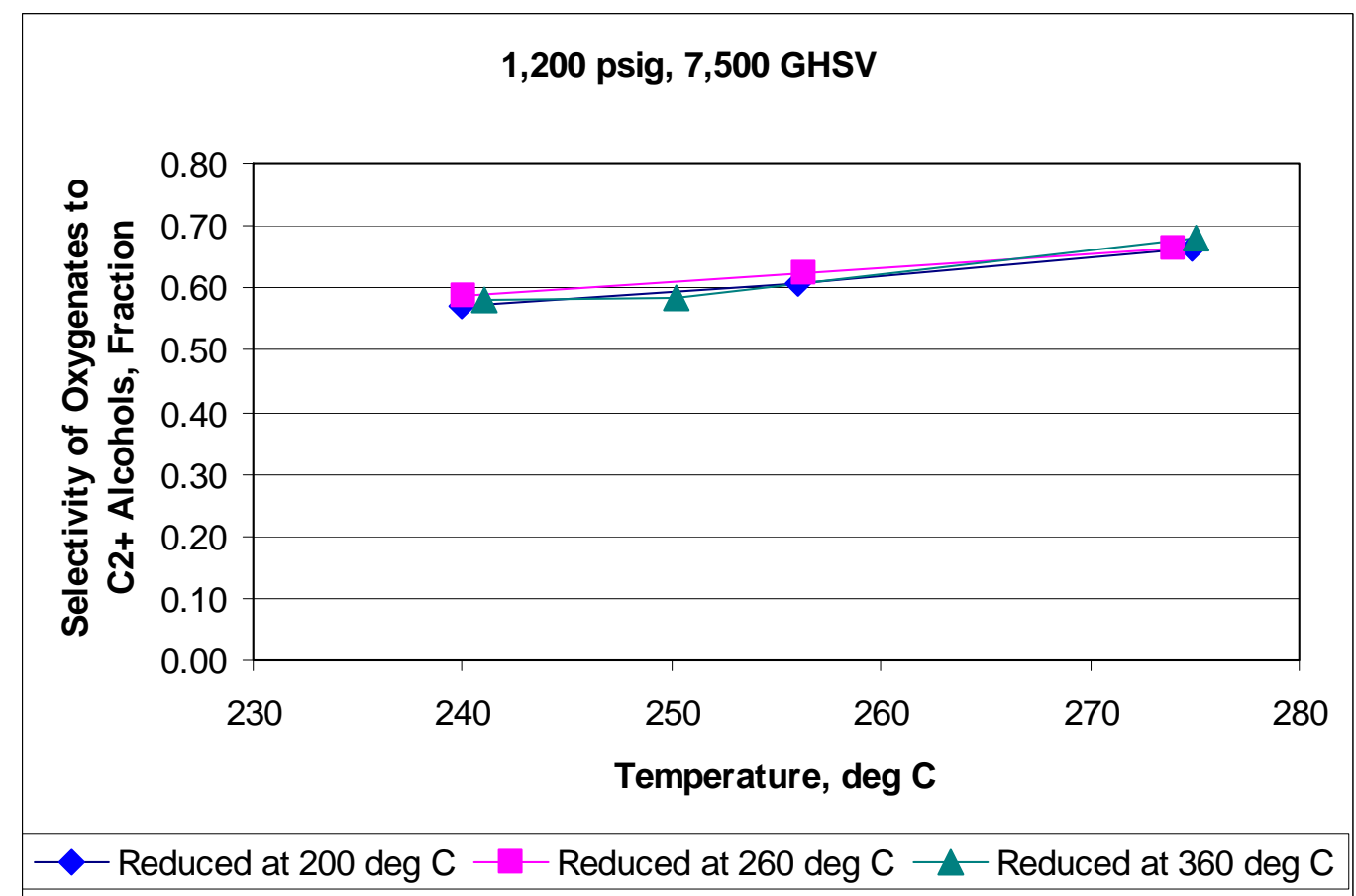

Figure 4.40. Effect of Catalyst Reduction Temperature on Selectivity of Oxygenates to $\mathrm{C}_{2}+$ Alcohols for Hyperion CS-02C-063-Supported 2.11X Baseline RhMnIr Catalysts 


\subsection{Conclusions}

A large number of catalyst tests were conducted to evaluate the effects of a variety of catalyst supports for catalysts containing Rh and $\mathrm{Mn}$, and to further optimize the effects of catalytic metal concentrations and ratios for $\mathrm{Rh}$ and $\mathrm{Mn}$ and, in some cases, a third metal promoter for selected silica and carbon supports. A limited number of tests also were conducted to examine the effect of the manner in which the metals were added to the catalyst support and the temperature profile during catalyst reduction. Based on the results of these tests, a number of general conclusions can be reached.

\subsection{Catalyst Supports}

Based on the catalyst supports evaluated to date, selected silica and carbon supports had superior performance compared to alumina, silica-alumina, titania, and zirconia supports. Within each category, however, there was considerable variation in the performance of different silica and carbon supports. The best silica supports containing Rh and Mn were the Davisil 645, Engelhard Mod D, Norpro SS61137, and Norpro SS61138. The best carbon supports were the two Engelhard Hi surface graphitic carbons, the Hyperion CS-02C-063 carbon nanotube, and the Timrex 300 high surface area graphitic carbon.

\subsection{Optimization of Silica-Supported Catalysts}

Catalyst optimization studies using Davisil 645 silica-supported RhMn catalysts further examined the effect of the concentration of a third metal (i.e., Ir, Pt, or Ga) on catalyst performance. Overall, there may be a minor increasing trend in carbon conversion, a decreasing trend in converted carbon selectivity to $\mathrm{C}_{2}+$ oxygenates, and no trend in $\mathrm{C}_{2}+$ oxygenates STY with increasing Ir concentration for the catalysts prepared with a single co-impregnation. However, with the scatter in the data for these catalysts as well as that for the double-impregnated catalysts, these trends should be treated with caution. No clear trends could be ascertained for the double-impregnated catalysts because of scatter in the data. Additional testing is needed to repeat tests with current catalyst samples and also with freshly made catalysts to examine a greater range of Ir concentrations before any conclusions can be drawn.

It appears that adding $\mathrm{Pt}$ to the $\mathrm{RhMn} / \mathrm{SiO}_{2}$ catalyst, via a single co-impregnation of all three metals, decreases the catalytic activity (i.e., carbon conversion) but increases the carbon selectivity to $\mathrm{C}_{2}+$ oxygenates. The net result is that there appears to be a maximum STY at the lower concentrations, possibly below a concentration of $1 / 3 \mathrm{X}$ of the baseline concentration of $1.05 \%$ Pt. Further testing would be required to confirm this observation. It also appears that the double-impregnated catalyst, where Pt is added in the second impregnation, is much more active, at least at the baseline Pt concentration with comparable or higher converted carbon selectivity to $\mathrm{C}_{2}+$ oxygenates, depending on the temperature. Further testing is needed to optimize Pt concentration for the double-impregnated catalysts.

The effect of adding Ga to the RhMn catalyst is very different from that of the other two promoters (Ir and $\mathrm{Pt}$ ). Addition of relatively small quantities of $\mathrm{Ga}$ causes a pronounced decrease in carbon conversion, although the effect is less pronounced at higher catalyst temperatures, On the other hand, addition of small amounts of $\mathrm{Ga}$ causes an increase in converted carbon selectivity to $\mathrm{C}_{2}+$ oxygenates that is more pronounced at higher operating temperatures. The net result is that there appears to be an optimum, but a low concentration of Ga that produces a maximum $\mathrm{C}_{2}+$ oxygenates STY when the catalyst is operated at higher temperatures. 
Three tests were conducted to examine the method of adding metals to the silica support. The methods included addition of both metals in a single impregnation, and adding either $\mathrm{Rh}$ or $\mathrm{Mn}$ in a single impregnation followed by a second impregnation of the other metal with drying between impregnations. It appears that the co-impregnated catalyst has the best overall performance combination at the lower temperatures with a higher $\mathrm{C}_{2}+$ oxygenates STY and converted carbon selectivity to $\mathrm{C}_{2}+$ oxygenates. The double-impregnated catalyst with Mn added first had a significantly lower STY, while the doubleimpregnated catalyst with $\mathrm{Rh}$ added first had a significantly lower selectivity. At higher temperatures, the double-impregnated catalyst, with $\mathrm{Mn}$ added in the first impregnation, had the best overall performance, in terms of these parameters, but that is attributed to the fact that it did not undergo temperature excursions at this temperature and apparently partially deactivated the other two catalysts. If heat management was better for all three catalysts, the other two may have behaved better at this temperature.

\subsection{Optimization of Carbon-Supported Catalysts}

Catalyst optimization tests were conducted using the Hyperion CS-05C-063 carbon-nanotube support. Optimization tests for RhMn/carbon catalysts examined total $\mathrm{Rh}$ and $\mathrm{Mn}$ metal loadings at a fixed metal ratio and the method of metal addition, and the effect of Mn concentration at a fixed Rh concentration. RhMnIr/carbon catalysts examined the effect of total metals loading and the method of loading at fixed metal ratios, Ir concentration effects at a fixed $\mathrm{Rh}$ and $\mathrm{Mn}$ concentrations, and the catalyst reduction temperature on catalyst performance.

For co-impregnated catalysts in which $\mathrm{Rh}$ and $\mathrm{Mn}$ were added at a fixed atomic ratio in a single impregnation, there appears to be a regular increase in carbon conversion and converted carbon selectivity to $\mathrm{C}_{2}+$ oxygenates with increasing total metals concentration, although there is a fair amount of scatter in the data for the latter parameter. It is noteworthy that the increase in the carbon conversion increases by a much greater multiple than the increase in concentration. The $\mathrm{C}_{2}+$ oxygenates STY generally follows the same behavior as carbon conversion. The selectivity of all oxygenates to $\mathrm{C}_{2}+$ alcohols decreases increasing total metals concentration.

Three tests were conducted to examine the method of adding metals to the carbon support. The methods included addition of both metals in a single impregnation, and adding either Rh or Mn in an impregnation followed by a second impregnation of the other metal with drying between impregnations. It appears that the co-impregnated catalyst is as good or superior to both double-impregnated catalysts. According to the data, the catalyst is superior in terms of carbon selectivity to $\mathrm{C}_{2}+$ oxygenates and $\mathrm{C}_{2}+$ oxygenates STYs at $275^{\circ} \mathrm{C}$ and higher temperatures. However, this may be attributed to the interruption of flow at the $275^{\circ} \mathrm{C}$ test condition for the co-impregnated catalyst that appeared to increase both its activity and converted carbon selectivity to $\mathrm{C}_{2}+$ oxygenates at the higher temperatures. Conversely, it is unlikely that the catalyst would have been less active or selective than the other two if the flow interruption had not occurred.

A series of tests were conducted to examine RhMn/carbon catalysts with different Mn concentrations and a fixed $\mathrm{Rh}$ concentration. The results of those tests indicate that increasing the Mn concentration results in improvements in all of the performance parameters over the entire range of concentrations examined. Further testing at even higher Mn concentrations is warranted to determine the optimum concentration. 
Tests were also conducted to examine the effect of different Ir concentrations on a RhMnIr/carbon catalyst where all three metals were added to the support in a single impregnation. It appears that increasing the Ir concentration above a threshold concentration significantly improves the performance of the catalyst in terms of carbon conversion, $\mathrm{C}_{2}+$ oxygenates STYs, and the converted carbon selectivity to $\mathrm{C}_{2}+$ oxygenates, without adversely affecting the selectivity of the oxygenates to $\mathrm{C}_{2}+$ alcohols. Additional testing at concentrations above $2.06 \%$ is needed to determine the upper limit for the beneficial affects effects of higher Ir concentrations.

A series of tests also examined the effect of total metals concentration at fixed metals ratios on catalyst performance with Ir either co-impregnated with the Rh and Mn or it was added by first coimpregnating of $\mathrm{Rh}$ and $\mathrm{Mn}$, drying the catalyst, and then impregnating with Ir. It appears that increasing the metal loading significantly increases the carbon conversion and $\mathrm{C}_{2}+$ oxygenates STYs, as would be expected, but does not significantly affect the selectivity of the converted carbon to $\mathrm{C}_{2}+$ oxygenates or the selectivity of the oxygenates to alcohols. There was no clear effect on the method of impregnating the catalyst support on catalyst performance, mainly because of scatter in the data.

Finally the effect of the reducing temperature on catalyst performance for the RhMnIr/carbon catalyst was investigated in a series of three tests. The results showed that a catalyst reduced at $200^{\circ} \mathrm{C}$ was inferior to catalysts reduced at $260^{\circ} \mathrm{C}$ or $360^{\circ} \mathrm{C}$. In some respects, the catalyst reduced at $260^{\circ} \mathrm{C}$, behaved similarly to the catalyst reduced at $360^{\circ} \mathrm{C}$. However, there were significant differences at some testing conditions that cannot be explained at this time, and additional tests are warranted to explain them.

\subsection{Summary}

In summary, selected carbons and silicas appear to be the best catalyst support materials for the RhMbased catalysts for mixed oxygenates synthesis. There appear to be opportunities to further improve catalyst performance by increasing Mn concentrations on the carbon supports, at least when both Rh and $\mathrm{Mn}$ are added to the support in a single impregnation. Increasing the total metals concentration at a fixed metals ratio also improved catalyst performance of the carbon-supported catalysts, which is different from the silica-supported catalysts, based on earlier research. The addition of Ir as a third metal has been shown to improve catalyst performance, particularly for the carbon-supported catalysts. When Ir is added in a second impregnation after first adding $\mathrm{Rh}$ and $\mathrm{Mn}$ in a single impregnation and drying the catalyst, there were widely scattered results that made it difficult to draw conclusions at this time. However, there are instances where the double-impregnated catalysts performed very well, which would justify further testing. Tests also have suggested that improvements may be possible through optimizing $\mathrm{Pt}$ or $\mathrm{Ga}$ as a third metal based on test results using a silica support. Similar testing with carbon supports is warranted based on these results. 



\subsection{References}

Gerber MA, JF White, and DJ Stevens. 2007. Mixed Alcohol Synthesis Catalyst Screening.

PNNL-16763, Pacific Northwest National Laboratory, Richland, Washington.

Gerber MA, JF White, MJ Gray, and DJ Stevens. 2008. Evaluation of Promoters for Rhodium-Based Catalysts for Mixed Alcohol Synthesis. PNNL-17857, Pacific Northwest National Laboratory, Richland, Washington.

Gerber MA, MJ Gray, DJ Stevens, JF White, and BL Rummel. 2010. Optimization of Rhodium-Based Catalysts for Mixed Alcohol Synthesis - 2009 Progress Report. PNNL-20115, Pacific Northwest National Laboratory, Richland, Washington. 




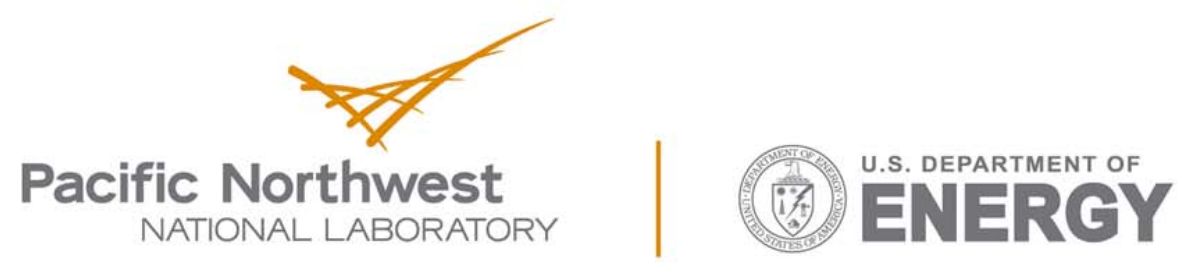

Proudly Operated by Battelle Since 1965

902 Battelle Boulevard

P.O. Box 999

Richland, WA 99352

1-888-375-PNNL (7665)

www.pnnl.gov 